\title{
jpen
}

AUTARQUIA ASSOCIADA À UNIVERSIDADE DE SÃO PAULO

EMPREGO DO MCNP NO ESTUDO DOS TLDS 600 E 700 VISANDO A IMPLEMENTAÇÃO DA CARACTERIZAÇÃO DO FEIXE DE IRRADIAÇÃO NA INSTALAÇÃO DE BNCT DO IEA-R1

Tássio Antonio Cavalieri

Dissertação apresentada como parte dos requisitos para obtenção do Grau de Mestre em Ciências na Área de Tecnologia Nuclear - Reatores

Orientador:

Prof. Dr. Paulo de Tarso Dalledone Siqueira 


\title{
INSTITUTO DE PESQUISAS ENERGÉTICAS E NUCLEARES
}

Autarquia associada à Universidade de São Paulo

\section{EMPREGO DO MCNP NO ESTUDO DOS TLDs 600 E 700 VISANDO A IMPLEMENTAÇÃO DA CARACTERIZAÇÃO DO FEIXE DE IRRADIAÇÃO NA INSTALAÇÃO DE BNCT DO IEA-R1}

Tássio Antonio Cavalieri

\author{
Dissertação apresentada como parte dos \\ requisitos para obtenção do Grau de \\ Mestre em Ciências na Área de Tecnologia \\ Nuclear - Reatores \\ Orientador: \\ Prof. Dr. Paulo de Tarso Dalledone Siqueira
}

Versão Corrigida

Versão Original disponível no IPEN 
Dedico este trabalho aos meus pais, Elourizel e Sandra, com todo meu amor e carinho 


\section{AGRADECIMENTOS}

Agradeço aos meus pais, Elourizel e Sandra, por todo apoio, incentivo e ajuda que recebi, para que fosse possível que eu completasse mais este estágio de minha vida.

Agradeço à minha irmã, Talissa, por dividir seu apartamento comigo nos meus primeiros meses em São Paulo e por todo o suporte médico que necessitei.

Agradeço à minha namorada, Ana Paula, por me ajudar e compartilhar comigo todos os momentos que passei. Pelos momentos felizes nos finais de semana! E por emprestar o notebook para que fosse possível que eu entregasse minha dissertação no prazo!

Agradeço aos meus avôs, Edisel e Lourdes, também pelo apoio para que eu conseguisse terminar mais este estágio de minha vida.

Agradeço ao meu orientador, professor Dr. Paulo de Tarso, por toda ajuda durante este meu processo de aprendizagem e por todo seu tempo que passou corrigindo meus trabalhos e esta dissertação!

Agradeço ao professor Dr. Paulo Rogério por ter primeiramente me aceitado no IPEN e por ter acompanhado meu trabalho durante todo o processo sempre auxiliando no que fosse necessário.

Agradeço aos professores Dr. Helio Yoriyaz, Dr. Tufic Maddi Filho, Dr. Ulysses Bitteli e Dr. Rogério por todos os ensinamentos e irradiações realizadas.

Agradeço ao Iremar Alves e a Dra. Maíra Goes Nunes pelos auxílios nas irradiações.

Agradeço ao Sr. Vinícius Castro pelo companheirismo e pelas inúmeras horas discutindo temas relacionados (ou não) a este trabalho e pelas inúmeras horas compartilhadas nas irradiações.

Agradeço a todos os bolsistas e amigos do CEN, Talita, Tiago, Luiza, Fábio, Eduardo, Murilo, Massicano, Felipe Cintra, Rodrigo Viana, Rodrigo Giarola, Chicão, Paula, Gregório, Gabriel e Pedrinho por todos os momentos compartilhados durante estes anos no IPEN.

Agradeço aos funcionários do IPEN, por manterem o local sempre agradável para a realização de meus trabalhos e estudos.

Agradeço ao amigo Fernando Zago (Fininho) pelas conversas nos almoços nos finais de semana sempre no shopping Eldorado. 
Agradeço ao amigo Bruno (Zeh) por todo incentivo e pelas noites de vídeo game e UFC.

Agradeço aos amigos JS, Leadrinho e Salgadão pela amizade, brincadeiras e apoio durante este período.

Agradeço a meus amigos Everson, o Fogaça, a Fogaça, Luciana, Marininha, Manu, Ana Le, Marcis, Nê, Bassi, Ivata e Thiago pelas baladas, barzinhos, churrascos...

E finalmente, agradeço a CNEN pela bolsa de estudos durante o desenvolvimento deste trabalho. 


\title{
EMPREGO DO MCNP NO ESTUDO DOS TLDS 600 E 700 \\ VISANDO A IMPLEMENTAÇÃO DA CARACTERIZAÇÃO DO \\ FEIXE DE IRRADIAÇÃO DA INSTALAÇÃO DE BNCT DO IEA-R1
}

\section{Tássio Antonio Cavalieri}

\begin{abstract}
RESUMO
A Terapia de Captura de Nêutron por Boro (BNCT) é uma terapia de combate ao câncer bimodal, na qual a energia útil da terapia vem da reação nuclear que ocorre pelo Boro quando irradiado com nêutrons térmicos. No IPEN há uma instalação de pesquisas em BNCT, na qual o feixe de radiação contendo nêutrons é proveniente do reator IEA-R1. Como condição desta terapia é necessário realizar a dosimetria do feixe de radiação, que atualmente é feito com o uso de folhas de ativação, para cálculo do fluxo de nêutrons, e do dosímetro TLD 400, para estimativa da dose gama. Para campos mistos de nêutrons e gamas, a Comissão Internacional de Unidades e Medidas (ICRU) recomenda o uso de dosímetros com sensibilidades distintas para as componentes do feixe, como o caso do par TLD 600 e TLD 700 que apresentam sensibilidades distintas a nêutrons térmicos, devido à diferente quantidade do isótopo ${ }^{6} \mathrm{Li}$ em sua composição, o qual apresenta uma alta seção de choque para nêutrons térmicos. Este trabalho constou da realização de simulações e experimentos visando a implementação da metodologia de dosimetria utilizando o par TLD 600 e TLD 700 e sua comparação com a metodologia atualmente utilizada pelo grupo de pesquisa em BNCT, que utiliza o TLD 400. Portanto, foi realizado um estudo das respostas de cada um destes TLDs a partir de irradiações em diferentes campos e sempre utilizando simulações com o MCNP para fornecer a discriminalização das componentes de dose depositadas em cada TLD. Foram realizadas varias irradiações em campo de gama puro e em campo misto de nêutrons e gamas para o estudo da reprodutibilidade destes TLDs. Este estudo mostrou que mesmo TLDs do mesmo tipo têm sensibilidades distintas, e assim foi criado um Fator de Normalização para cada um dos TLDs, eliminando assim a necessidade de selecionamento. Foi realizado um estudo sobre a diferença das respostas destes TLDs devido à diferentes campos. Este estudo mostrou ser possível estimar o fluxo relativo
\end{abstract}


entre gamas e nêutrons a partir da relação existente entre as duas regiões de interesse dos TLDs 600 e 700. Também foi possível observar que o TLD 700 apresenta resposta para nêutrons, e se a recomendação da ICRU for seguida, a resposta devido à radiação gama será superestimada. Foram obtidas as curvas de calibração dose - resposta destes TLDs para campos de gamas puro e campos mistos. Este trabalho propõe o uso desta metodologia com o uso do par TLD 600 e TLD 700, por apresentar maior precisão de resposta frente a atual metodologia que utiliza o TLD 400, porém precauções devem ser tomadas para evitar que a dose gama seja superestimada. 


\title{
EMPLOYMENT OF MCNP IN THE STUDY OF TLDS 600 AND 700 \\ SEEKING THE IMPLEMENTATION OF RADIATION BEAM \\ CHARACTERIZATION OF BNCT FACILITY AT IEA-R1
}

\author{
Tássio Antonio Cavalieri
}

\begin{abstract}
Boron Neutron Capture Therapy, BNCT, is a bimodal radiotherapic procedure for cancer treatment. Its usefull energy comes from a nuclear reaction driven by impinging thermal neutron upon Boron 10 atoms. A BNCT research facility has been constructed in IPEN at the IEA-R1 reactor, to develop studies in this area. One of its prime experimental parameter is the beam dosimetry which is nowadays made by using activation foils, for neutron measurements, and TLD 400, for gamma dosimetry. For mixed field dosimetry, the International Commmission on Radiation Units and Measuments, ICRU, recommends the use of pair of detectors with distinct responses to the field components. The TLD 600/ TLD 700 pair meets this criteria, as the amount of ${ }^{6} \mathrm{Li}$, a nuclide with high thermal neutron cross section, greatily differs in their composition. This work presents a series of experiments and simulations performed in order to implement the mixed field dosimetry based on the use of TLD 600/TLD 700 pair. It also intended to compare this mixed field dosimetric methodology to the one so far used by the BNCT research group of IPEN. The response of all TLDs were studied under irradiations in different irradiation fields and simulations, underwent by MCNP, were run in order to evaluate the dose contribution from each field component. Series of repeated irradiations under pure gamma field and mixed field neutron/gamma field showed differences in the TLD individual responses which led to the adoption of a Normalization Factor. From the use of Normalization Factor the TLD selection it has allowed to overcome TLD selection. TLD responses due to different field components and spectra were studied. It has shown to be possible to evaluate the ralative gamma/neutron fluxes from the relative responses observed in the two Regions of Interest of TLDs glow curves, ROIs, from TLD 600 and TLD 700. It has also been possible to observe the TLD 700 response to neutron, which leads to a gamma dose
\end{abstract}


overstimation when one follows the ICRU recommended mixed field dosimetric procedure. Dose response curves were obtained for the distinct types of TLDs for pure gamma and mixed fields. This work recommends the TLD 600/TLD 700 pair methodology for mixed field dosimetry, this methodology presents a better precision than the one based on TLD 400, however one has to be carefull to avoid gamma dose superestimation. 


\section{Sumário}

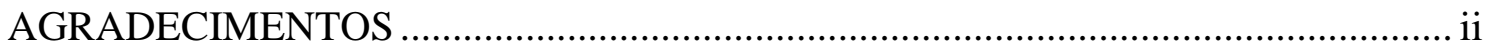

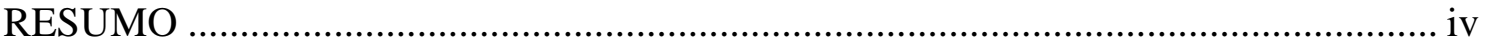

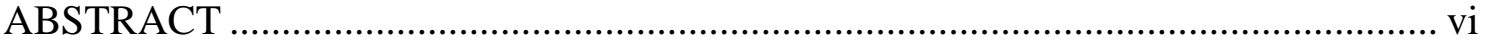

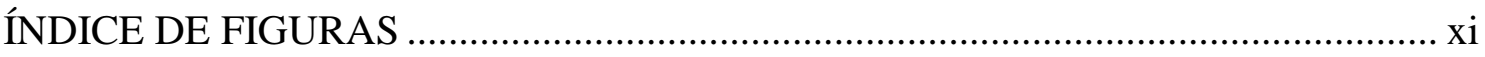

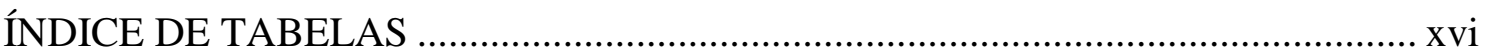

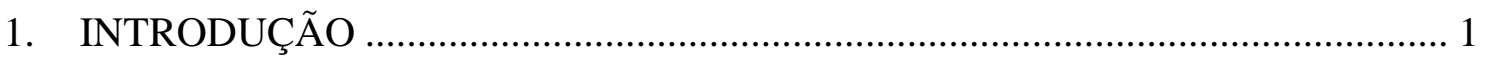

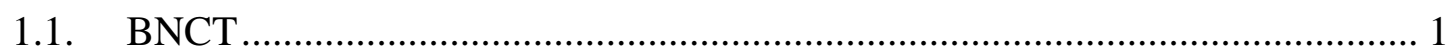

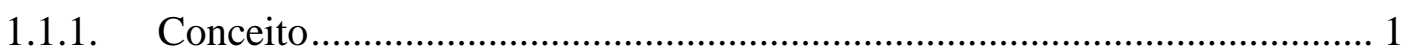

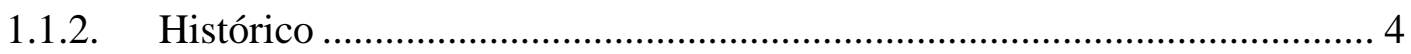

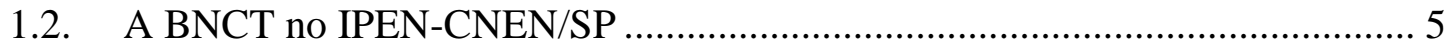

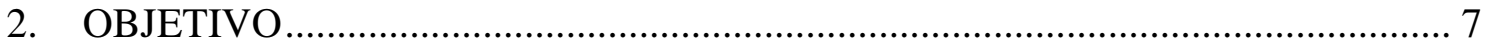

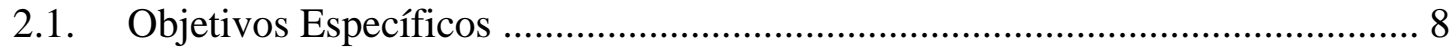

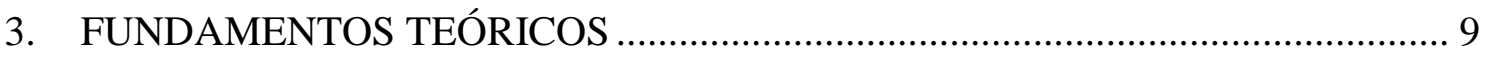

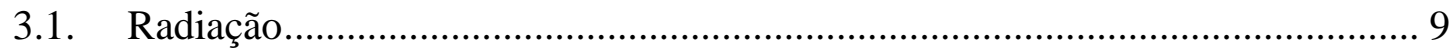

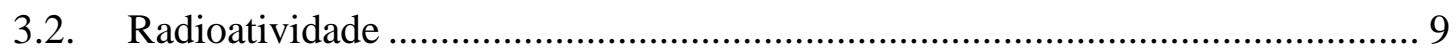

3.3. Interação de Fótons com a Matéria .............................................................. 10

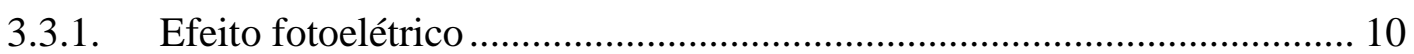

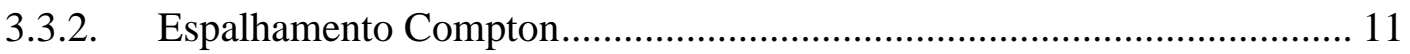

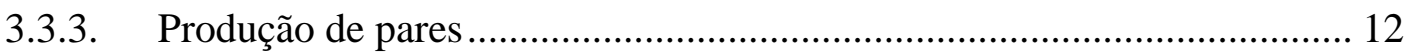

3.3.4. Importância relativa de cada efeito............................................................ 13

3.4. Interação dos Nêutrons com a Matéria ........................................................... 14

3.4.1. Interações com Nêutrons Lentos ....................................................... 14

3.4.2. Interações com Nêutrons Rápidos ......................................................... 14

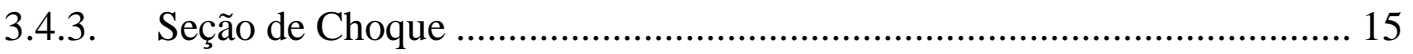

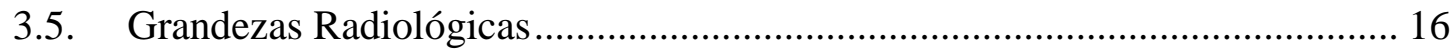




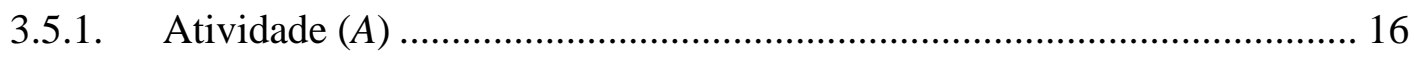

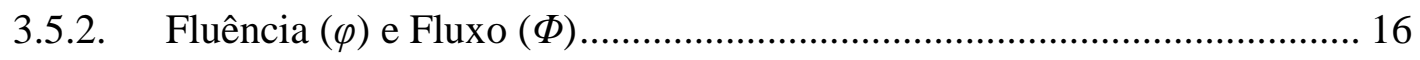

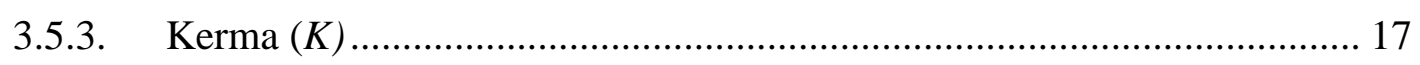

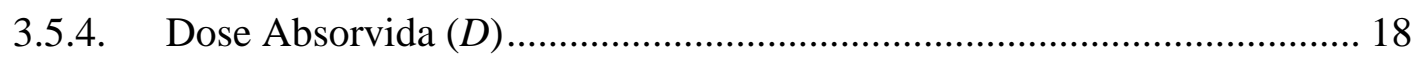

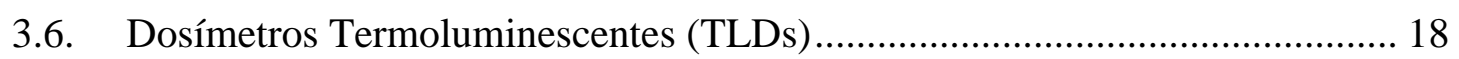

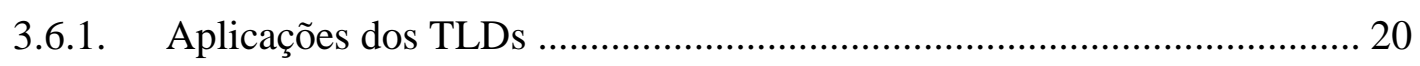

3.6.2. Utilização de pares de TLDs para a dosimetria de campos mistos .......... 21

3.7. MCNP - Monte Carlo N-Particle Radiation Transport Code ......................... 22

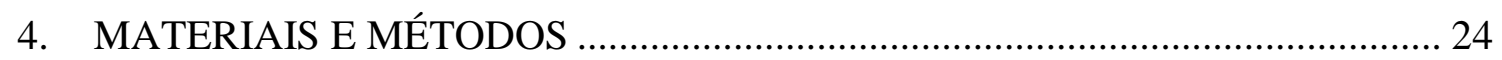

4.1. Dosímetros Termoluminescentes............................................................ 24

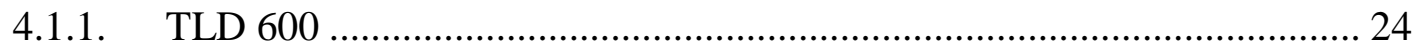

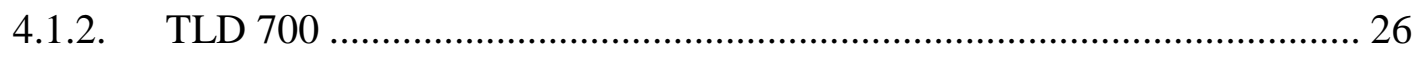

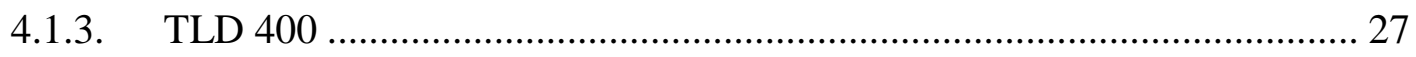

4.1.4. Sensibilidade dos TLDs aos Nêutrons ................................................ 28

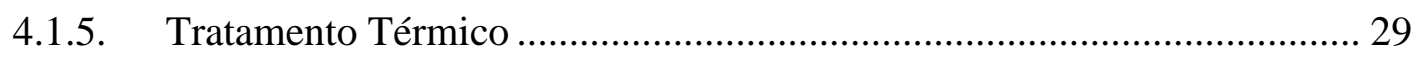

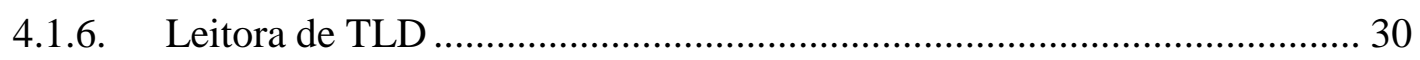

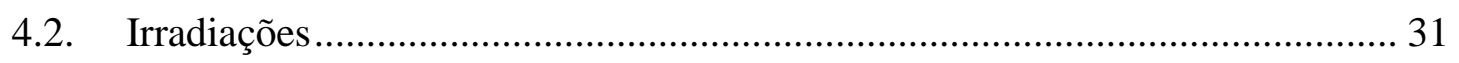

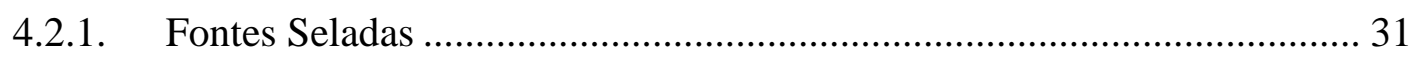

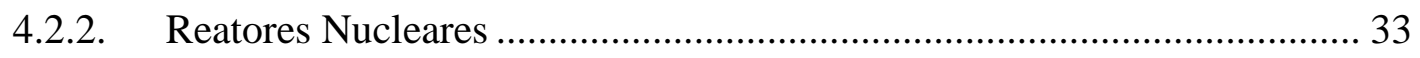

4.3. Instalação para Pesquisa em BNCT do IPEN .................................................... 34

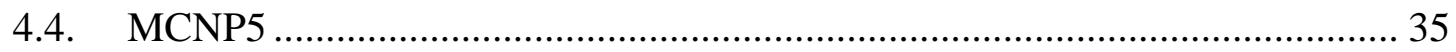

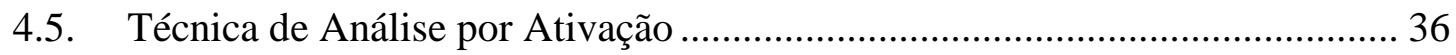

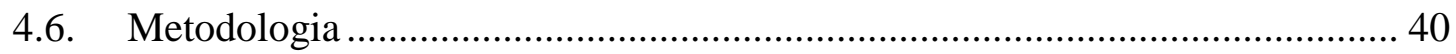

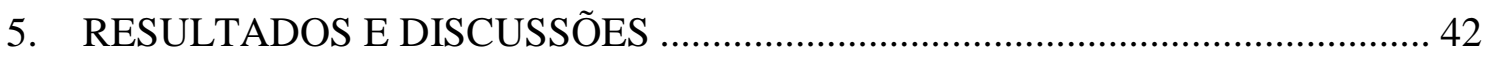

5.1. Estudo da Reprodutibilidade dos TLDs em Campo de Gama Puro ................ 43

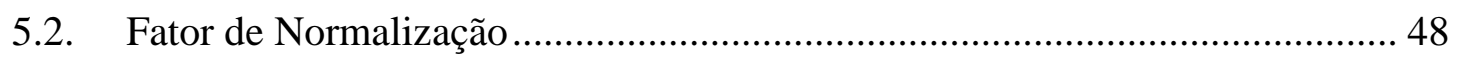

5.2.1. Fatores de Normalização para a Fonte de Gama Puro............................. 51 
5.3. Estudo da Reprodutibilidade dos TLDs em Campo Misto.... 54

5.3.1. Fatores de Normalização para o sistema com a fonte de AmBe 61

5.4. Comparação da Nova Metodologia com a Metodologia Anterior Utilizada pelo

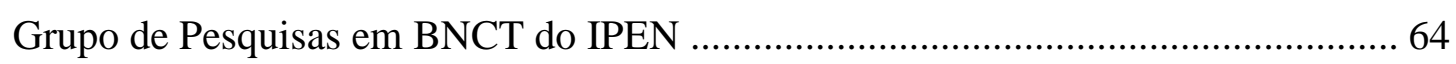

5.5. Diferenças das Curvas Termoluminescentes em Diferentes Campos.............. 65

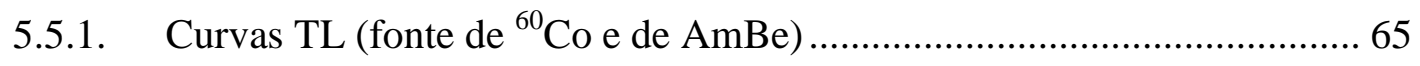

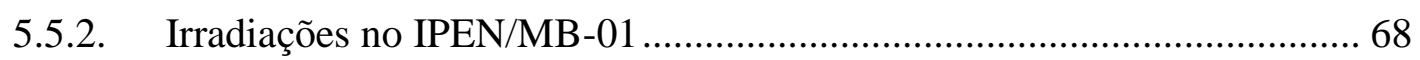

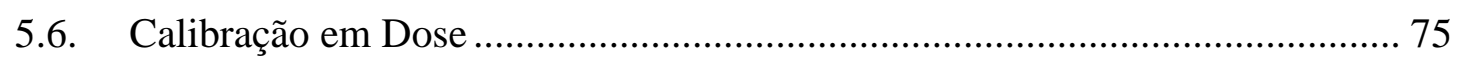

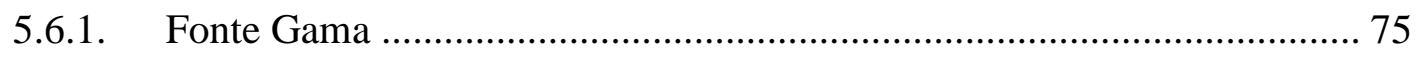

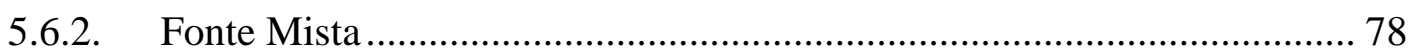

5.7. Irradiação na Instalação de Pesquisa em BNCT ............................................. 80

5.7.1. Dosimetria da Instalação para Pesquisas em BNCT ............................... 83

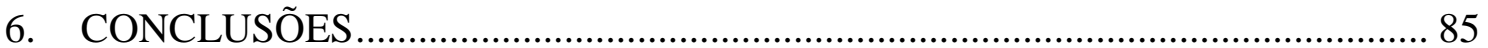

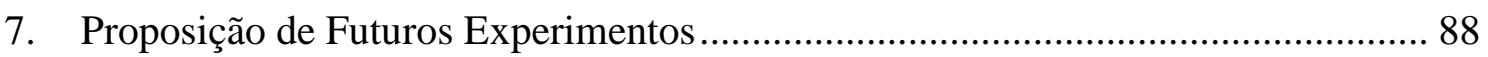

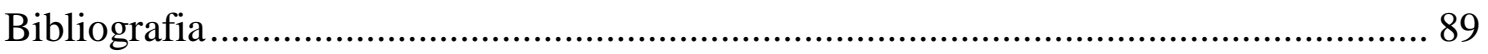

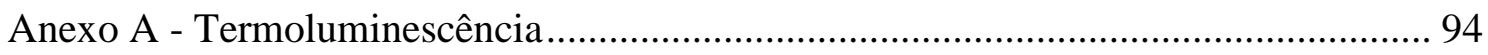

Anexo B - Estudo dos Parâmetros de Operação da Leitora de TLDs Harshaw 3500 .... 99

Anexo C - Estudo dos Sistemas de Moderação para a Fonte de AmBe ....................... 104

C.1 Sistema Original ...................................................................................... 104

C.2 Estudo Para o Novo Sistema de Moderação ..................................................... 107

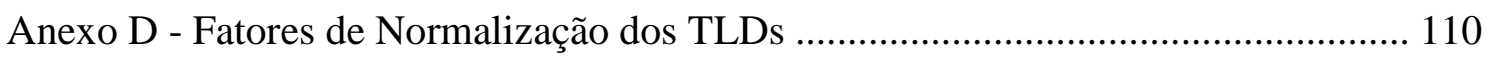

Anexo E - Arquivo de Entrada do MCNP para Simulações das Irradiações no Reator

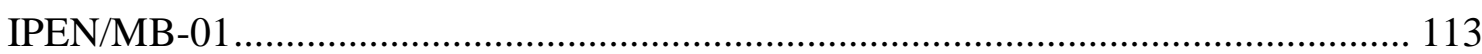

Anexo F - Estudo da Dependência Energética dos TLDs para Fontes de Gama puro. 118 


\section{ÍNDICE DE FIGURAS}

Figura 1 - Seções de choque total para os nêutrons dos átomos de ${ }^{10} \mathrm{~B}$ (vermelho), Hidrogênio (verde escuro), Carbono (azul), Nitrogênio (roxo) e Oxigênio (verde claro) [4]

Figura 2 - Esquema da instalação de pesquisas em BNCT junto ao reator IEA-R1 no IPEN/CNEN [22].

Figura 3 - Representação do efeito fotoelétrico [29].

Figura 4 - Representação do espalhamento Compton [30]. 12

Figura 5 - Representação da produção de pares [29]. 13

Figura 6 - Importâncias relativas dos diversos processos de interação dos fótons com a matéria em função da energia do fóton e do número atômico do material [29]............. 13

Figura 7 - Processo termoluminescente [29] 19

Figura 8 - Curvas termoluminescentes de três diferentes tipos de TLDs irradiados em um fonte de ${ }^{60} \mathrm{Co}$ [34] 19

Figura 9 - Seção de choque total para nêutrons do ${ }^{6} \mathrm{Li}$ (vermelho) e ${ }^{7} \mathrm{Li}$ (verde) [4] ..... 25

Figura 10 - Curva termoluminescente do TLD 600 e suas regiões de interesse ............. 25

Figura 11 - Curva termoluminescente do TLD 700 e sua região de interesse................. 26

Figura 12 - Curva termoluminescente do TLD 400 e sua região de interesse................. 27

Figura 13 - Muflas utilizadas para o tratamento térmico dos TLDs.............................. 30

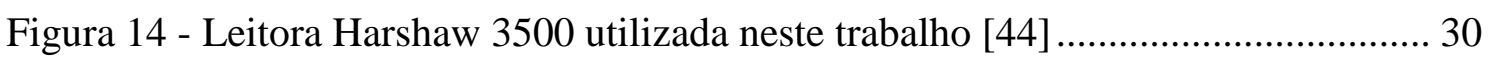

Figura 15 - Espectro de emissão de nêutrons da fonte de ${ }^{241} \mathrm{AmBe}$ [45] ....................... 32

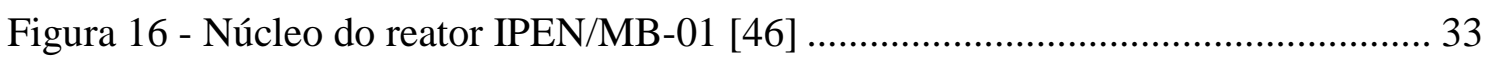

Figura 17 - Esquema ilustrativo da instalação de pesquisas em BNCT do IPEN [22]... 34

Figura 18 - Sistema para colocação e retirada da amostra [47] .................................... 35

Figura 19 - Seção de choque total para o átomo de ${ }^{197} \mathrm{Au}$ (vermelho) e para o cádmio (verde) [4] 37

Figura 20 - Atividade da folha de ativação em função do tempo de irradiação $\left(t_{i}\right)$ [50] 38 Figura 21 - Curvas termoluminescentes dos diferentes tipos de TLDs com suas respectivas regiões de interesse: a) TLD 600; b) TLD 700; c) TLD 400 ....................... 43

Figura 22 - Fonte panorâmica de ${ }^{60} \mathrm{Co}$ do LDT/IPEN ................................................... 44 
Figura 23 - Dispersão das respostas do ROI 1 individuais dos TLDs 600 em uma irradiação na fonte de ${ }^{60} \mathrm{Co}$ 45

Figura 24 - Médias das Respostas dos TLDs 600 obtidas nas 15 irradiações na fonte de ${ }^{60} \mathrm{Co}$

Figura 25 - Médias das Respostas dos TLDs 700 obtidas nas 15 irradiações na fonte de ${ }^{60} \mathrm{Co}$. 46

Figura 26 - Médias das Respostas dos TLDs 400 obtidas nas 14 irradiações na fonte de ${ }^{60} \mathrm{Co}$ 46

Figura 27 - Respostas individuais dos TLDs em diferentes irradiações na fonte de ${ }^{60} \mathrm{Co}$

Figura 28 - Histogramas das respostas dos TLDs 600 quando aplicado (a) e não aplicado (b) o Fator de Normalização 50

Figura 29 - Histograma dos Fatores de Normalização do TLD 600 .............................. 51

Figura 30 - Histograma dos Fatores de Normalização do TLD 700 .............................. 51

Figura 31 - Histograma dos Fatores de Normalização do TLD 400 ............................. 52

Figura 32 - Histograma com os desvios padrões do Fator de Normalização obtida pelos TLDs 600 nas diferentes irradiações na fonte de ${ }^{60} \mathrm{Co}$.

Figura 33 - Histograma com os desvios padrões dos Fatores de Normalização obtida pelos TLDs 700 nas diferentes irradiações na fonte de ${ }^{60} \mathrm{Co}$. 53 Figura 34 - Histograma com os desvios padrões dos Fatores de Normalização obtida pelos TLDs 400 nas diferentes irradiações na fonte de ${ }^{60} \mathrm{Co}$......................................... 53 Figura 35 - Imagens do novo sistema para estuda da reprodutibilidade dos TLDs........ 55 Figura 36 - Dispersão das respostas individuais (ROI 1 e ROI 2) dos TLDs 600 em uma irradiação no sistema com a fonte de AmBe

Figura 37 - Gráfico de correlação entre os valores do ROI 1 pelo ROI 2 dos TLDs 600 em uma irradiação no sistema com a fonte de ${ }^{241} \mathrm{AmBe}$ 58 Figura 38 - Médias das Respostas dos TLDs 600 nas 8 irradiações na fonte de AmBe 58 Figura 39- Médias das Respostas dos TLDs 700 nas 8 irradiações na fonte de AmBe 59 Figura 40- Médias das Respostas dos TLDs 400 nas 8 irradiações na fonte de AmBe 59 Figura 41 - Gráfico de correlação das respostas médias dos TLDs 600 e TLDs 700 nas irradiações no sistema com a fonte de AmBe. Figura 42 - Respostas das regiões de interesse individuais dos TLDs em diferentes irradiações na fonte de AmBe: a) TLD 600; b) TLD 700; c) TLD 400 60 
Figura 43 - Histograma com os valores do Fator de Normalização dos TLDs 600 nas irradiações no sistema com a fonte de AmBe.....

Figura 44 - Histograma com os valores do Fator de normalização dos TLDs 700 nas irradiações no sistema com a fonte de AmBe.

Figura 45 - Histograma com os valores do Fator de Normalização dos TLDs 400 nas irradiações no sistema com a fonte de AmBe.

Figura 46 - Histograma com os desvios padrões do Fator de Normalização dos TLDs 600 nas irradiações no sistema com a fonte de AmBe

Figura 47 - Histograma com os desvios padrões do Fator de Normalização dos TLDs 700 nas irradiações no sistema com a fonte de AmBe

Figura 48 - Histograma com os desvios padrões do Fator de Normalização dos TLDs 400 nas irradiações no sistema com a fonte de AmBe

Figura 49 - Curvas termoluminescentes do TLD 600 nas irradiações em fonte de: a) ${ }^{60} \mathrm{Co}$; b) $\mathrm{AmBe}$ 66

Figura 50 - Curvas termoluminescentes do TLD 700 nas irradiações em fonte de: a) ${ }^{60} \mathrm{Co}$; b) $\mathrm{AmBe}$

Figura 51 - Diagrama esquemático da configuração cilíndrica do reator IPEN/MB-01 68 Figura 52 - Diagrama esquemático das posições de irradiação dos TLDs dentro do reator IPEN/MB-01

Figura 53 - Montagem da placa para a irradiação dos TLDs no reator IPEN/MB-01 ... 69 Figura 54 - Imagem das simulações do IPEN/MB-01 pelo MCNP5: a) vista da lateral do núcleo do reator; b) vista do núcleo do reator, onde podem ser vistas as posições dos TLDs 70

Figura 55 - Valores de fluxo normalizados para cada posição, calculados pelo MCNP5, para cada uma das 6 posições . 71

Figura 56 - Valores calculados pelo MCNP5 dos fluxos normalizados, pelo valor máximo de fluxo de fótons, das diferentes componentes de campo, nas diferentes posições

Figura 57 - Respostas das duas regiões de interesse do TLD 600 de acordo com a posição destes TLDs na irradiação no reator IPEN/MB-01

Figura 58 - Respostas das duas regiões de interesse do TLD 700 de acordo com a posição destes TLDs na irradiação no reator IPEN/MB-01

Figura 59 - Resposta da região de interesse do TLD 400 de acordo com a posição destes TLDs na irradiação no reator IPEN/MB-01 75 
Figura 60 - Curva de calibração dos TLDs 600 para doses entre 20 mGy e 1 Gy (fonte de $\left.{ }^{60} \mathrm{Co}\right)$ 76

Figura 61 - Curva de calibração dos TLDs 700 para doses entre 20 mGy e 1 Gy (fonte $\left.\mathrm{de}{ }^{60} \mathrm{Co}\right)$ 76

Figura 62 - Curva de calibração dos TLDs 400 para doses entre 20 mGy e 1 Gy (fonte de $\left.{ }^{60} \mathrm{Co}\right)$ 76

Figura 63 - Curva de calibração dos TLDs 600 para doses entre 0,5 Gy e 5 Gy (fonte de $\left.{ }^{60} \mathrm{Co}\right)$ 77

Figura 64 - Curva de calibração dos TLDs 700 para doses entre 0,5 e 5 Gy (fonte de $\left.{ }^{60} \mathrm{Co}\right)$ 77

Figura 65 - Curva de calibração dos TLDs 400 para doses entre 0,5 e 5 Gy (fonte de $\left.{ }^{60} \mathrm{Co}\right)$ 78

Figura 66 - Curvas de calibração para os diferentes ROIs do TLD 600 na irradiação no sistema com a fonte de $\mathrm{AmBe}$ 79 Figura 67 - Curvas de calibração para os diferentes ROIs do TLD 700 na irradiação no sistema com a fonte de AmBe 79 Figura 68 - Curvas de Calibração para as duas regiões de interesse do TLD 600 para as irradiações na instalação de BNCT 81 Figura 69 - Curvas de Calibração para as duas regiões de interesse do TLD 700 para as irradiações na instalação de BNCT 82 Figura 70 - Curva de calibração para nêutrons térmicos a partir da subtração das respostas dos TLDs. 83

Figura 71 - Representação das transições dos elétrons dentro da rede cristalina (Adaptado de [35]). 95

Figura 72 - Curva TL (a) calculada da Eq. 3.23 com $E=0,19 \mathrm{eV}, \alpha_{0}=7 \times 10^{15} \mathrm{~s}^{-1} ; \ldots .98$ Figura 73 - Curva Termoluminescente saturada no caso da tensão de $850 \mathrm{~V}$ para um TLD de LiF. 100

Figura 74 - Curvas Termoluminescentes dos TLDs obtidas com a leitora operando a 500V: Linha 1 - TLD 600; Linha 2 - TLD 700; Linha 3 - TLD 400; Coluna 1 Irradiações por 1h no BH3; Coluna 2 - Irradiações de 10' no BH3 100 Figura 75 - Curvas Termoluminescentes dos TLDs obtidas com a leitora operando a 500V: Linha 1 - TLD 600; Linha 2 - TLD 700; Linha 3 - TLD 400; Coluna 1 Irradiações por 50' fora do BH3; Coluna 2 - Irradiações na fonte de AmBe 101 
Figura 76 - Diferenças nas posições do pico de três TLDs 600 irradiados na mesma condição

Figura 77 - Exemplo da posição dos picos para as definições das áreas de interesse: a) e b) são TLDs 600 ; c) e d) são TLDs 700; e e) e f) são TLDs 400 103

Figura 78 - Arranjo inicialmente utilizado nas irradiações para selecionamento e estudo de reprodutibilidade dos TLDs. 104

Figura 79 - Desenho da geometria da simulação com MCNP5 do sistema de selecionamento e reprodutibilidade dos TLDs para campo misto 105

Figura 80 - Resposta TL para os suportes. Valores normalizados 105

Figura 81 - Fluxos de nêutrons e fótons obtidos pela simulação com o MCNP5 106 Figura 82 - Fluxos normalizados de nêutrons térmicos obtidos pelo MCNP5 nos casos com e sem a presença do suporte e dos TLDs 107

Figura 83 - Esquema para construção do novo sistema para estudo da reprodutibilidade dos TLDs 108

Figura 84 - Fotos das duas peças que constituem o novo sistema de irradiação 108 Figura 85 - Curvas de calibração do TLD 600 para baixas doses: a) ${ }^{60} \mathrm{Co}$; b) ${ }^{137} \mathrm{Cs}$... 118 Figura 86 - Comparação entre as curvas de calibração dos TLDs 600 para baixas doses entre as fontes de ${ }^{60} \mathrm{Co} \mathrm{e}{ }^{137} \mathrm{Cs}$

Figura 87 - Curvas de calibração do TLD 700 para baixas doses: a) ${ }^{60} \mathrm{Co}$; b) ${ }^{137} \mathrm{Cs}$... 119 Figura 88 - Comparação entre as curvas de calibração dos TLDs 700 para baixas doses entre as fontes de ${ }^{60} \mathrm{Co}$ e ${ }^{137} \mathrm{Cs}$ 120

Figura 89 - Curvas de calibração do TLD 400 para baixas doses: a) ${ }^{60} \mathrm{Co}$; b) ${ }^{137} \mathrm{Cs}$... 120 Figura 90 - Comparação entre as curvas de calibração dos TLDs 400 para baixas doses entre as fontes de ${ }^{60} \mathrm{Co} \mathrm{e}{ }^{137} \mathrm{Cs}$ 120 


\section{ÍNDICE DE TABELAS}

Tabela 1 - Comparação entre a sensibilidade dos diferentes TLDs [42] ........................ 27

Tabela 2 - Sensibilidade aos nêutrons térmicos relativo ao ${ }^{60} \mathrm{Co}[35]$........................... 28

Tabela 3 - Sensibilidade do LiF para nêutrons de alta energia relativo ao ${ }^{60} \mathrm{Co}[35]$..... 29

Tabela 4 - Tratamento térmico utilizado nos diferentes tipos de TLD........................... 29

Tabela 5 - Parâmetros de operação da leitora Harshaw 3500, utilizados neste trabalho 31

Tabela 6 - Energias dos fótons emitidos pelas diferentes fontes utilizadas neste trabalho

Tabela 7 - Configurações dos sistemas utilizados nas simulações com o MCNP5 ........ 36

Tabela 8 - Canais correspondentes as Regiões de Interesse dos diferentes tipos de TLDs

Tabela 9 - Comparação entre os valores calculados de kerma no ar e as doses depositadas nos diferentes TLDs nas irradiações com a fonte de ${ }^{60} \mathrm{Co}$. 44

Tabela 10 - Valores médios calculados de fluxo de fótons e a respectiva taxa de kerma no ar no novo sistema de irradiação

Tabela 11 - Valores médios calculados de fluxo de nêutrons e respectiva taxa de kerma no ar e a fração de contribuição de cada faixa energética no novo sistema de irradiação com a fonte de $\mathrm{AmBe}$

Tabela 12 - Estimativas calculadas de doses, e componentes energéticas, devido aos nêutrons nos diferentes tipos de TLDs 56

Tabela 13 - Valores calculados de kerma no ar e de dose depositada nos TLDs nas irradiações com a fonte de ${ }^{60} \mathrm{Co}$ e $\mathrm{AmBe}$

Tabela 14 - Resposta das diferentes regiões de interesse dos TLDs irradiados nas fontes de ${ }^{60} \mathrm{Co}$ e AmBe (experimentos de reprodutibilidade das seções 5.1 e 5.3)

Tabela 15 - Valores da razão entre a segunda e a primeira região de interesse dos TLDs 600 para as posições de irradiação no reator IPEN/MB-01

Tabela 16 - Valores da razão entre a segunda e a primeira região de interesse dos TLDs 700 para as posições de irradiação no reator IPEN/MB-01 74

Tabela 17 - Parâmetros da reta ajustada para a curva de calibração dos TLDs 600, TLDs 700 e TLDs 400 na fonte de ${ }^{60}$ Co entre as doses de 20 mGy e 1 Gy. 77 
Tabela 18 - Parâmetros da resta ajustada para a curva de calibração dos TLDs 400 na fonte de ${ }^{60} \mathrm{Co}$ entre as doses de 0,5 e 5 Gy. 78

Tabela 19 - Valores de kerma no ar para o sistema com a fonte de AmBe nos diferentes tempos de irradiação

Tabela 20 - Coeficientes das curvas de calibração para os diferentes ROIs do TLD 600 e TLD 700 nas irradiações no sistema com a fonte de ${ }^{241} \mathrm{AmBe}$ 80

Tabela 21 - Fluência de nêutrons térmicos e epitérmicos e dose gama para os diferentes tempos de irradiação na instalação de BNCT. 81

Tabela 22 - Coeficientes das curvas de calibração para os TLDs 600 nas irradiações na instalação de BNCT

Tabela 23 - Coeficientes das curvas de calibração para os TLDs 700 nas irradiações na instalação de BNCT 82

Tabela 24 - Canais correspondentes a cada Região de Interesse de cada tipo de TLD 102

Tabela 25 - Respostas normalizadas dos TLDs nas mesmas alturas ..... 106 Tabela 26 - Valores médios calculados de fluxo de fótons e o respectivo kerma no ar no novo sistema de irradiação

Tabela 27 - Valores médios calculados de fluxo de nêutrons e respectivo kerma no ar e a fração de contribuição de cada faixa energética no novo sistema de irradiação com a fonte de AmBe 109

Tabela 28 - Fatores de Normalização do TLD 600 ...................................................... 110

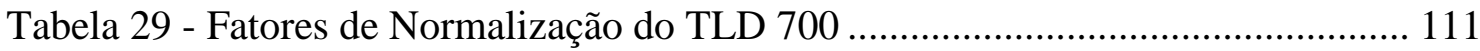

Tabela 30 - Fatores de Normalização do TLD 400 .................................................... 112

Tabela 31 - Coeficientes ajustados para as curvas de calibração do TLD 600 ............. 118

Tabela 32 - Coeficientes ajustados para as curvas de calibração do TLD 700 ............. 119

Tabela 33 - Coeficientes ajustados para as curvas de calibração do TLD 400............ 120 


\section{INTRODUÇÃO}

Câncer é o nome dado a um conjunto de mais de 100 doenças que têm em comum o crescimento desordenado (maligno) de células que invadem os tecidos e órgãos, podendo espalhar-se (metástase) para outras regiões do corpo [1].

Dividindo-se rapidamente, estas células tendem a ser muito agressivas e incontroláveis, determinando a formação de tumores (acúmulo de células cancerosas) ou neoplasias malignas. Por outro lado, um tumor benigno significa simplesmente uma massa localizada de células que se multiplicam vagarosamente e se assemelham às células do tecido original, raramente constituindo um risco de vida.

O câncer atinge milhões de pessoas por todo o mundo e, portanto estudos para seu tratamento são realizados em várias frentes visando à destruição ou enfraquecimento de células cancerígenas e ao mesmo tempo minimizando os danos a células sadias. Atualmente, as técnicas mais utilizadas no combate ao câncer são a cirurgia, a radioterapia e a quimioterapia. Estas técnicas podem ser aplicadas juntas ou separadamente, dependendo do desenvolvimento do câncer e do órgão atingido.

Outra técnica que vem sendo estudada para o combate ao câncer é a Terapia de Captura de Nêutron pelo Boro (BNCT - Boron Neutron Capture Therapy). Esta é uma complexa técnica de terapia, e tem levado um tempo significativo para seu desenvolvimento desde sua primeira proposição [2].

\subsection{BNCT}

\subsubsection{Conceito}

A BNCT é uma técnica, que, como outras técnicas de combate ao câncer, visa destruir ou enfraquecer as células cancerígenas, minimizando a ocorrência de danos nas células sadias. A BNCT se baseia na produção de uma reação de captura gerada pela incidência de um feixe de nêutrons térmicos (nêutrons de até $0,5 \mathrm{eV}$ de energia) sobre os átomos de ${ }^{10} \mathrm{~B}$. A energia útil desta terapia não provém do feixe de irradiação, como no caso da radioterapia, mas sim da reação nuclear $(n, \alpha)$ promovida ao incidir-se 
nêutron no ${ }^{10} \mathrm{~B}$, fazendo com que duas novas partículas sejam geradas, e estas, por sua vez depositam suas energias localmente, levando as células que continham os átomos de ${ }^{10} \mathrm{~B}$ à destruição. Para uma boa aplicação da técnica há a necessidade de primeiramente injetar um composto contendo átomos de Boro no paciente. Este composto deve ser depositado na região que contem as células cancerígenas, e posteriormente esta região deve ser irradiada com nêutrons térmicos.

Portanto, para o sucesso da BNCT é necessário atender a duas condições primordiais:

- que haja um número suficiente de átomos de ${ }^{10} \mathrm{~B}$ em cada célula cancerígena, mas com baixa concentração nos átomos dos tecidos sadios. Para um tratamento perfeito se indica uma concentração de $10^{8}$ átomos de ${ }^{10} \mathrm{~B}$ por célula [3];

- que haja um número suficiente de nêutrons térmicos incidindo em cada célula contendo Boro. O tipo de feixe de nêutrons para a BNCT depende do tipo de tumor a ser tratado [3], sendo que, para tumores superficiais, deve-se utilizar nêutrons térmicos diretamente, pois estes nêutrons têm pouca capacidade de penetração, enquanto que, para regiões mais internas do corpo, se utilizam nêutrons epitérmicos (com energias entre $0,5 \mathrm{eV}$ e $100 \mathrm{keV}$ ), os quais perdem suas energias conforme atravessam as camadas de pele e órgãos. A regra é que se tente obter feixes de nêutrons térmicos na região do tumor com um fluxo de $5.10^{8} \mathrm{n} / \mathrm{cm}^{2} \mathrm{~s}$, com uma dose máxima de $1 \mathrm{~Gy} / \mathrm{h}$ de radiação gama e de $0,5 \mathrm{~Gy} / \mathrm{h}$ de nêutrons rápidos [3].

Porém estes parâmetros de concentração de átomos de ${ }^{10} \mathrm{~B}$ por célula e fluxo de nêutrons podem variar dependendo do tumor a ser tratado e tempo de exposição.

Hoje em dia é grande o número de estudos na busca por compostos borados que apresentem maior seletividade às células cancerígenas e com um maior tempo de permanência nestas células. É também realizado um estudo nas instalações para que seus feixes de tratamento atendam as exigências da terapia.

A necessidade de que os nêutrons estejam na faixa térmica vem do fato do átomo de ${ }^{10} \mathrm{~B}$ ter uma alta seção de choque para nêutrons desta energia e que outros nuclídeos que compõem nosso corpo (como os isótopos de Hidrogênio, Carbono, Oxigênio e Nitrogênio) terem baixas seções de choque nesta faixa energética. Sendo 
que para esta faixa de energia a seção de choque do ${ }^{10} \mathrm{~B}$ é quase que totalmente para a reação $(n, \alpha)$, e para os outros nuclídeos como o Hidrogênio a seção de choque para próton de recuo é a que prevalece. Para outras faixas de energia do nêutron, além do ${ }^{10} \mathrm{~B}$ não apresentar uma seção de choque tão alta, sua seção de choque é semelhante às seções de choque dos elementos que compõe o corpo humano, como pode ser visto na Figura 1.

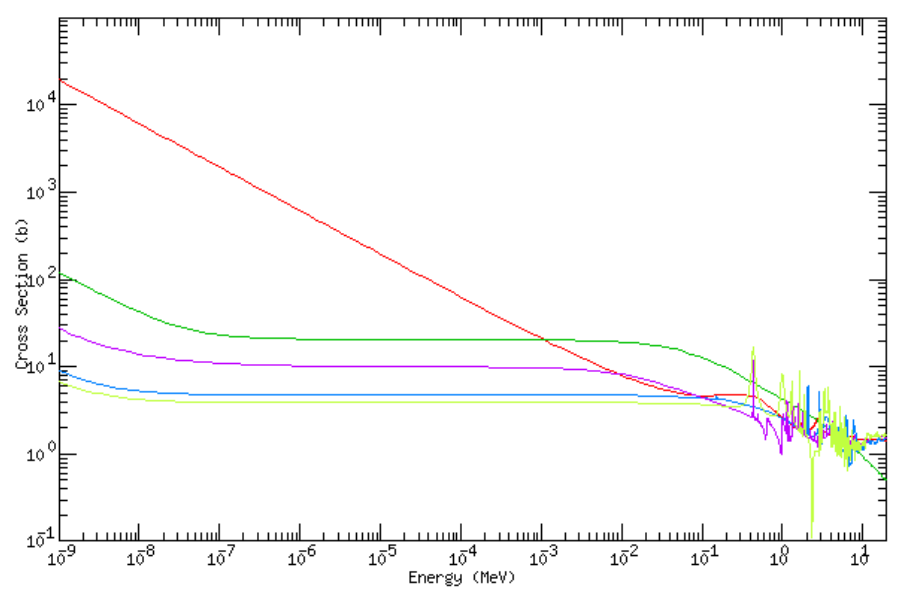

Figura 1 - Seções de choque total para os nêutrons dos átomos de ${ }^{10} \mathrm{~B}$ (vermelho), Hidrogênio (verde escuro), Carbono (azul), Nitrogênio (roxo) e Oxigênio (verde claro) [4]

Quando os nêutrons térmicos interagem com o átomo de ${ }^{10} \mathrm{~B}$, a principal reação que ocorre é a reação $(n, \alpha)$ :

$$
.{ }^{10} B(n, \alpha){ }^{7} \mathrm{Li}
$$

Esta equação mostra que a reação de captura do ${ }^{10} \mathrm{~B}$ gera duas partículas: o átomo de ${ }^{7} \mathrm{Li}$ e a partícula alfa. A reação mostrada na Eq. 1.1 pode ocorrer de duas formas liberando uma energia de 2,79 MeV: na primeira é gerado o átomo de Lítio no estado excitado (com uma energia de excitação de $480 \mathrm{keV}$ ), na qual a energia liberada é de 2,31MeV (este caso tem uma probabilidade de ocorrência de 93,7\%); e na segunda é gerado o átomo de Lítio no estado fundamental (com uma probabilidade de ocorrência de 6,3\%) [3]. Esta energia liberada vem na forma de energia cinética nas duas partículas geradas e devido às partículas produzidas terem uma alta taxa de Transferência Linear de Energia (LET - Linear Energy Transfer), estas por sua vez transferem esta energia para as células tumorais ao colidirem, destruindo ou enfraquecendo o tumor. 


\subsubsection{Histórico}

A proposição de uma terapia que utilizaria as propriedades dos nêutrons ocorreu logo após sua descoberta em 1932. Goldhaber [5], em 1934, mostrou que os átomos de Boro sofrem a reação de captura $(n, \alpha)$ ao serem irradiados por nêutrons térmicos, produzindo as duas partículas com alto LET. Em 1936, Locher [2], em seu trabalho, propõe os princípios para uma terapia por captura de nêutrons, postulando que se o Boro pudesse ser incorporado seletivamente aos tumores e estes pudessem ser expostos a nêutrons térmicos, resultaria em uma alta taxa de dose no tumor em comparação aos tecidos adjacentes [6] [7].

Os primeiros grandes avanços da técnica começaram a aparecer nos anos 50, quando se realizaram os primeiros testes em pacientes no Brookhaven Graphite Research Reactor (BGRR) [8], enquanto Soloway e seus colaboradores trabalhavam em um composto não tóxico de Boro no Massachusetts General Hospital.

Entre os anos de 1959 e 1961 uma série de irradiações foram realizadas no Massachussetts Institute of Technology Reactor (MITR) na tentativa de tratamento de tumores cerebrais, enquanto outras tentativas de tratamento eram realizadas com uma série de pacientes no recém construído Brookhaven Medical Research Reactor (BMRR). Entretanto, após as irradiações nenhuma melhora em comparação com as terapias convencionais havia sido notada, e por isso os testes nos EUA foram praticamente encerrados [3].

O grande problema associado ao fracasso da técnica neste período estava no fato de que o composto contendo os átomos de Boro utilizado (BORAX) não apresentava uma seletividade adequada e apresentava um baixo tempo de residência, o que fazia com que o composto se espalhasse pela corrente sanguínea do paciente durante a irradiação. Outro fato adivinha dos feixes de nêutrons térmicos, até então utilizados, que eram pouco penetrantes, o que gerava altas doses nas primeiras camadas do tecido, mas não atingia de forma eficiente a região do tumor.

Apesar destas dificuldades iniciais, a busca por melhores compostos e pela melhoria das instalações continuou. Até 1967 Soloway e Hatanaka já haviam estudado mais de 150 compostos de Boro [9], quando Soloway desenvolveu o composto BSH. Com isto, testes clínicos se reiniciam em 1968 por Hatanaka no Japão, utilizando o Hitachi Training Reactor (HTR) em Tóquio [10], o que culminou no primeiro tratamento de tumor cerebral no Japão [7] [3]. Dos 90 casos de gliomas malignos que Hatanaka pesquisou, 40 foram tratados pela BNCT enquanto os outros 50 foram 
tratados pela combinação de multimodalidades (fóton-radioterapia e quimioterapia). Ao final dos tratamentos foi observado que o grupo da BNCT apresentou 5 anos de sobrevida, valor 4 vezes maior do que a sobrevida observada pelo grupo da multimodalidade [7].

Em 1994, já havia mais de 100 pacientes com tumores cerebrais tratados no Japão [11], em um total de 5 diferentes instalações distribuídas pelo país. Em todos estes procedimentos foram utilizados feixes de nêutrons térmicos.

Além dos tumores cerebrais, Mishima utiliza, a partir de 1988, outro composto de Boro, o BPA, para o tratamento de pacientes com melanomas inoperáveis e metastáticos e novamente algumas respostas positivas foram reportadas [12].

Devido ao sucesso divulgado pelos japoneses, tanto EUA como Europa se interessam pela BNCT, considerando que esta poderia ser uma boa alternativa para o tratamento de gliomas. Em 1994, recomeçam-se os estudos em BNCT nos EUA. Em 1996 são realizados testes clínicos com pacientes com glioma utilizando feixes epitérmicos de nêutrons em Petten na Holanda [3]. Em 1997, os testes em Petten já haviam tratado 15 pacientes com gliobastomas multiformes [6].

Atualmente vários países vêm realizando pesquisas na área do BNCT, e, em alguns, já houve a aplicação comercial do tratamento, como é o caso da Finlândia que comercializava seu tratamento para GBM [13]. No Japão, novas instalações e novas técnicas estão sendo planejadas para ampliar o programa de BNCT japonês, enquanto que na Itália já há pesquisas em técnicas dosimétricas e métodos de irradiação extracorpórea para o tratamento de câncer no fígado [14]. Outro país que teve forte avanço foi a Argentina, se tornando um dos principais centros de pesquisas em BNCT [15] [16].

\subsection{A BNCT no IPEN-CNEN/SP}

Os avanços apresentados pela técnica de BNCT nos últimos anos levou o interesse de pesquisadores do Instituto de Pesquisa Energéticas e Nucleares (IPENCNEN/SP) a unir esforços para implementar a técnica no Brasil e contribuir para o seu avanço. Para isto foi projetada e construída uma instalação de pesquisa em BNCT, (Figura 2), junto ao BH-3 do IEA-R1 do IPEN-CNEN/SP [17], nela se visavam pesquisas nas áreas de Física das Radiações e Radiobiologia; permite modular campo de 
irradiação (nêutrons e gamas) adequados para a aplicação da técnica de BNCT. Atualmente o grupo de pesquisas em BNCT do IPEN realiza pesquisas em conjunto com a UNICAMP, na área de dosimetria [18] [19], e com o Instituto Butantan, em estudos biológicos "in vitro" e "in vivo" [20] [21].

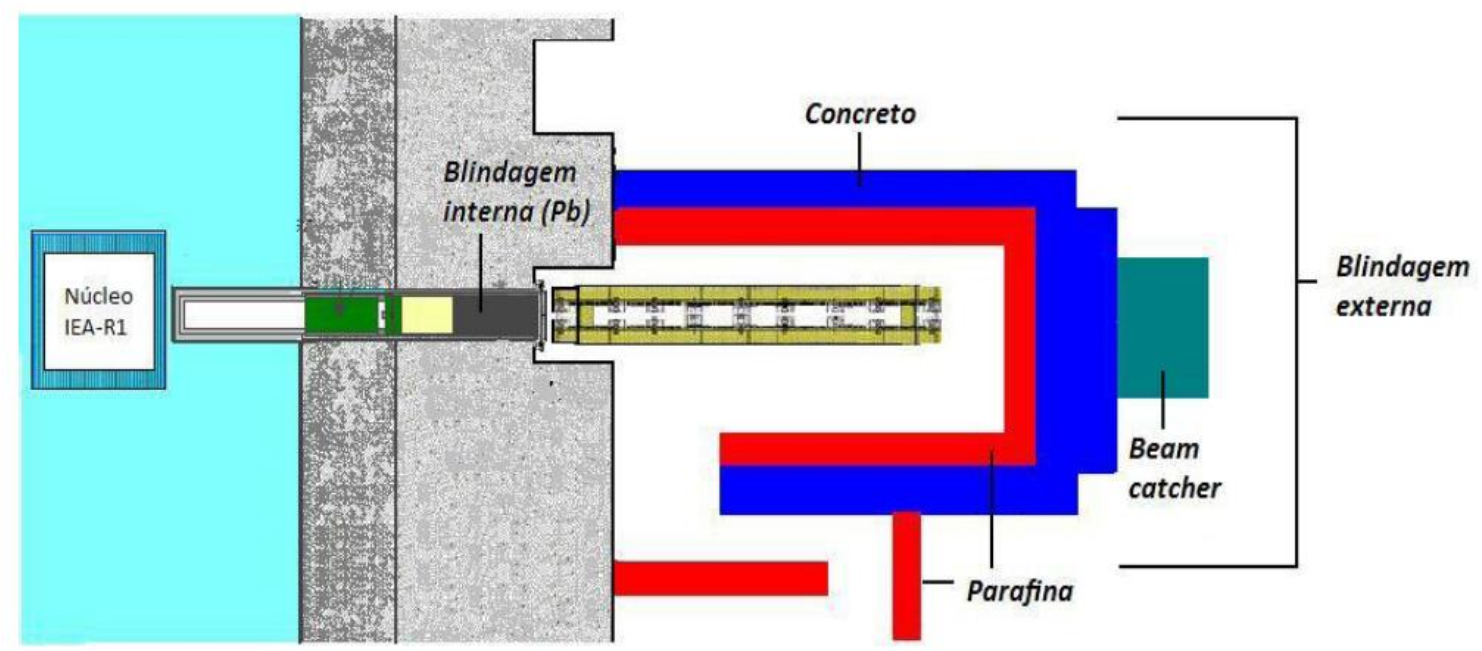

Figura 2 - Esquema da instalação de pesquisas em BNCT junto ao reator IEA-R1 no IPEN/CNEN [22]

Assim como em outros reatores nucleares, o campo proveniente do IEAR1 é um campo misto (sendo formado por gamas e nêutrons de diferentes energias). Uma das alternativas para a realização da dosimetria de campos mistos é a utilização de pares de detectores com respostas distintas para cada componente de campo [23]. Atualmente a caracterização do campo de irradiação é feita com folhas de ativação para os nêutrons e o TLD 400 para a monitoração gama. O grupo de pesquisas em BNCT do IPEN optou pelos TLDs 400 por estes não apresentarem sensibilidade aos nêutrons do feixe da instalação. 


\section{OBJETIVO}

A instalação para estudo em BNCT está disposta ao longo do extrator de feixe, Beam Hole, número 3 (BH-3) no reator IEA-R1. Para a realização dos estudos em BNCT há a necessidade de realizar a caracterização do feixe de irradiação e posteriormente maximizar a componente de nêutrons térmicos na posição de irradiação, minimizando as componentes de nêutrons epitérmicos, rápidos e radiação gama.

O objetivo deste trabalho é propor uma nova metodologia de dosimetria de campos mistos para o grupo de pesquisas em BNCT do IPEN, e assim possibilitar a adequada caracterização do campo de irradiação da instalação de BNCT do IPEN. A metodologia atual emprega folhas de ativação de ouro para realizar o cálculo do fluxo de nêutrons térmicos e epitérmicos e os TLDs 400 para a dosimetria gama.

Para a dosimetria de campos mistos, a Comissão Internacional de Unidades e Medidas (ICRU) recomenda a utilização de pares de detectores com sensibilidades distintas aos diferentes componentes do feixe [23]. A utilização do par de TLDs de LiF, TLD 600 e TLD 700, atende a esta recomendação. Estes TLDs têm sensibilidades distintas para nêutrons térmicos devido às diferentes concentrações do isótopo ${ }^{6} \mathrm{Li}$ em suas composições. Contudo os sinais de cada TLD não são devidos exclusivamente a esta única componente. Além da distinção quanto às suas sensibilidades, é necessário estar ciente da diminuição destas sensibilidades devido a sua degradação, além da auto-deposição de energia pelo decaimento do trítio produzido na reação entre os nêutrons e o ${ }^{6} \mathrm{Li}$ [24].

O emprego adequado de uma metodologia de medida num grupo de pesquisas requer o domínio sobre as ferramentas de medida utilizadas. Buscando a implementação da metodologia de utilização do par de TLDs para a caracterização do campo de radiação de nossa instalação para finalidade de pesquisas do grupo de BNCT do IPEN, verificou-se a necessidade de um estudo mais aprofundado destes detectores quando empregados em campo misto de nêutrons e gamas [25].

Códigos de transporte de radiação baseados no método de Monte Carlo, apresentam-se como a ferramenta mais exata para cálculos de dose desde que adequadamente manipulados (correta modelagem do sistema). O código MCNP [26], um código de transporte de radiação amplamente consagrado, apresenta-se como ferramenta ideal para investigar os diferentes processos de deposição de energia nos 
TLDs além de atender os requisitos quanto à possibilidade da correta simulação dos experimentos idealizados. Portanto o MCNP apresenta-se como ferramenta ideal no encaminhamento do estudo proposto por possibilitar o entendimento da contribuição das diferentes componentes do campo na dose depositada sobre os distintos TLDs estudados.

\subsection{Objetivos Específicos}

Neste trabalho foram estudados os TLDs de LiF, TLD 600 e TLD 700, assim como o TLD de $\mathrm{CaF}_{2}$, TLD 400, que são utilizados pelo grupo de BNCT do IPEN para a dosimetria gama.

Um estudo mais profundo do uso e sensibilidade do par TLD 600/TLD 700 se faz necessário, pois mesmo a ICRU recomendando o uso de pares de detectores com respostas distintas para as diferentes componentes do campo [23], os sinais apresentados pelos TLDs não são devido a uma única componente do campo, sendo necessário obter o conhecimento de como estes sinais variam para os diferentes TLDs quando estes são irradiados em campos de diferentes intensidades e espectros.

Para melhor compreensão dos usos e respostas dos TLDs foram realizadas irradiações em fontes de gamas puro e fontes mistas. Para obter as estimativas de dose e fluxo das diferentes componentes de campo às quais os TLDs estavam expostos nas irradiações foram realizadas simulações com o MCNP5 e irradiações com as folhas de ativação.

Assim o objetivo primário deste trabalho, foi propor a adoção de uma nova metodologia utilizando os TLD 600 e TLD 700, e, portanto, necessitou-se o melhor entendimento das respostas de cada TLD frente aos diferentes campos, sua reprodutibilidade, a calibração dose versus resposta e seu uso na instalação de BNCT. 


\section{FUNDAMENTOS TEÓRICOS}

Nesta seção são apresentados os conceitos físicos presentes neste trabalho que envolve os fótons e nêutrons, a teoria dosimétrica termoluminescente e o código de transporte de radiação MCNP.

\subsection{Radiação}

O termo radiação passou a ser empregado a partir de 1900 para descrever ondas eletromagnéticas. Atualmente este termo se refere a todo espectro eletromagnético e também a todas as partículas atômicas e subatômicas já descobertas [27].

As radiações podem ser divididas em dois grupos: as radiações ionizantes e as não ionizantes. Uma radiação é dita ionizante se esta tem a capacidade de ionizar um átomo ou molécula do meio por qual esta irradiação atravessa. Este tipo de radiação compreende as radiações de Raios-X e gamas além dos átomos e partículas subatômicas (elétrons, prótons, nêutrons, alfas, íons pesados, etc.). As radiações não ionizantes compreendem as radiações eletromagnéticas com comprimento de onda igual ou maior que $10 \mathrm{~nm}$ (ondas de rádio, micro-ondas, espectro visível e radiação ultravioleta) [27].

\subsection{Radioatividade}

O fenômeno da radioatividade consiste na emissão de radiação por elementos radioativos, por exemplo, os nuclídeos muito energéticos, que por terem excesso de partículas ou de energia, tendem a se estabilizar a partir da emissão de partículas.

A radioatividade foi observada pela primeira vez em 1936 pelo físico Antoine H. Becquerel, que constatou que sais de urânio emitiam algum tipo de radiação que era capaz de produzir a imagem de objetos metálicos em chapas fotográficas. Após a descoberta de Becquerel, o casal Curie passou a estudar o assunto, até que em 1898 
conseguem obter uma pequena quantidade de um material muito radioativo, ao qual deram o nome de Radium, o que levou a criação do termo radioatividade [28].

\subsection{Interação de Fótons com a Matéria}

As interações entre fótons e a matéria ocorrem também para os raios-X (fótons com energias entre alguns $\mathrm{keV}$ até $1 \mathrm{MeV}$ ) e radiações gama (fótons com energia superiores a $1 \mathrm{MeV}$ ). Os raios-X são geralmente produzidos por transições atômicas ou pelo efeito de bremsstrahlung e os raios gamas são emitidos em transições nucleares [27].

Há várias maneiras de como a interação entre os fótons e a matéria podem ocorrer, e nos tópicos subsequentes serão discutidas as três mais importantes.

\subsubsection{Efeito fotoelétrico}

O efeito fotoelétrico é caracterizado pela interação entre o fóton e um elétron orbital do átomo (geralmente das camadas $\mathrm{K}$ ou L). Neste efeito o fóton desaparece, fornecendo toda sua energia para o elétron que é ejetado com uma energia cinética bem definida $\left(E_{c}\right)$, Eq. 3.1. Este elétron ejetado, por vezes, é chamado de fotoelétron.

$$
E_{c}=h v-B_{e}
$$

onde $E_{c}$ é a energia cinética com que o elétron foi ejetado, $h$ é a constante de Planck, $v$ é a frequência do fóton incidente e $B_{e}$ é a energia de ligação do elétron orbital. $O$ valor da multiplicação de $h$ por $v$ fornece a energia do fóton incidente.

A direção de saída do elétron em relação a de incidência do fóton varia com a energia. Para altas energias (acima de $3 \mathrm{MeV}$ ), a probabilidade do elétron sair na direção e sentido do fóton é alta; e para baixas energias (abaixo de $20 \mathrm{keV}$ ) a maior probabilidade é a de o elétron sair com um ângulo de $70^{\circ}$. Isto devido a ação dos campos elétricos e magnéticos [29]. 


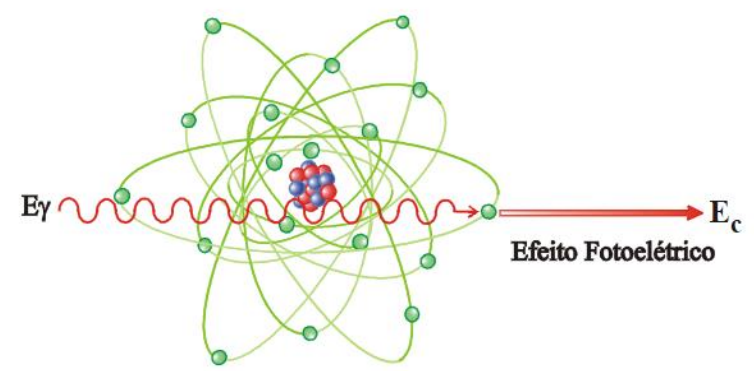

Figura 3 - Representação do efeito fotoelétrico [29]

O efeito fotoelétrico tem maior probabilidade de ocorrência para materiais com alto valor de $Z$, e também é mais provável para as energias dos fótons entre 10 e $500 \mathrm{keV}$ no mesmo material.

\subsubsection{Espalhamento Compton}

Neste efeito ocorre a interação de um fóton incidente com um elétron de baixa energia de ligação (alguns $\mathrm{eV}$ ), porém, neste caso, o fóton não desaparece, ele apenas muda a direção de propagação e cede parte de sua energia para o elétron (Figura 4). Conforme a energia de ligação do elétron se torna desprezível frente à energia do fóton incidente, a probabilidade de que ocorra o espalhamento Compton cresce consideravelmente.

Assumindo que o elétron estava em repouso antes da colisão, a energia cedida ao elétron, $E_{c}$, pode ser calculada através da conservação de energia:

$$
E_{c}=E_{\gamma}-E_{\gamma}^{\prime}
$$

onde $E_{\gamma}$ e $E_{\gamma}^{\prime}$ são respectivamente a energia do fóton incidente e a energia do fóton espalhado.

Porém, levando-se em conta também a conservação do momento, podese calcular a energia do fóton espalhado e a energia cinética do elétron a partir do ângulo de espalhamento do fóton $(\theta)$, a partir das Eq. 3.3 e Eq. 3.4.

$$
E_{\gamma}^{\prime}=\frac{E_{\gamma}}{1+(1-\cos \theta) E_{\gamma} / m c^{2}}
$$




$$
E_{c}=\frac{(1-\cos \theta) E_{\gamma} / m c^{2}}{1+(1-\cos \theta) E_{\gamma} / m c^{2}} E_{\gamma}
$$

O mais importante para a medição de radiação são os casos de máxima e mínima energia do fóton espalhado após a colisão. A energia mínima do fóton após a colisão (máxima energia do elétron) ocorre quando $\theta=\pi$, que de acordo com a Eq. 3.3 é de $E_{\gamma} /\left(1+2 E_{\gamma} / m c^{2}\right)$, existe então uma energia mínima do fóton espalhado, diferente de zero e, portanto, no espalhamento Compton, é impossível que toda energia do fóton incidente seja transferida para o elétron. A máxima energia do fóton após a colisão ocorre para $\theta=0$, que significa essencialmente que a colisão não existiu e o fóton espalhado continua com a mesma energia do fóton incidente [27].

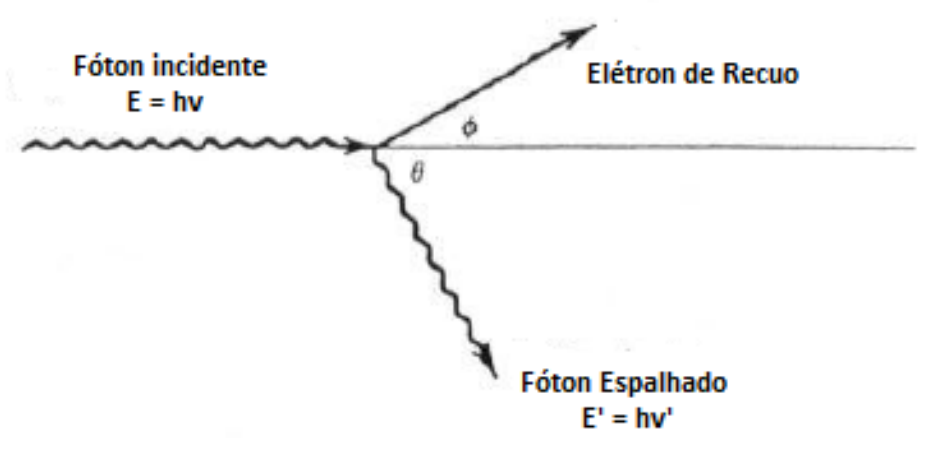

Figura 4 - Representação do espalhamento Compton [30]

\subsubsection{Produção de pares}

Para energias superiores a alguns $\mathrm{MeV}$, uma das formas predominantes de interação de fótons é a produção de pares elétrons-pósitrons. A produção de pares é uma interação entre o fóton e um núcleo, onde o fóton desaparece dando origem ao par elétron-pósitron, porém o núcleo não sofre nenhuma alteração, sua presença só é necessária para que haja a conservação de momento.

Para ocorrer este tipo de interação o fóton deve ter uma energia inicial igual ou maior que 1,022 MeV (duas vezes a massa de repouso do elétron), e a partir da conservação da energia temos a energia cinética do elétron e do pósitron gerados, conforme a Eq. 3.5 


$$
E_{c}^{e}=E_{c}^{p}=\frac{1}{2}\left(E_{\gamma}-1,022 \mathrm{MeV}\right)
$$

onde $E_{c}{ }^{e}$ é a energia cinética do elétron, $E_{c}{ }^{p}$ é a energia cinética do pósitron e $E_{\gamma}$ é a energia do fóton incidente.

A produção de pares elimina o fóton original, mas dois novos fótons são gerados quando o pósitron é aniquilado, estes fótons são chamados de fótons de aniquilação [27].

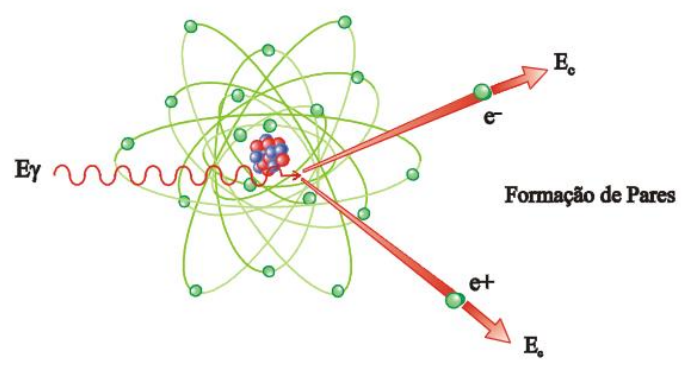

Figura 5 - Representação da produção de pares [29]

\subsubsection{Importância relativa de cada efeito}

A ocorrência destes eventos depende da energia $(E)$ e do número atômico do material (Z). A Figura 6 apresenta as regiões onde a ocorrência de cada um destes eventos é mais predominante.

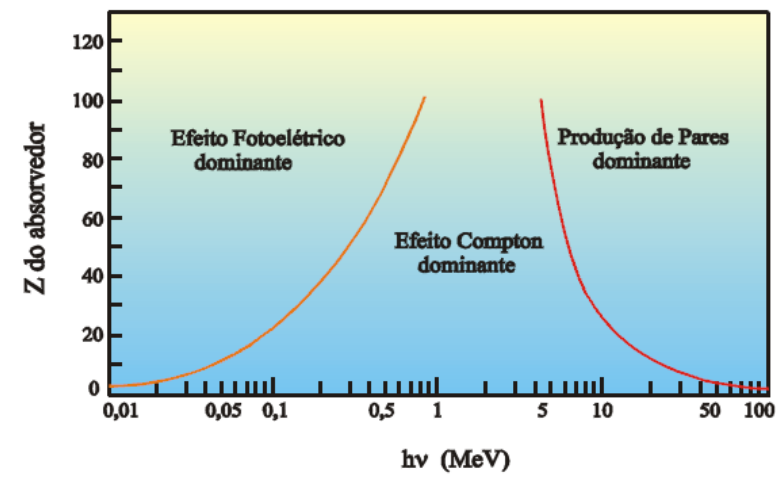

Figura 6 - Importâncias relativas dos diversos processos de interação dos fótons com a matéria em função da energia do fóton e do número atômico do material [29] 
É possível observar que as interações fotoelétricas predominam para todos os materiais em energias de fótons suficientemente baixas $(\mathrm{E} \leq 50 \mathrm{keV})$, mas à medida que a energia cresce, o efeito fotoelétrico diminui e o efeito Compton torna-se o efeito predominante. Acima da energia de alguns $\mathrm{MeV}$, a produção de pares passa a ser a principal interação de fótons com a matéria [29].

\subsection{Interação dos Nêutrons com a Matéria}

Os nêutrons, juntamente com os prótons, são os constituintes do núcleo atômico, porém estes não apresentam carga se tornando muito penetrantes, pois não interagem com a matéria através da força coulombiana. Assim, os nêutrons interagem com os núcleos atômicos somente através das forças nucleares. Como resultado desta interação, ou o nêutron pode desaparecer completamente e dar origem a radiações secundárias ou apenas altera a sua energia e direção [30].

A probabilidade de interação dos nêutrons com a matéria muda drasticamente com o nuclídeo alvo e com a energia do nêutron. Para simplificação destas interações, os nêutrons são divididos em dois grupos de energia: nêutrons lentos, com energia até $0,5 \mathrm{eV}$, e nêutrons rápidos, com energia superior a $0,5 \mathrm{eV}$.

\subsubsection{Interações com Nêutrons Lentos}

As interações mais prováveis para nêutrons nesta faixa energética são o espalhamento elástico ou um grande número de reações induzidas por nêutrons. Devido à baixa energia cinética destes nêutrons, pouca energia é transferida para os núcleos no espalhamento elástico, sendo que este serve apenas para trazer os nêutrons para o equilíbrio térmico com o meio antes que diferentes tipos de reações ocorram. Os chamados nêutrons térmicos apresentam sua energia média em torno dos $0,025 \mathrm{eV}$ [30].

Neste trabalho a principal interação que ocorre é a $(\mathrm{n}, \alpha)$, quando o ${ }^{6} \mathrm{Li}$ dos TLDs de LiF é irradiado em campos com nêutrons da faixa térmica.

\subsubsection{Interações com Nêutrons Rápidos}

Para esta faixa energética dos nêutrons, após a interação o núcleo recebe uma significativa quantidade de energia e então é chamado de núcleo de recuo. Em cada 
colisão os nêutrons vão perdendo sua energia, sendo então moderados até baixas energias. Materiais com grande quantidade de átomos de Hidrogênio são considerados melhores moderadores para nêutrons, isto porque o nêutron pode perder quase toda sua energia com apenas uma colisão com o átomo de Hidrogênio [30].

Se a energia do nêutron for suficientemente alta, o espalhamento inelástico passa a ser a interação mais provável. Neste caso o núcleo que sofre a colisão e vai para um estado excitado, e quando este núcleo volta para seu estado fundamental ele acaba emitindo raios gama.

\subsubsection{Seção de Choque}

No caso de nêutrons ou fótons com uma energia determinada, a probabilidade de interação é constante para cada tipo de interação. Esta probabilidade é normalmente expressa em termos da seção de choque por núcleos ou seção de choque microscópica $(\sigma)$ para cada tipo de interação. A seção de choque microscópica tem unidade de área e comumente é utilizado o barn em suas medidas, em que 1 barn equivale a $10^{-28} \mathrm{~m}^{2}$.

A seção de choque macroscópica $(\Sigma)$ é definida como sendo a seção de choque microscópica multiplicada pelo número de núcleos presentes por unidade de volume $(N)$, tendo como unidade o inverso do comprimento.

$$
\Sigma=N . \sigma
$$

A interpretação de seção de choque macroscópica é a probabilidade por unidade de comprimento, de certa interação ocorrer. Pode ser calculada a seção de choque macroscópica total, onde são somadas as seções de choque macroscópicas de cada interação [Eq.3.7]. Esta seção de choque macroscópica total representa a probabilidade de que qualquer tipo de interação ocorra por unidade de comprimento.

$$
\Sigma_{\text {total }}=\Sigma_{\text {espalhamento }}+\Sigma_{\text {captura }}+\cdots
$$




\subsection{Grandezas Radiológicas}

Desde que surgiram as primeiras preocupações com a possibilidade das radiações ionizantes induzirem detrimentos à saúde humana, apareceram métodos de produção, caracterização e medição da radiação, bem como de definição de grandezas que expressem com realismo a sua interação com tecido humano [29].

As publicações da ICRP n ${ }^{\circ}$ 26, de 1977 [31], e $n^{\circ} 60$ de 1990 [32] foram duas importantes referências no tocante estabelecimento de grandezas radiológicas, suas relações e métodos de medição, dentro de uma concepção mais coerente possível. Na ICRP 60 surgiram novas grandezas, algumas em substituição às grandezas definidas na ICRP 26.

\subsubsection{Atividade $(A)$}

Atividade é o número de transformações nucleares que ocorrem no material por unidade de tempo. A unidade atualmente utilizada para esta grandeza é o becquerel $(B q)$ que corresponde a uma transformação por segundo, porém em alguns casos ainda se utiliza a unidade curie $(\mathrm{Ci})$ que corresponde a $3,7.10^{10} \mathrm{~Bq}$.

$$
A=-\frac{d N}{d t}
$$

onde $N$ é o número de núcleos radioativos contidos na amostra, sendo que uma transformação não significa necessariamente a emissão de apenas uma radiação, pois numa transformação nuclear podem ser emitidas mais de uma partícula e com diferentes energias.

\subsubsection{Fluência $(\varphi)$ e Fluxo $(\Phi)$}

A fluência é o número de partículas, $d N$, que incidem sobre uma seção de área $d a$, a unidade utilizada para fluência no Sistema Internacional é o $\mathrm{m}^{-2}$.

$$
\varphi=\frac{d N}{d a}
$$


As partículas $N$ correspondem às partículas emitidas, transferidas ou recebidas.

Define-se a grandeza fluxo (ou taxa de fluência), como a razão entre a grandeza fluência pelo tempo decorrido. Normalmente a unidade utilizada é $\mathrm{m}^{-2}$.s.

$$
\phi=\frac{d \varphi}{d t}
$$

\subsection{3. $\operatorname{Kerma}(K)$}

O kerma (Kinectic Energy Released per unit of Mass) é relevante para campos de radiação indiretamente ionizantes (como o caso dos fótons e nêutrons) [33].

Kerma é definido como a energia transferida pela radiação não ionizante para partículas carregadas, $E_{t r}$, por unidade de massa [33]. A energia do fóton é transferida para a matéria em dois passos: primeiro a energia é transferida para partículas carregadas do meio através de vários processos (efeito fotoelétrico, efeito Compton, produção de pares, etc.); posteriormente estas partículas carregadas secundárias transferem a energia para o meio através de excitações atômicas e ionizações.

$$
K=\frac{d E_{t r}}{d m}
$$

A unidade utilizada para o kerma é o gray (Gy), que corresponde a 1 $\mathrm{J} / \mathrm{kg}$.

O kerma apresenta duas componentes, pois a energia pode ser dissipada de dois modos: uma através de interações com a força coulombiana dos elétrons do material absorvedor, resultando em uma dissipação de energia próxima ao local do caminho do elétron, este modo é chamado de interação por colisão; o outro modo ocorre através da interação radioativa com o campo coulombiano do átomo, onde raios-X são emitidos pelos elétrons ao serem desacelerados, e assim carregam a energia mais longe do que o caminho da partícula carregada, este modo é chamado de interação radioativa. 
Portanto o kerma total pode ser dividido em duas partes, o kerma de colisão $\left(K_{c}\right)$ e o kerma radioativo $\left(K_{r}\right)$.

$$
K=K_{c}+K_{r}
$$

\subsubsection{Dose Absorvida (D)}

A dose absorvida é relevante para todos os tipos de radiações, tanto direta como indiretamente ionizantes, e também por qualquer fonte de radiação distribuída dentro do material absorvedor [33].

Dose absorvida é definida como a energia transmitida para a matéria por unidade de massa em um ponto de interesse.

$$
D=\frac{d E}{d m}
$$

Como no caso do kerma, a unidade utilizada para dose absorvida também é o gray (Gy).

\subsection{Dosímetros Termoluminescentes (TLDs)}

Os dosímetros termoluminescentes (TLDs) são cristais ou policristais inorgânicos dopados com quantidades adequadas de ativadores e, como o próprio nome já diz, funcionam baseado na propriedade termoluminescente que apresentam.

Os ativadores presentes criam alguns tipos de imperfeições na rede cristalinas: armadilhas para elétrons, que capturam e aprisionam os portadores de carga, e os centros de luminescência [29].

A radiação ionizante, ao interagir com os elétrons, cede energia para estes elétrons que então saem da camada de valência indo para a camada de condução e podem ser presos em armadilhas criadas pelos ativadores. Após a irradiação se o material é submetido a um aquecimento, os elétrons aprisionados nas armadilhas podem 
ser liberados para a banda de condução, fazendo com que estes elétrons emitam fótons ao retornarem à banda de valência (Figura 7).

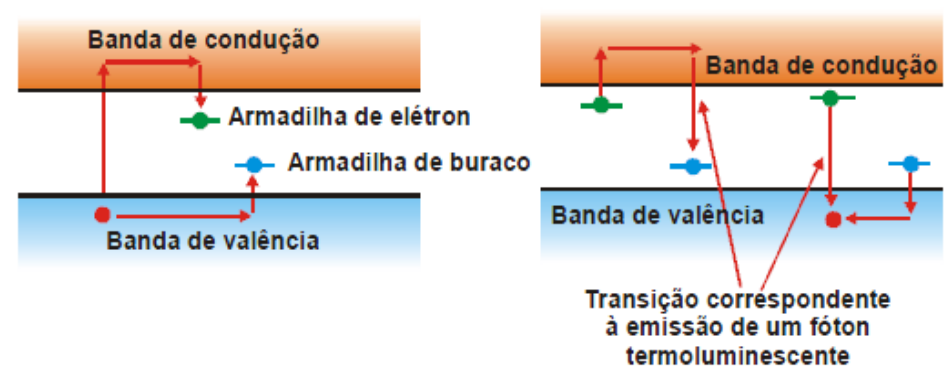

Figura 7 - Processo termoluminescente [29]

A sensibilidade dos TLDs está diretamente relacionada com a quantidade de luz liberada, quando aquecidos por unidade de dose de radiação absorvida.

O procedimento de uso destes dosímetros consiste em irradiá-los e posteriormente realizar suas medições em uma leitora de TLD, que aquece os TLDs de forma controlada e mede a intensidade de luz emitida. Esta intensidade luminosa é dada pelas curvas de emissão termoluminescente, Figura 8, que podem apresentar vários picos. Entre estes picos, aqueles que apresentam boa sensibilidade e estabilidade são selecionados para a realização das medidas dosimétricas, e por isto recebem o nome de picos dosimétricos.

Pode ser definida uma região na qual se encontram os picos dosimétricos. A esta região é dado o nome de Região de Interesse (ROI - Region of Interest).

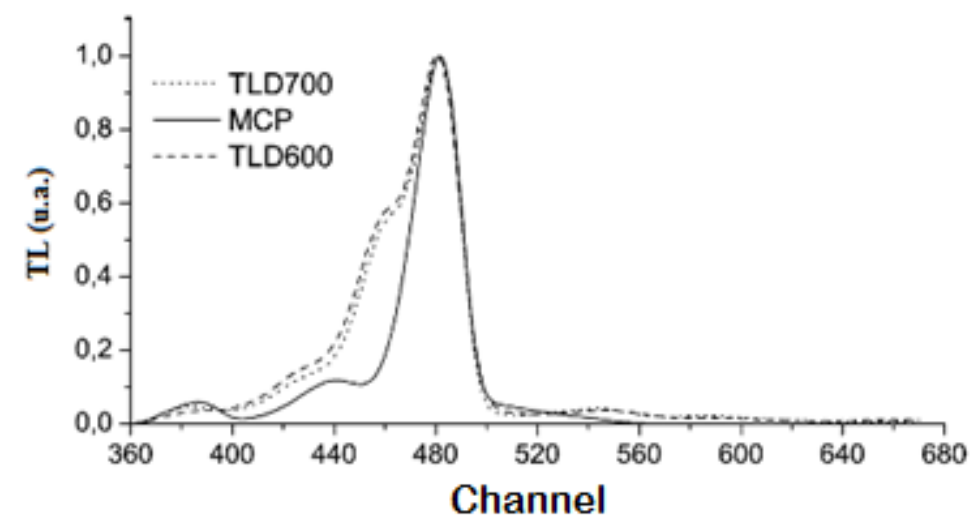

Figura 8 - Curvas termoluminescentes de três diferentes tipos de TLDs irradiados em um fonte de ${ }^{60} \mathrm{Co}[34]$ 
A intensidade luminosa em forma de pico da curva termoluminescente pode ser estimada teoricamente a partir das probabilidades de elétrons escaparem de uma armadilha, de ele ser preso nas armadilhas, dentre outros fatores. Este modelo teórico pode ser visto no trabalho de M. Böhm e A. Scharmann [35]. Uma breve descrição deste modelo pode ser encontrada no Anexo A.

Os TLDs podem ser reutilizados e, para isto, basta realizar seu tratamento térmico. Este tratamento térmico consiste em deixar os TLDs dentro de muflas, mantidas aquecidas em temperaturas determinadas por certo período de tempo. Cada tipo de TLD apresenta seu tratamento térmico específico. Durante este tratamento é fornecido aos TLDs energia suficiente para que os elétrons que ainda estejam presos nas armadilhas possam se libertar, fazendo então com que as informações dosimétricas armazenadas nestes TLDs sejam apagadas.

Assim a utilização do TLD compreende um ciclo: tratamento térmico, irradiação e leitura.

\subsubsection{Aplicações dos TLDs}

Devido à grande variedade de tipos de TLDs, seu uso é bastante diversificado, como por exemplo, para monitoramento pessoal, monitoramento ambiental, dosimetria gama, dosimetria beta e dosimetria de nêutrons.

Neste trabalho foi visada a dosimetria de campo misto (gamas e nêutrons) do feixe de irradiação da instalação de BNCT no reator IEA-R1, e para isto uma das técnicas utilizadas é o uso de pares de detectores com respostas distintas para cada uma das componentes do campo. Os TLDs podem ser usados para este propósito, pois há diferentes tipos de TLDs que respondem de diferentes maneiras para cada componente do campo de irradiação.

Esta técnica de uso dos TLDs já vem sendo estudadas há um bom tempo e sendo realizadas em algumas instalações de BNCT pelo mundo [36] [37]. 


\subsubsection{Utilização de pares de TLDs para a dosimetria de campos mistos}

Na utilização de pares de TLDs para dosimetria de campos mistos pode se utilizar o par TLD 600 e TLD 700, no qual comumente é realizada a suposição de que o TLD 700 seja sensível somente à radiação gama e o TLD 600 seja sensível tanto à radiação gama como aos nêutrons térmicos.

Nesta técnica se realiza a irradiação dos dois TLDs e considera-se que a leitura do TLD $700\left(\mathrm{~L}_{7}\right)$ apresenta a dose gama deste campo a menos de uma constante de conversão da leitura do TLD para dose, e a leitura do TLD $600\left(L_{6}\right)$ apresenta a soma da dose devido aos nêutrons e a dose devido à radiação gama a menos de uma constante. Partindo do princípio que o TLD 600 e o TLD 700 respondem da mesma forma para a radiação gama, uma vez que apresentam a mesma composição química, para se obter a dose devido a nêutrons basta então converter as respostas dos TLDs para dose $\left(R_{6}\right.$ e $\left.R_{7}\right)$ e realizar a subtração destas respostas.

$$
\begin{gathered}
D_{\gamma}=R_{7} \\
D_{n}=R_{6}-R_{7}
\end{gathered}
$$

Porém certo cuidado deve ser tomado quando se utiliza esta técnica em campos com alta componente de nêutrons térmicos, pois mesmo o TLD 700 tendo baixa concentração do isótopo ${ }^{6} \mathrm{Li}$, este ainda se faz presente e tem influência sobre a resposta final do TLD, e a autoblindagem gerada no TLD 600 faz com que sua resposta seja menor do que a esperada [24]. Outro fato é que apesar de uma menor sensibilidade dos isótopos de Li para nêutrons de alta energia, em um campo contendo alto fluxo de nêutrons rápidos, os TLDs também podem armazenar informações devido a estes nêutrons também. Portanto esta técnica não deve ser utilizada sem um conhecimento claro de suas limitações. 


\subsection{MCNP - Monte Carlo N-Particle Radiation Transport Code}

O MCNP é um código computacional de transporte de radiação que utiliza o método de Monte Carlo para estimar as respostas dos sistemas simulados.

O método de Monte Carlo baseia-se na solução numérica (estocástica) de problemas, e quando utilizados em física de radiações modelam as interações das radiações com objetos à partir de funções de probabilidades para as diferentes interações possíveis. O código MCNP fornece a solução de sistemas macroscópicos através de simulações das interações microscópicas [38].

O método Monte Carlo é comumente utilizado em diversos segmentos da ciência e da engenharia que podem ser representados por processos estocásticos. Entre estes se destaca seu uso em física médica, no qual é uma ferramenta fundamental para cálculos de dose absorvida e outras grandezas de interesse relacionadas ao tratamento do câncer por radiação [39].

Neste trabalho foi utilizado o MCNP5 [26] nas simulações. Este código foi desenvolvido pelo Los Alamos National Laboratory (LANL), e pode ser usado para o transporte de nêutrons, fótons, elétrons individualmente ou de modo acoplado [40]. Para o propósito deste trabalho o MCNP5 foi utilizado para simular as configurações de irradiações nas quais os TLDs estavam expostos e assim calcular quais seriam os fluxos e as doses devido aos nêutrons, em seus diferentes grupos energéticos, e aos gamas.

Para realizar as simulações com o MCNP é necessário entrar com arquivos de entrada (input) que é composto por três blocos:

- $1^{\circ}$ bloco: contendo as células, para caracterização das unidades de volume que fazem parte da simulação, com seus materiais e densidades, além das importâncias para as diferentes componentes do campo;

- $\quad 2^{\circ}$ bloco: contendo as superfícies utilizadas para delimitar as células;

- $3^{\text {o }}$ bloco: contendo a descrição dos materiais e seções de choque a serem utilizados; o espectro energético e o formato/distribuição das fontes; partículas a serem simuladas; tempo ou partículas geradas na simulação; e os tallies, que são os cálculos a serem apresentados.

Os resultados obtidos pelo MCNP, assim como as demais informações, são apresentados no arquivo de saída (output). 
O MCNP5 foi utilizado neste trabalho para o cálculo de fluxos, kermas no ar devido aos fótons e aos nêutrons, e, discriminalizar as doses devido a cada componente do campo. Para isto o MCNP5 utiliza cartões (tallies) que especificam a realização destes cálculos, os valores apresentados como resultado são valores médios da grandeza calculada, normalizados por partícula da fonte. O MCNP também apresenta a incerteza estatística associada a cada resultado.

Para realizar o cálculo de fluxo para nêutrons e/ou fótons foi utilizado o cartão F4. Este cartão considera uma partícula com peso $W$ e energia $E$ que realiza um trajeto, $T$ (traço), em um volume específico, $V$. Este segmento realiza uma contribuição de $W T / V$ para a fluência na célula. Tecnicamente, se $\Phi(r, E, \Omega)$ é a fluência em função da posição da energia e da distribuição angular, o cartão F4 irá calcular [41]:

$$
F 4=\frac{1}{V} \int d V \int d E \int d \vec{\Omega} \cdot \phi(\vec{r}, E, \vec{\Omega})
$$

A resposta deste cartão é dada em partículas por $\mathrm{cm}^{2}$ por partícula gerada na fonte.

Para efetuar os cálculos de kerma no ar e para doses nas células foi utilizado o cartão F6. Este cartão tem como base o cartão F4, mas leva em conta agora a densidade atômica, $\rho_{a}$, a massa da célula, $m$, a seção de choque total microscópica, $\sigma_{t}(E)$, e a energia liberada por colisões, $H(E)$ [26].

$$
F 6=\frac{\rho_{a}}{m} \int d V \int d E \int d \vec{\Omega} \cdot \sigma_{t}(E) \cdot H(E) \cdot \phi(\vec{r}, E, \vec{\Omega})
$$

A unidade da resposta obtida por este cartão é $\mathrm{MeV} / \mathrm{g}$ por partícula gerada na fonte. 


\section{MATERIAIS E MÉTODOS}

Nesta seção serão apresentados os materiais e as metodologias utilizadas neste trabalho.

\subsection{Dosímetros Termoluminescentes}

Neste trabalho foram utilizados 3 tipos de TLDs: TLD 600, TLD 700 e TLD 400. Foram utilizados um total de 42 TLDs de cada tipo nunca antes utilizados, os quais foram separados em 2 grupos: o grupo principal, contendo 30 TLDs, e o grupo de testes, contendo 12 TLDs.

O grupo principal foi utilizado em um estudo mais minucioso, no qual se verificou a reprodutibilidade destes TLDs, que foram calibrados em fonte de radiação gama pura e em campos mistos. Já o grupo teste foi utilizado inicialmente nas irradiações nos reatores, para se ter uma ideia inicial do comportamento dos TLDs nestes campos mais intensos.

Para minimizar possíveis diferenças nas respostas destes TLDs devido à diferenças no ciclo de uso dos TLDs, os TLDs sempre passaram pelo tratamento térmico um dia antes da irradiação e a leitura foi realizada um dia após a irradiação.

\subsubsection{TLD 600}

Este TLD é do tipo LiF:Mg,Ti enriquecido com ${ }^{6} \mathrm{Li}(95,62 \%)$. O ${ }^{6} \mathrm{Li}$ apresenta uma alta seção de choque para nêutrons térmicos, ao contrário do ${ }^{7} \mathrm{Li}$ como pode ser observado na Figura 9, e portanto o TLD 600 além de ser sensível à radiação gama também é sensível aos nêutrons térmicos. 


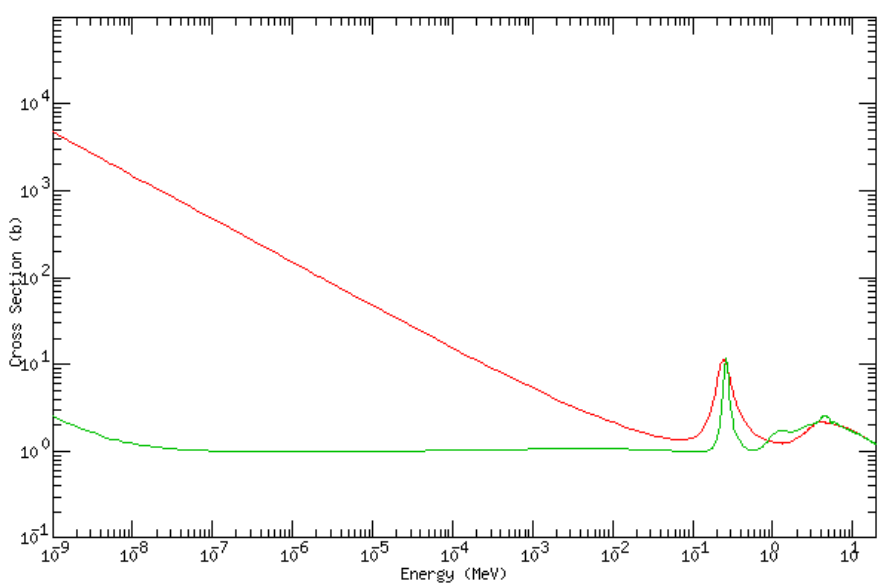

Figura 9 - Seção de choque total para nêutrons do ${ }^{6} \mathrm{Li}$ (vermelho) e ${ }^{7} \mathrm{Li}$ (verde) [4]

Segundo o fabricante, este TLD pode ser utilizado entre doses que variam de $10 \mu \mathrm{G}$ a $10 \mathrm{~Gy}$, tendo uma taxa de perda de sinal de $5 \%$ ao ano a uma temperatura de $20^{\circ} \mathrm{C}$ [42].

Este TLD apresenta duas regiões de interesse principais, uma por volta dos $195^{\circ} \mathrm{C}$ (que é comumente utilizada como pico dosimétrico) [43] e outra por volta de $250^{\circ} \mathrm{C}$, Figura 10 , sendo que estas regiões são formadas por vários picos dosimétricos que apresentam maior estabilidade.

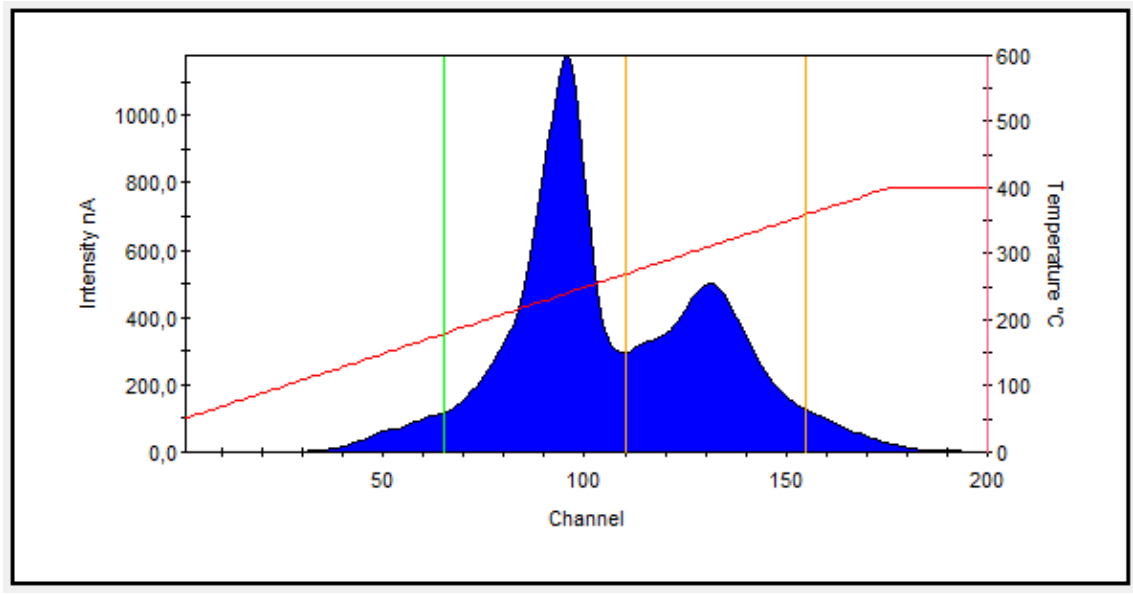

Figura 10 - Curva termoluminescente do TLD 600 e suas regiões de interesse

Analisando a temperatura de ocorrência das regiões de interesse do TLD 600 na Figura 10 e a temperatura de ocorrência das regiões de interesse obtidas na literatura, 
pode ser visto uma diferença entre estas temperaturas. Isto porque a leitora fornece a temperatura da bandeja e não a temperatura real do TLD.

\subsubsection{TLD 700}

Este TLD também é do tipo LiF:Mg,Ti, mas neste caso, enriquecido com ${ }^{7} \mathrm{Li}(99,99 \%)$. Portanto, devido à baixa concentração de ${ }^{6} \mathrm{Li}$ e como o ${ }^{7} \mathrm{Li}$ não apresenta alta seção de choque para nêutrons térmicos, este TLD apresenta uma sensibilidade devido a nêutrons térmicos muito inferior ao TLD 600, e a sensibilidade devido à radiação gama é semelhante a sensibilidade do TLD 600, pois estes TLDs têm a mesma composição química.

Este TLD, como no caso do TLD 600, pode ser utilizado entre as faixas de dose $10 \mu \mathrm{G}$ a 10 Gy e apresenta uma taxa de perda de sinal de $5 \%$ ao ano a uma temperatura de $20^{\circ} \mathrm{C}$, segundo o fabricante [42].

O TLD 700 apresenta regiões de interesse parecidas com o TLD 600, porém para o TLD 700 a segunda região não é muito significativa como no caso do TLD 600. O pico dosimétrico deste TLD é considerado como sendo o pico por volta dos $195^{\circ} \mathrm{C}$ [43], Figura 11.

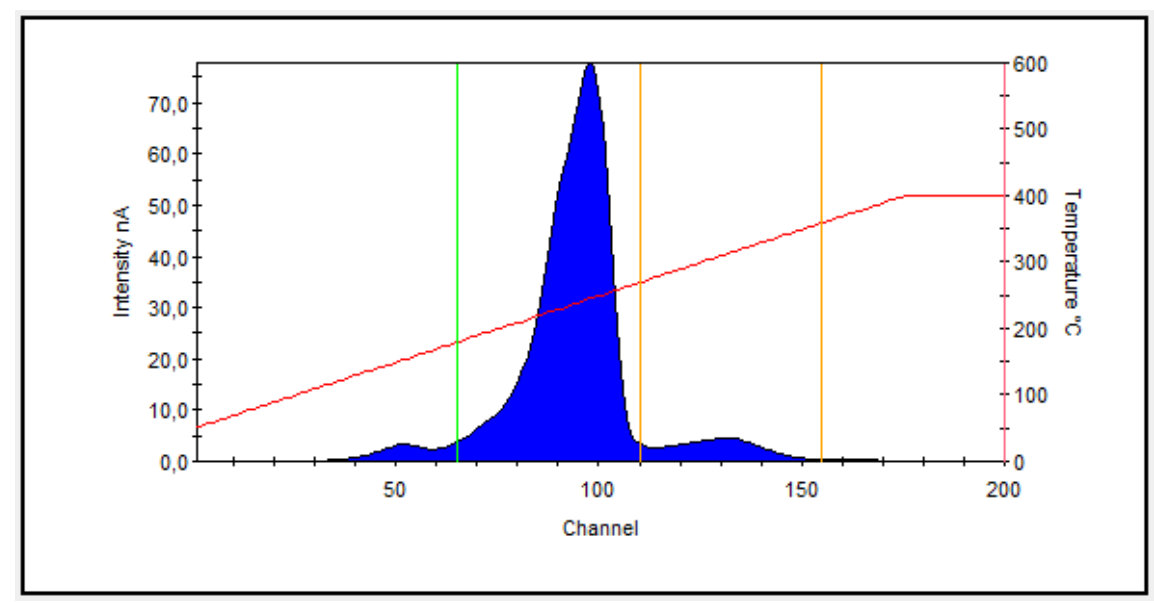

Figura 11 - Curva termoluminescente do TLD 700 e sua região de interesse 


\subsubsection{TLD 400}

Este TLD é do tipo $\mathrm{CaF}_{2}: \mathrm{Mn}$, e é considerado como sendo apenas sensível à radiação gama, uma vez que seus componentes não apresentam alta seção de choque para nêutrons.

O TLD 400 é mais sensível à radiação gama em comparação aos TLDs de LiF, o que pode ser observado na Tabela 1.

Tabela 1 - Comparação entre a sensibilidade dos diferentes TLDs [42]

\begin{tabular}{ccc}
\hline TLD & Zeff $^{1}$ & $\begin{array}{c}\text { Sensibilidade ao } \\
{ }^{\mathbf{6 0}} \mathbf{C o} \\
\text { relativo ao } \mathbf{~ L i F}\end{array}$ \\
\hline TLD 600 & 8,2 & 1,0 \\
TLD 700 & 8,2 & 1,0 \\
TLD 400 & 16,3 & $\sim 13$ \\
\hline
\end{tabular}

Segundo o fabricante, este TLD pode ser usado entre $0,1 \mu \mathrm{G}$ e $100 \mathrm{~Gy}$, e apresenta uma taxa de perda de sinal de $8 \%$ nas primeiras horas após a irradiação e posteriormente de $12 \%$ a cada 3 meses [42].

O TLD 400 apresenta apenas uma região de interesse, com o pico dosimétrico por volta dos $260^{\circ} \mathrm{C}$ [43], como pode ser visto na Figura 12.

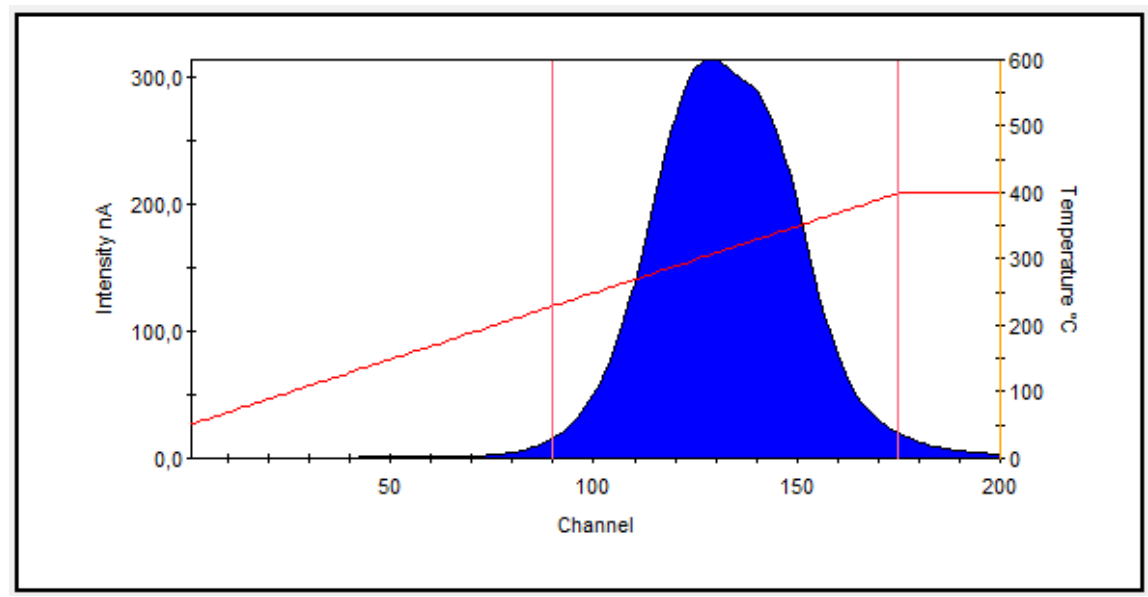

Figura 12 - Curva termoluminescente do TLD 400 e sua região de interesse

\footnotetext{
${ }^{1}$ Número atômico efetivo para a absorção fotoelétrica
} 


\subsubsection{Sensibilidade dos TLDs aos Nêutrons}

Conforme já explicado na seção anterior, o TLD 600 é dito sensível aos nêutrons térmicos devido à sua alta concentração do isótopo ${ }^{6} \mathrm{Li}$. Quando analisamos o TLD 700, muitos trabalhos o consideram apenas sensível à radiação gama, desconsiderando a baixa concentração de ${ }^{6} \mathrm{Li}$ presente nele. Porém mesmo esta baixa concentração é capaz de gerar respostas no TLD 700 devido à presença de nêutrons, o que levaria a uma subestimação da dose de nêutrons se fosse realizada a dosimetria de campo misto, utilizando o par TLD 600 - TLD 700, de um campo com alto fluxo de nêutrons térmicos, segundo a metodologia apresentada na seção 3.6.2.

Para melhor demonstrar a sensibilidade dose - resposta dos diferentes TLDs aos nêutrons térmicos, é apresentada, na Tabela 2, a resposta do material TL para uma fluência de $10^{10}$ de nêutrons térmicos por $\mathrm{cm}^{2}$, em termos da exposição equivalente em dose à radiação gama do ${ }^{60} \mathrm{Co}$ [35].

Tabela 2 - Sensibilidade aos nêutrons térmicos relativo ao ${ }^{60} \mathrm{Co}$ [35]

\begin{tabular}{cc}
\hline Material & $\begin{array}{c}\text { Sensibilidade aos } \\
\text { Nêutrons Térmicos }\end{array}$ \\
\hline TLD 600 & 1930 \\
TLD 700 & 1,5 \\
TLD 400 & 0,6 \\
\hline
\end{tabular}

Mas se for analisada novamente a curva de seção de choque da Figura 9, pode-se notar que para os nêutrons rápidos, a seção de choque do ${ }^{6} \mathrm{Li}$ e do ${ }^{7} \mathrm{Li}$ são equivalentes, e assim, a resposta dos TLD 600 e TLD 700 seriam muito parecidas para campos com alto fluxo de nêutrons rápidos. Na Tabela 3, estão apresentadas as respostas do LiF para uma fluência de $10^{10}$ de nêutrons monoenergéticos de diferentes energias em termos da exposição equivalente a radiação gama do ${ }^{60} \mathrm{Co}$ [35]. 
Tabela 3 - Sensibilidade do LiF para nêutrons de alta energia relativo ao ${ }^{60} \mathrm{Co}$ [35]

\begin{tabular}{cc}
\hline Energia $(\mathbf{M e V})$ & Sensibilidade do LiF \\
\hline $\mathbf{0 , 5}$ & 0,2 \\
$\mathbf{1 , 0}$ & 0,3 \\
$\mathbf{2 , 7}$ & 1,2 \\
$\mathbf{4 , 2}$ & 1,7 \\
$\mathbf{1 5}$ & 10 \\
\hline
\end{tabular}

\subsubsection{Tratamento Térmico}

Todos os TLDs, antes de serem irradiados, passaram por um tratamento térmico que teve como finalidade eliminar os elétrons aprisionados nas armadilhas ainda presentes nos TLDs após a realização da leitura. Cada tipo de TLD possui um tratamento padrão fornecido pelo fabricante.

A Tabela 4, apresenta as especificações dos tratamentos térmicos recomendados pela fabricante [42] e utilizados para os diferentes tipos de TLD utilizados.

Tabela 4 - Tratamento térmico utilizado nos diferentes tipos de TLD

\begin{tabular}{cc}
\hline Tipo de TLD & Tratamento Térmico \\
\hline LiF & 1 hora a $400^{\circ} \mathrm{C}$ e posteriormente \\
& 2 horas a $100^{\circ} \mathrm{C}$. \\
$\mathbf{C a F}_{2}$ & 1 hora a $400^{\circ} \mathrm{C}$. \\
\hline
\end{tabular}

Para realizar o tratamento térmico dos TLDs o grupo de BNCT dispõe de duas muflas, Figura 13. 

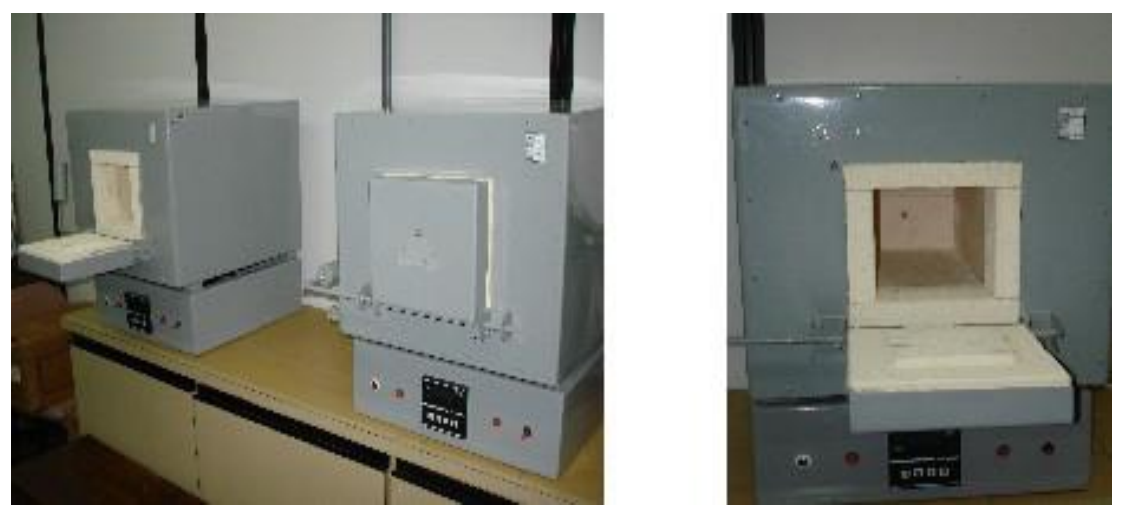

Figura 13 - Muflas utilizadas para o tratamento térmico dos TLDs

\subsubsection{Leitora de TLD}

Neste trabalho, os TLDs foram lidos na leitora de TLD Harshaw 3500, mostrada na Figura 14. Esta leitora foi adquirida pelo grupo de BNCT do IPEN, mas nunca havia sido utilizada e, portanto, foi realizado um estudo preliminar para a melhor utilização desta leitora.

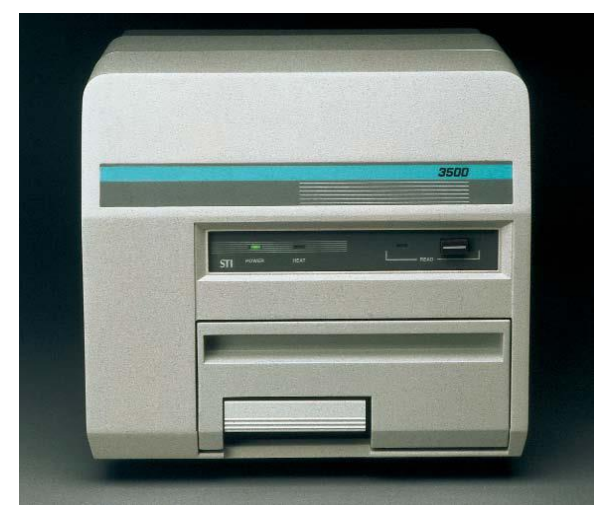

Figura 14 - Leitora Harshaw 3500 utilizada neste trabalho [44]

O mecanismo de funcionamento das leitoras de TLD consiste em uma prancheta para o aquecimento do TLD, o que libera os elétrons presos nas armadilhas nos TLDs, e estes elétrons, ao retornarem a banda de valência, emitem fótons. Estes fótons emitidos incidem sobre uma fotomultiplicadora que gera um sinal elétrico, que é enviado para o sistema de aquisição e análise, que no nosso caso era o programa WinRens [44] da própria Harshaw. Neste programa é possível visualizar a curva termoluminescente do TLD, esta curva apresenta o sinal produzido após a amplificação 
do sinal pela fotomultiplicadora, em função da temperatura na prancheta de aquecimento.

Para o seu funcionamento, as leitoras precisam de certos parâmetros de operação para a realização das leituras e no, caso deste trabalho, os parâmetros utilizados são apresentados na Tabela 5.

Tabela 5 - Parâmetros de operação da leitora Harshaw 3500, utilizados neste trabalho

\begin{tabular}{lc}
\hline Parâmetro & Valor \\
Temperatura Inicial & $60^{\circ} \mathrm{C}$ \\
Temperatura Final & $400^{\circ} \mathrm{C}$ \\
Taxa de Aquecimento & $10^{\circ} \mathrm{C} / \mathrm{s}$ \\
Tempo de Leitura & $45 \mathrm{~s}$ \\
\hline
\end{tabular}

Como a resposta final das leituras dos TLDs foi considerada a integral das cargas acumuladas nas regiões de interesse (ROI) da curva termoluminescente ao invés de se considerar a integral das cargas totais acumuladas em toda a curva termoluminescente, isto devido a maior estabilidade dos picos presentes nestas regiões (picos dosimétricos) frente aos outros picos presentes na curva termoluminescente.

\subsection{Irradiações}

Neste trabalho, os TLDs foram irradiados em diferentes locais com diferentes campos de radiação com complexidades crescentes para ser possível realizar uma análise de como os TLDs se comportam em cada campo.

\subsubsection{Fontes Seladas}

Foram utilizadas algumas fontes seladas para a realização das irradiações nos TLDs. Estas fontes foram: ${ }^{60} \mathrm{Co},{ }^{137} \mathrm{Cs}$ e ${ }^{241} \mathrm{AmBe}$, onde as duas primeiras são fontes de gama puro e a AmBe é uma fonte de nêutrons e gamas.

Junto ao GMR/IPEN (Grupo de Metrologia das Radiações) há o Laboratório de Dosimetria Termoluminescente (LDT/IPEN) que possui uma fonte de 
baixa intensidade de ${ }^{60} \mathrm{Co}$. Neste local foram realizadas as irradiações para estudar a reprodutibilidade dos TLDs. Foram realizadas diversas irradiações com a mesma dose, observando as reprodutibilidades das respostas dos TLDs.

O GMR/IPEN também possui fontes de ${ }^{60} \mathrm{Co}$ e ${ }^{137} \mathrm{Cs}$ mais intensas, e por isso neste local foram realizadas as calibrações dose-resposta dos TLDs para campos puros de radiação gama.

O grupo de BNCT possui algumas fontes de ${ }^{241} \mathrm{AmBe}$ de diferentes atividades. As fontes de ${ }^{241} \mathrm{AmBe}$ são fontes de campo misto, que emitem preferencialmente nêutrons rápidos. Devido à necessidade de se obter um campo de irradiação com uma maior incidência de nêutrons térmicos, a fonte de ${ }^{241} \mathrm{AmBe}$ foi posicionada no interior de um disco de parafina, que serviu para diminuir a energia dos nêutrons, devido à alta concentração de átomos de hidrogênio.

Na Tabela 6 estão representadas as energias dos fótons emitidos por cada fonte, e na Figura 15 está representado o espectro de emissão de nêutrons da fonte de ${ }^{241} \mathrm{AmBe}$.

Tabela 6 - Energias dos fótons emitidos pelas diferentes fontes utilizadas neste trabalho

\begin{tabular}{cc}
\hline Fonte & Energia (MeV) \\
\hline${ }^{137} \mathbf{C s}$ & 0,66 \\
${ }^{60} \mathrm{Co}$ & 1,17 e 1,33 \\
${ }^{{ }^{241} \mathrm{AmBe}}$ & 4,4 \\
\hline
\end{tabular}

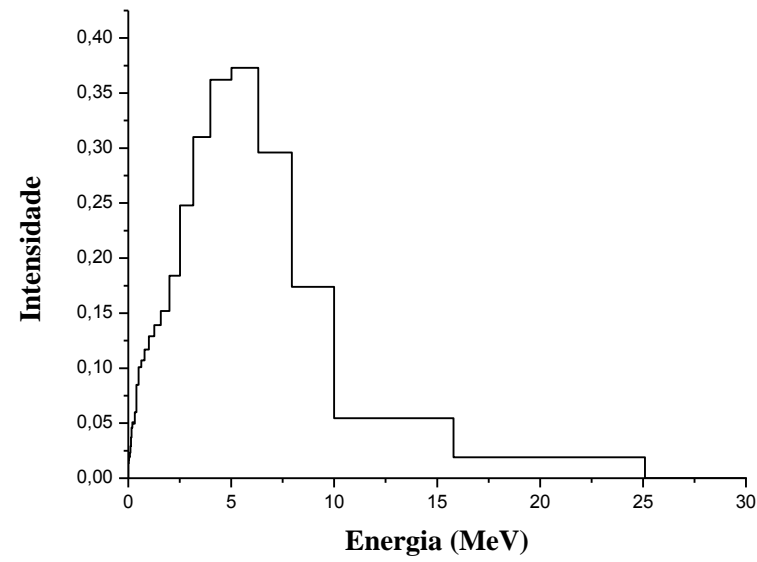

Figura 15 - Espectro de emissão de nêutrons da fonte de ${ }^{241} \mathrm{AmBe}$ [45] 


\subsubsection{Reatores Nucleares}

Os reatores nucleares IPEN/MB-01 e o canal BH-3 do reator IEA-R1 também foram utilizados como fonte de radiação para a irradiação dos TLDs.

O Reator IPEN/MB-01, Figura 16, é uma instalação nuclear que permite a simulação de todas as características nucleares de um reator de grande porte em escala reduzida, sem que haja a necessidade de se construir um complexo sistema de remoção de calor. Esse tipo de reator é conhecido mundialmente como reator de potência zero ou Unidade Crítica, sendo no caso do IPEN/MB-01, projetado para operar a uma potência máxima de $100 \mathrm{~W}$. Esses reatores representam uma ferramenta básica, que permitem aos pesquisadores validar cálculos teóricos e dados, e também, com medidas experimentais, avaliar o desempenho e as características do núcleo de um reator de potência ou de propulsão naval, antes da sua efetiva instalação, simulando as condições de projeto na própria instalação [46].

Neste reator foi realizado o estudo do comportamento dos TLDs quando sujeitos a campos mais intensos e com diferentes composições de cada componente do campo.

Este reator foi utilizado, pois para este reator já há o arquivo de entrada para simulações com o código computacional MCNP, e com isto é possível obter os fluxos e doses das diferentes componentes de campo em cada posição no interior do reator.

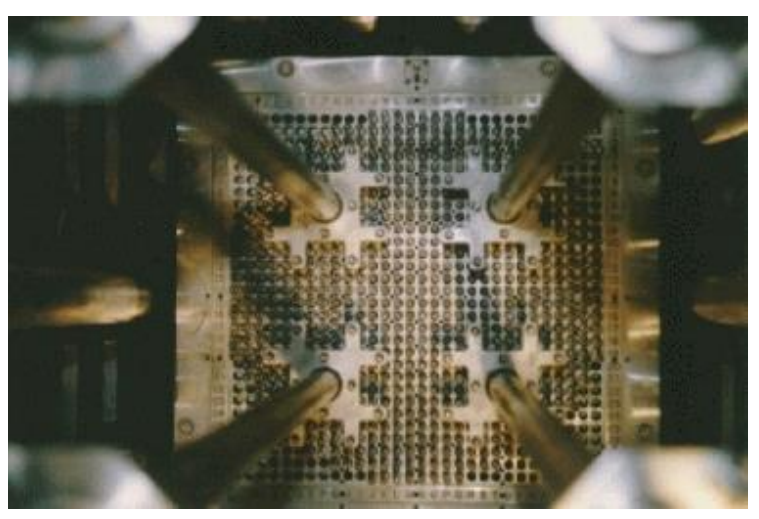

Figura 16 - Núcleo do reator IPEN/MB-01 [46] 


\subsection{Instalação para Pesquisa em BNCT do IPEN}

O grupo de BNCT do IPEN tem uma instalação de pesquisas em BNCT junto ao BH-3 do reator IEA-R1, que é um reator de pesquisa tipo piscina, moderado e refrigerado por água leve. O projeto do IEA-R1 permite que ele opere em uma potência máxima de $5 \mathrm{MW}$, mas atualmente sua potência de operação tem sido entre 3 e 4,5 MW.

A instalação para pesquisas em BNCT do IPEN tem uma de suas extremidades próxima a face do núcleo do reator IEA-R1, e por isto apresenta um alto fluxo de nêutrons dentro deste canal devido às reações que ocorrem no interior do reator.

A instalação consiste de um conjunto de filtros e moderadores no início do canal de irradiação, seguido da posição de amostra e posteriormente uma blindagem de chumbo, conforme mostrado na Figura 17. Há também uma blindagem, constituída de parafina, concreto, chumbo e um beam catcher.

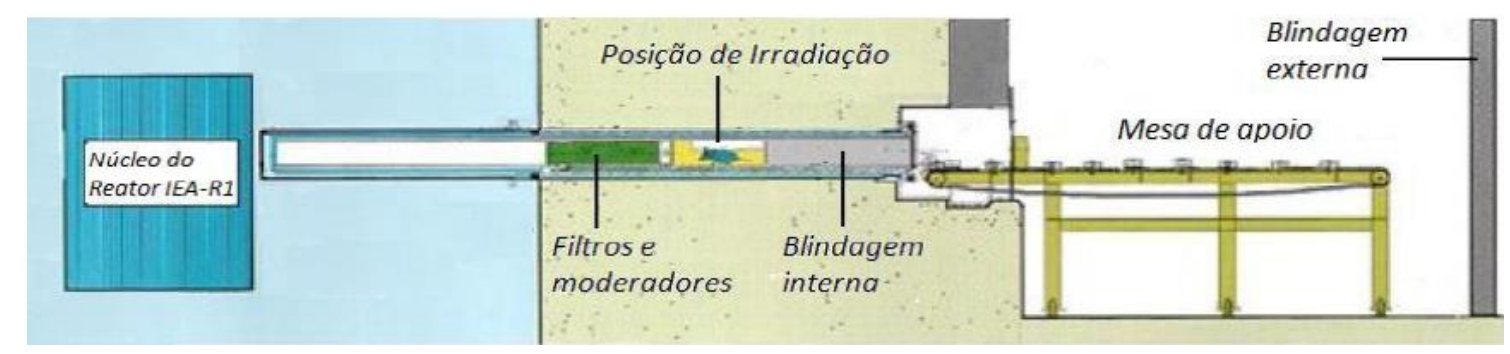

Figura 17 - Esquema ilustrativo da instalação de pesquisas em BNCT do IPEN [22]

Devido à presença da blindagem é possível realizar as trocas de amostras sem a necessidade de desligar o reator. O sistema de troca de amostras é composto por uma garra que transfere a amostra do lado externo da blindagem para o lado interno da blindagem até a mesa de apoio. E há também um sistema controlado remotamente que extrai o conjunto amostra/blindagem, e com este sistema é possível inserir ou retirar a amostra de dentro do BH. Na Figura 18 estão as fotos destes sistemas. 


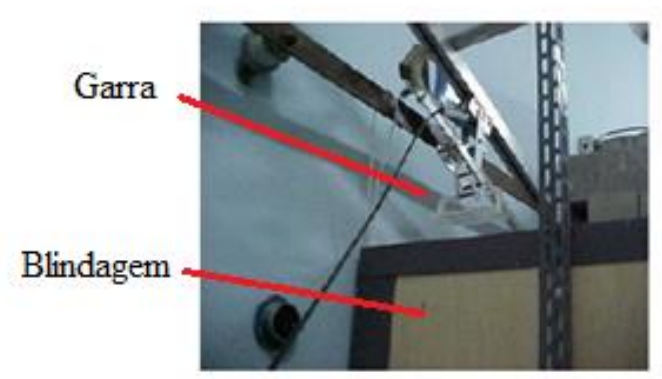

(a)

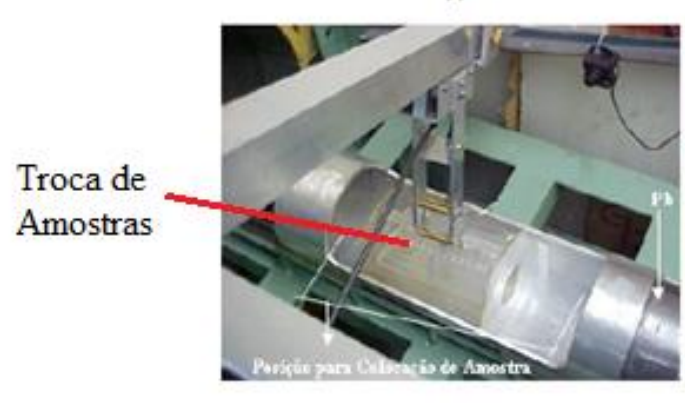

(c)

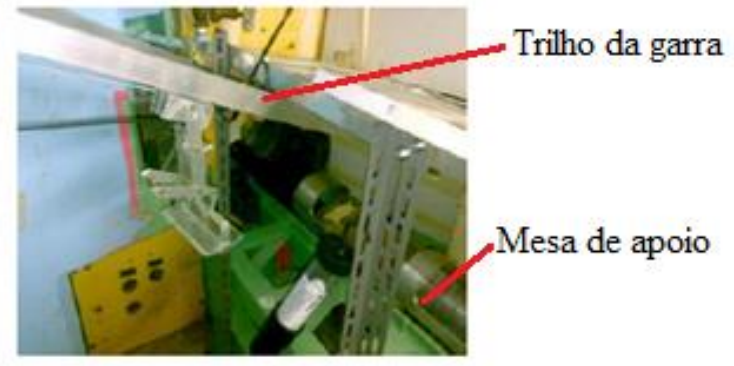

(b)

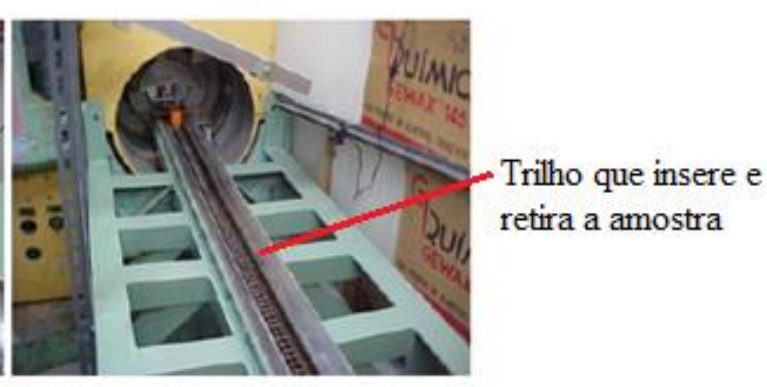

(d)

Figura 18 - Sistema para colocação e retirada da amostra [47]

\subsection{MCNP5}

O código de Monte Carlo MCNP5 foi utilizado durante este trabalho para verificar os fluxos e as doses de nêutrons e gamas nos TLDs em cada irradiação e assim possibilitar o estudo do comportamento dos TLDs obtendo as informações necessárias dos campos em que os TLDs estavam expostos, como fluxos, doses e kerma no ar, além da discriminação das componentes de campo e de suas contribuições para a dose depositada no TLD.

Para realizar a simulação utilizando o MCNP5, há a necessidade de entrar com os dados dos materiais e sua composição além das bibliotecas de seção de choque de cada material.

As composições e materiais utilizados nas simulações foram todos retirados do Compendium of Material Composition Data for Radiation Transport Modeling [48]. As bibliotecas de seção de choque utilizadas foram ENDF/B-VI.

Todas as simulações deste trabalho foram realizadas em um dos dois sistemas: um notebook e um computador. As características de cada um dos sistemas estão descritas na Tabela 7. 
Tabela 7 - Configurações dos sistemas utilizados nas simulações com o MCNP5

\begin{tabular}{ccc}
\hline & Notebook & Computador \\
\hline Processador & Intel Core 2 Duo - 2,20 GHz & Pentium D - 3 GHz \\
Memória RAM & $6 \mathrm{~GB}$ & $3 \mathrm{~GB}$ \\
Sistema Operacional & Windows 7 64 bits & Windows XP 32 bits \\
\hline
\end{tabular}

\subsection{Técnica de Análise por Ativação}

Neste trabalho foram utilizadas folhas de ouro hiperpuras $\left(99 \%\right.$ de $\left.{ }^{197} \mathrm{Au}\right)$ para realizar o monitoramento do fluxo e dose de nêutrons térmicos e epitérmicos. Como esta metodologia já é bem conhecida pelo grupo de BNCT do IPEN, as folhas de ouro foram utilizadas para validar as simulações com o MCNP5, para verificar o fluxo de nêutrons térmicos e epitérmicos presente na instalação de BNCT e realizar o monitoramento da calibração dos TLDs realizada na própria instalação.

Para a obtenção dos fluxos de nêutrons térmicos e epitérmicos foram utilizados pares de folhas na qual uma era mantida nua e a outra era coberta com uma caixa de cádmio.

O átomo de ${ }^{197} \mathrm{Au}$ apresenta alta seção de choque para nêutrons da faixa térmica e epitérmica, ele é sensível a estes nêutrons, e a caixa de cádmio é utilizada para poder realizar a diferenciação entre o fluxo devido aos nêutrons térmicos e o fluxo devidos aos nêutrons epitérmicos, pois o Cádmio apresenta uma alta seção de choque para nêutrons térmicos (Figura 19). 


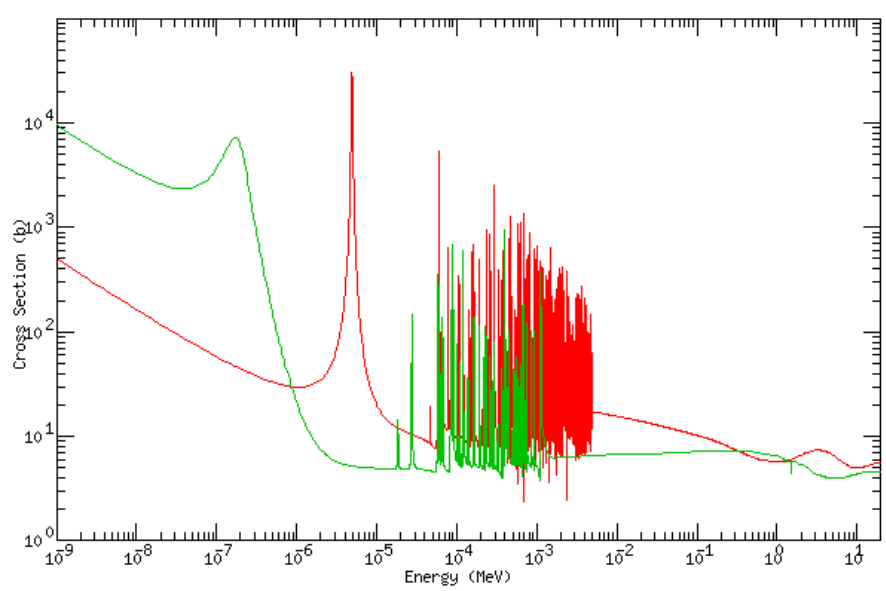

Figura 19 - Seção de choque total para o átomo de ${ }^{197} \mathrm{Au}$ (vermelho) e para o cádmio (verde) [4]

As folhas de ouro, ao serem irradiadas por nêutrons, sofrem a seguinte reação de captura:

$$
{ }^{197} A u+n \rightarrow{ }^{198} A u+\gamma
$$

Após as irradiações as folhas foram analisadas através de espectroscopia gama utilizando um detector de estado sólido de Germânio Hiperpuro (HPGe), o qual fornecia o espectro do material em análise. Pôde-se então obter a contagem (desintegrações por segundo) da radiação liberada pelos diferentes fotopicos.

Através do número de contagens obtidas no detector é possível saber a atividade da folha ao término da irradiação, $A_{0}$, e a atividade de saturação, $A^{\infty}$, que é atividade máxima do detector se ele fosse irradiado por um tempo infinito, e esta atividade de saturação é igual à taxa de reação que a folha de ativação estava exposta [49]. A curva de decaimento da atividade do detector pode ser vista na Figura 20. 


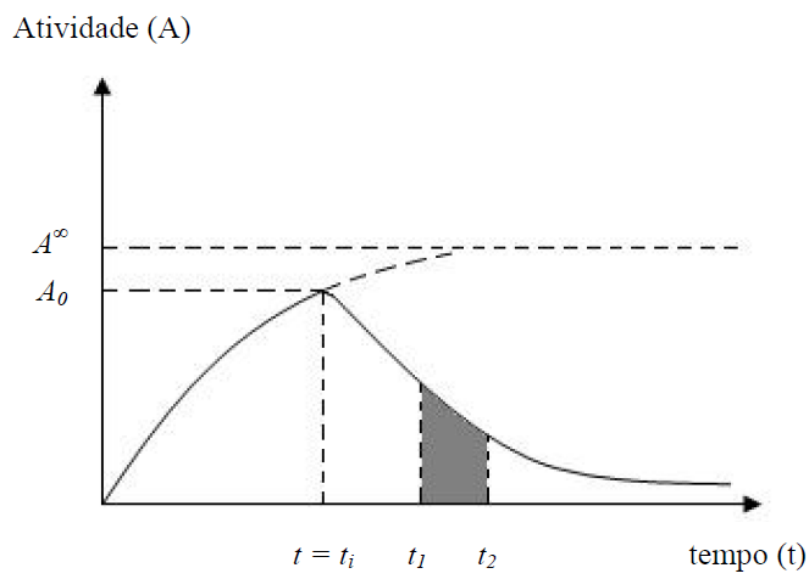

Figura 20 - Atividade da folha de ativação em função do tempo de irradiação $\left(t_{i}\right)$ [50]

A partir das contagens obtidas no detector pode-se obter a atividade de saturação da folha realizando a seguinte conta:

$$
A^{\infty}=\frac{\lambda(C-B G) e^{-\lambda t e}}{\varepsilon . I\left(1-e^{-\lambda t}\right)\left(1-e^{-\lambda t c}\right)}
$$

onde:

$\lambda$ é a constante de decaimento do radioisótopo formado;

$C$ é a contagem do fotopico;

$B G$ ("Background") é a radiação de fundo;

$t_{e}$ é o tempo de espera entre o término da irradiação e a contagem;

$t$ é o tempo de irradiação;

$t_{c}$ é o tempo de contagem;

I é a probabilidade de emissão gama do isótopo formado

$\varepsilon$ é a eficiência total de contagem do fotopico.

Como sempre é utilizado um par de folhas de ouro (uma nua e outra coberta por cádmio), a atividade de saturação induzida na folha nua é devido aos nêutrons térmicos e epitérmicos. Já na folha coberta por cádmio a atividade é devido aos nêutrons epitérmicos. Porém, como o cádmio não é um filtro ideal, o valor da atividade 
de saturação das folhas com cádmio deve ser corrigido por um fator que é conhecido com Fator de Cádmio, $F_{C d}$, cujo valor é tabelado na literatura [49].

Outro fator importante é a Razão de Cádmio, $R_{C d}$, que é dado pela razão da atividade de saturação da folha nua pela atividade de saturação da folha com Cádmio.

Como a atividade de saturação é dada também por:

$$
A^{\infty}=\Sigma . V . \phi
$$

onde:

$\Sigma$ é a seção de choque macroscópica média de ativação;

$V$ é o volume do detector;

$\phi$ é o fluxo de nêutrons.

O fluxo de nêutrons térmicos é dado pela Eq. 4.4.

$$
\phi_{t h}=\frac{A_{n u a}^{\infty}\left(1-\frac{F_{C d}}{R_{C d}}\right) \cdot P_{a}}{N_{a} \cdot m \cdot \sigma \cdot F P}
$$

onde:

$P_{a}$ é o peso atômico do núcleo alvo;

$N_{a}$ é o número de Avogadro;

$m$ é a massa do detector de ativação;

$\sigma_{a t v}$ é a seção de choque microscópica média de ativação.

Enquanto o fluxo de nêutrons epitérmicos é dado pela Eq. 4.5.

$$
\phi_{\text {epi }}=\frac{A_{C d}^{\infty}}{N_{T} \cdot I_{R}^{\infty}} \cdot \ln \frac{E_{2}}{E_{C d}}
$$


onde:

$I_{R}^{\infty}$ é conhecida como integral de ressonância e é utilizada na literatura entre os limites $E_{c d}$ e $E_{2}$, que se referem à energia de corte do cádmio e o limiar da região intermediária e a região rápida do espectro neutrônico;

$N_{T}$ é o número de núcleos alvo.

\subsection{Metodologia}

Visando o melhor entendimento do uso do par TLD 600/TLD 700, foram elaborados experimentos que visavam o estudo das respostas destes TLDs em campos diferentes e com crescente grau de sofisticação.

Assim os experimentos com os TLDs foram divididos em quatro grupos:

i. Fonte de gama puro, ${ }^{60} \mathrm{Co}$;

ii. Fonte de campo misto, ${ }^{241} \mathrm{AmBe}$ com sistema de moderação;

iii. Irradiações em reator de potência zero, IPEN/MB-01;

iv. Irradiações na instalação de BNCT.

Nas etapas i. e ii. foi visado o estudo da reprodutibilidade destes TLDs, a normalização das respostas para campo puro de gama e campo misto de nêutrons e gamas, a calibração dos TLDs para estes campos e as diferenças apresentadas nas curvas termoluminescentes destes TLDs quando irradiados somente com gama e quando era irradiado em campo misto.

Nestas etapas, simulações com o MCNP5 foram realizadas para acompanhar as doses e fluxos que os TLDs estavam expostos nas diferentes irradiações.

$\mathrm{Na}$ etapa iii., foi visado o entendimento das curvas termoluminescentes dos TLDs quando estes estavam expostos em um fluxo mais intenso e com diferentes composições das componentes do campo de irradiação, além da dependência das respostas dos TLDs com as diferentes componentes de campo. Para tal foi realizada a irradiação dos TLDs em diferentes posições em uma das faces do reator IPEN/MB-01,

Folhas de ativação de ouro foram utilizadas nestes experimentos para fazer o monitoramento do fluxo de nêutrons térmicos e epitérmicos. Simulações com o 
MCNP5 também foram realizadas para se ter um melhor entendimento sobre os fluxos aos quais os TLDs estavam expostos de acordo com a posição que se encontravam.

$\mathrm{Na}$ última etapa, iv., os TLDs foram irradiados na instalação de BNCT para verificar suas curvas termoluminescentes e realizar as calibração destes TLDs na própria instalação na qual os TLDs serão utilizados futuramente para dosimetria.

Para realizar o acompanhamento do fluxo de nêutrons térmicos e epitérmicos e a dose de radiação gama nas irradiações na instalação de pesquisas em BNCT foram utilizadas folhas de ouro e TLDs 400, que já eram utilizados pelo grupo de pesquisas em BNCT do IPEN/CNEN-SP. 


\section{RESULTADOS E DISCUSSÕES}

Primeiramente foi realizado um estudo na leitora de TLD Harshaw 3500, que visava encontrar a melhor tensão de trabalho da fotomultiplicadora desta leitora, assim como definir as regiões de interesse da curva termoluminescente de cada tipo de TLD (Anexo B).

A partir deste estudo ficou definido que seriam utilizadas duas tensões de trabalho para a leitora, dependendo da dose de radiação a que os TLDs ficaram expostos. Assim foi definido que para altas doses (a cima de $1 \mathrm{~Gy}$ ) como, por exemplo, em irradiações na instalação de BNCT, a tensão na fotomultiplicadora seria de $500 \mathrm{~V}$ e para baixas doses (até $1 \mathrm{~Gy}$ ), como nas irradiações na fonte de ${ }^{241} \mathrm{AmBe}$, a tensão seria de $1000 \mathrm{~V}$.

Esta diferença de tensões foi necessária, pois não foi encontrada nenhuma tensão que satisfizesse os dois casos, sendo que para altas doses a curva termoluminescente dos TLDs saturava a leitora quando lidos em altas tensões e para baixas doses a curva termoluminescente não apresentava ganho suficiente para obter os resultados de suas leituras para baixas tensões.

A leitora de TLD Harshaw 3500 apresenta 200 canais no gráfico da curva termoluminescente, onde estes canais estão diretamente relacionados com a temperatura. As regiões de interesse (ROI's) foram definidas a partir da seleção de um conjunto de canais para cada tipo de TLD. Para os diferentes TLDs os canais das diferentes regiões de interesse estão representados na Tabela 8, e as curvas termoluminecentes dos diferentes TLDs com suas respectivas regiões de interesse estão representadas na Figura 21.

Tabela 8 - Canais correspondentes as Regiões de Interesse dos diferentes tipos de TLDs

\begin{tabular}{ccc}
\hline TLD & ROI 1 & ROI 2 \\
\hline LiF & 65 ao 110 & 110 ao 155 \\
CaF $_{2}$ & 90 ao 175 & --- \\
\hline
\end{tabular}



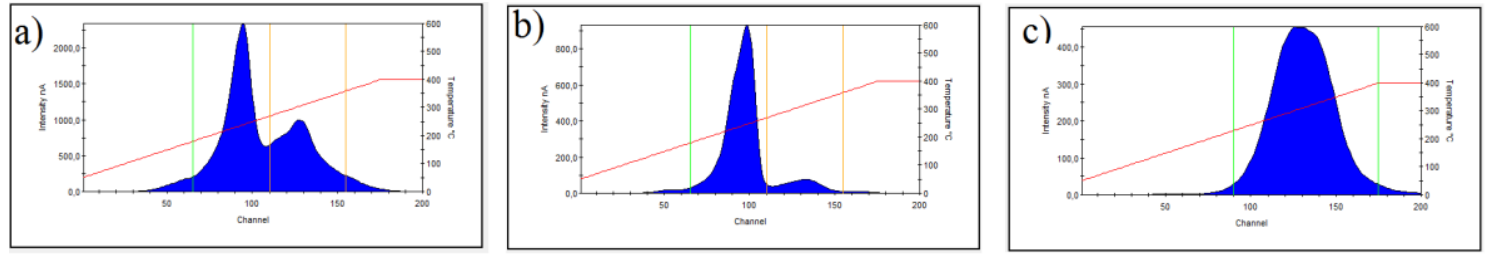

Figura 21 - Curvas termoluminescentes dos diferentes tipos de TLDs com suas respectivas regiões de interesse: a) TLD 600; b) TLD 700; c) TLD 400

Maiores detalhes dos experimentos realizados para a definição das tensões utilizadas e das definições das regiões de interesse se encontram no Anexo B.

\subsection{Estudo da Reprodutibilidade dos TLDs em Campo de Gama Puro}

O primeiro estudo realizado com os TLDs foi o estudo da reprodutibilidade dos diferentes tipos de TLD em fontes de radiação gama.

Este estudo visou estudar a reprodutibilidade das respostas dos TLDs de mesmo tipo em uma mesma irradiação, também as diferenças das respostas individuais e das médias dos TLDs em diferentes irradiações em que era fornecida a mesma dose e analisar a capacidade das simulações.

Para estes estudos foram utilizados 30 TLDs de cada tipo, onde todos eram irradiados em cada irradiação.

Neste estudo foi utilizada uma fonte panorâmica de ${ }^{60}$ Co do LDT/IPEN com atividade de 5,46 mCi em Junho de 2007 [47], onde os TLDs ficaram expostos por um tempo necessário para fornecer $20 \mathrm{mGy}$ de kerma no ar na posição que estariam os TLDs.

Os TLDs, nestas irradiações, foram posicionados em suportes de acrílico com configuração matricial de 3 x 3 . Estes suportes foram posicionados ao longo de uma circunferência de $15 \mathrm{~cm}$ de raio, com a fonte posicionada no seu centro, conforme a Figura 22, para que todos os TLDs fossem submetidos à mesma dose nas diferentes irradiações. Os TLDs do mesmo tipo foram colocados no mesmo suporte, sobrando então 3 TLDs de cada tipo que foram colocados em um mesmo suporte, utilizando assim um total de dez suportes, todos irradiados juntos. 


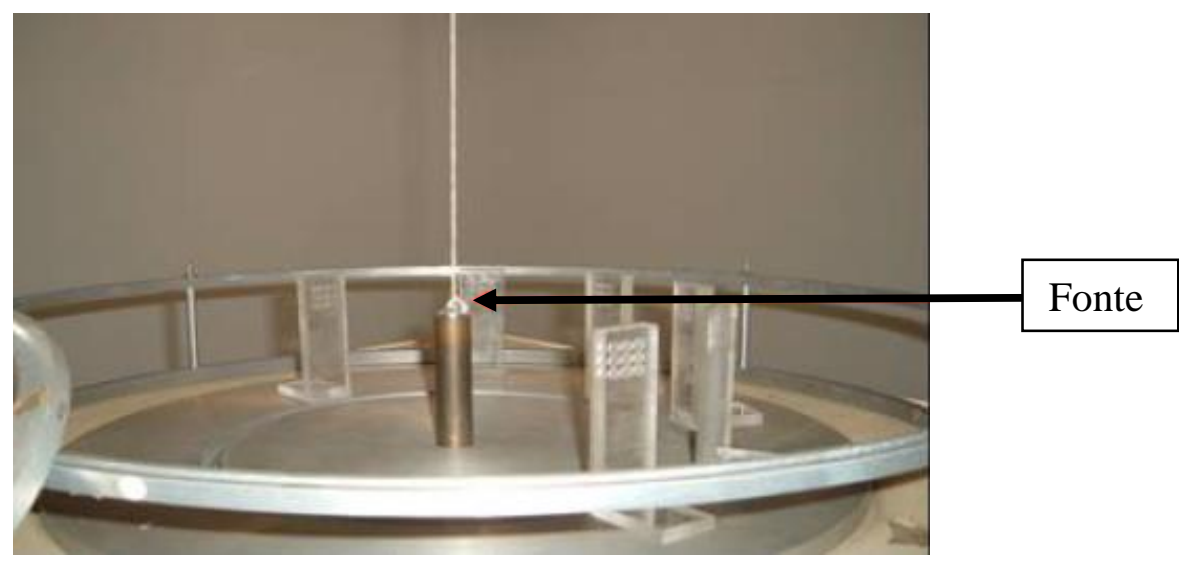

Figura 22 - Fonte panorâmica de ${ }^{60} \mathrm{Co}$ do LDT/IPEN

Nestas irradiações era esperado que os TLDs estivessem sujeitos a um mesmo fluxo e a uma mesma dose. Para realizar esta análise foi simulada, com o auxílio do MCNP5, a configuração na qual os TLDs estavam expostos.

As simulações mostraram que o fluxo de fótons nas diferentes posições do suporte onde estariam os TLDs tem uma diferença máxima na resposta calculada de $0,4 \%$ e o kerma no ar tem uma diferença máxima na resposta calculada de $0,3 \%$. Ao realizar as simulações com a presença dos TLDs, não se observou diferenças no fluxo, mas foi possível observar diferenças nas doses depositadas nos diferentes tipos de TLD. Na Tabela 9 estão apresentadas as diferenças que ocorrem entre o kerma no ar e as doses depositadas nos diferentes tipos de TLD.

Tabela 9 - Comparação entre os valores calculados de kerma no ar e as doses depositadas nos diferentes TLDs nas irradiações com a fonte de ${ }^{60} \mathrm{Co}$

\begin{tabular}{ccc}
\hline Kerma no ar & Dose no LiF & Dose no $\mathbf{C a F}_{\mathbf{2}}$ \\
\hline $20 \mathrm{mGy}$ & $18,5 \pm 0,1 \mathrm{mGy}$ & $19,5 \pm 0,2 \mathrm{mGy}$ \\
\hline
\end{tabular}

A partir destas simulações foi possível constatar a maior dose absorvida pelo TLD de $\mathrm{CaF}_{2}$ frente ao $\mathrm{LiF}$.

Como a simulação deste experimento mostrou que a diferença de fluxos e doses nas diferentes posições que os TLDs foram dispostos eram desprezíveis, foram realizadas 15 irradiações nesta configuração para o estudo da reprodutibilidade dos TLDs. 
Porém mesmo os TLDs de mesmo tipo em uma mesma irradiação, apresentaram dispersões nas respostas, o que pode ser visto na Figura 23.

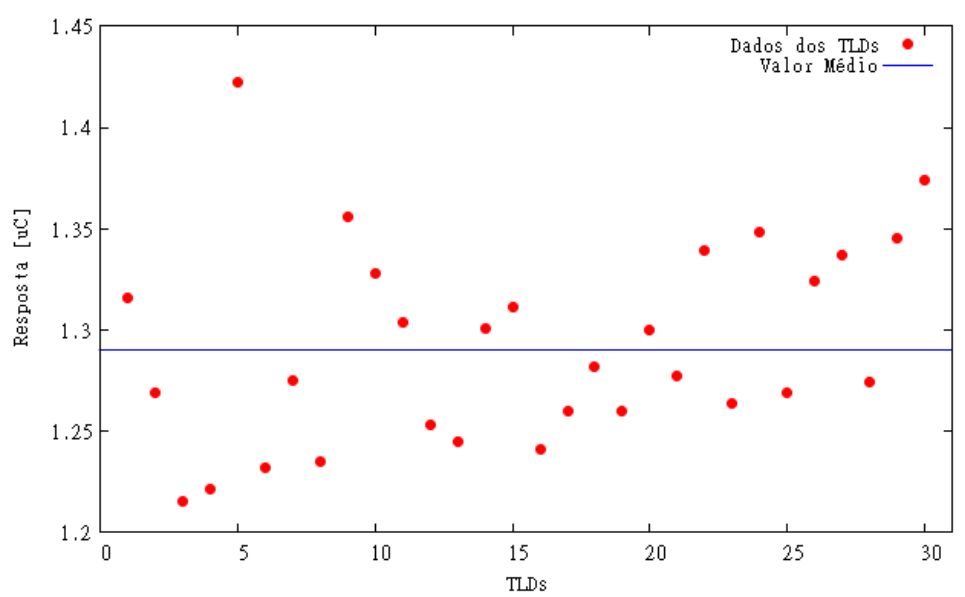

Figura 23 - Dispersão das respostas do ROI 1 individuais dos TLDs 600 em uma irradiação na fonte de ${ }^{60} \mathrm{Co}$

Este comportamento, apresentado pelos TLDs 600 na Figura 23, é semelhante ao comportamento observado por estes TLDs em todas as irradiações, assim como para os TLDs 700 e TLDs 400.

As diferenças de respostas entre os TLDs de mesmo tipo em uma mesma irradiação na fonte de ${ }^{60} \mathrm{Co}$ chegavam a ser superiores a $10 \%$, o que não era o esperado pelas simulações, que apresentava uma diferença máxima de $0,4 \%$ do fluxo nas diferentes posições. Isto se deve ao fato de que mesmo os TLDs de mesmo tipo apresentavam sensibilidades individuais distintas.

Foram realizadas varias irradiações nesta configuração para quantificar estas diferenças nas sensibilidades individuais dos TLDs e quantificar também as possíveis mudanças nas médias das respostas dos TLDs nas diferentes irradiações.

As médias das respostas dos TLDs nas diferentes irradiações em uma mesma dose não foram as mesmas, os gráficos apresentados na Figura 24, Figura 25, Figura 26 apresentam os valores médios da região de interesse nas diferentes irradiações dos TLDs 600, TLDs 700 e TLDs 400, respectivamente. 


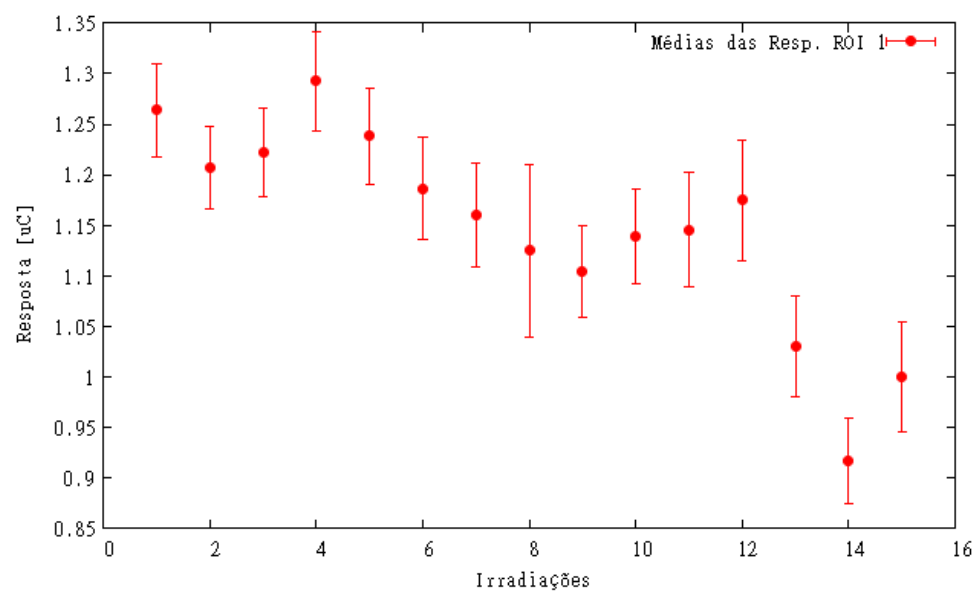

Figura 24 - Médias das Respostas dos TLDs 600 obtidas nas 15 irradiações na fonte de ${ }^{60} \mathrm{Co}$

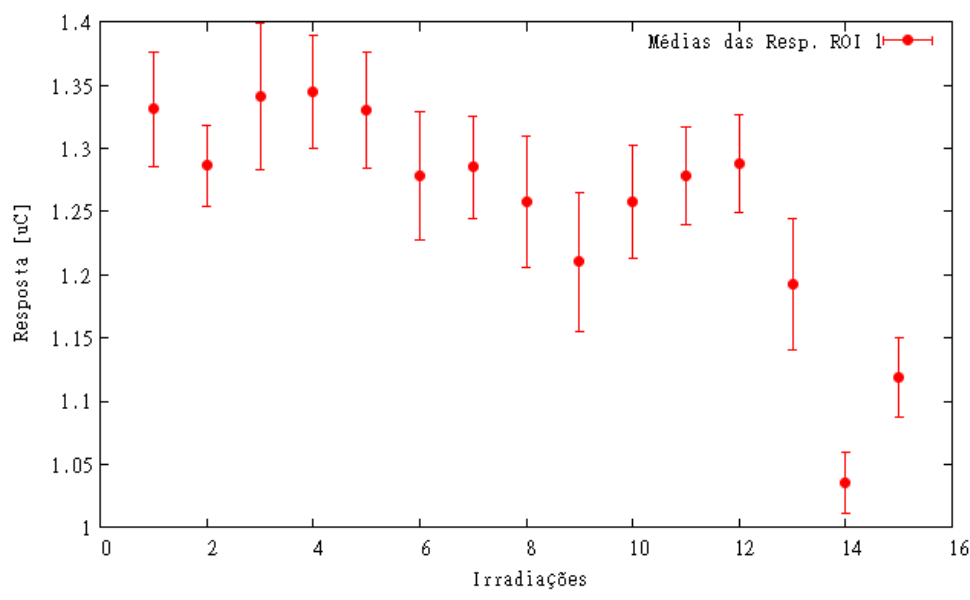

Figura 25 - Médias das Respostas dos TLDs 700 obtidas nas 15 irradiações na fonte de ${ }^{60} \mathrm{Co}$

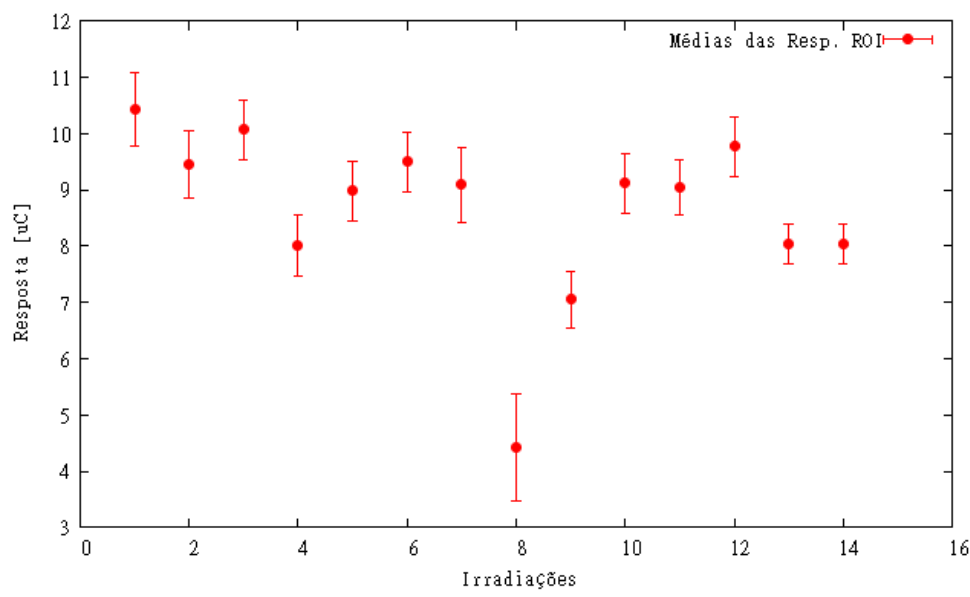

Figura 26 - Médias das Respostas dos TLDs 400 obtidas nas 14 irradiações na fonte de ${ }^{60} \mathrm{Co}$ 
Observando as respostas das médias dos TLDs 600 e TLDs 700, Figura 24 e Figura 25 respectivamente, pode-se notar que estes dois tipos de TLDs apresentam comportamentos semelhantes e respostas com valores próximos, quando irradiados com fonte gama.

Assim foi possível observar que os TLDs de LiF respondem de forma semelhante quando irradiados em fonte de gama puro, e que o TLD 400 apresenta uma maior sensibilidade frente aos TLDs de LiF, o que era o esperado.

A partir das respostas das médias dos diferentes TLDs, foi observado que as diferenças nas respostas médias dos TLDs em diferentes irradiações eram superiores a diferença de resposta individual de diferentes TLDs em uma mesma irradiação. O que mostra que diferenças durante alguma parte do ciclo do TLD (tratamento - irradiação leitura) geram maior dispersão nas respostas dos TLDs do que a diferença de sensibilidade individual dos TLDs.

Mas apesar dos TLDs de mesmo tipo apresentarem respostas diferentes nas mesmas irradiações e as respostas médias serem diferentes também em diferentes irradiações, foi observado que a relação entre a resposta individual de um TLD e a resposta média de todos os TLDs de mesmo tipo em certa irradiação se mantinha aproximadamente constante, ou seja, em diferentes irradiações ou as respostas dos TLDs subiam de forma parecida, ou baixavam, também de forma parecida, como é possível observar na Figura 27.
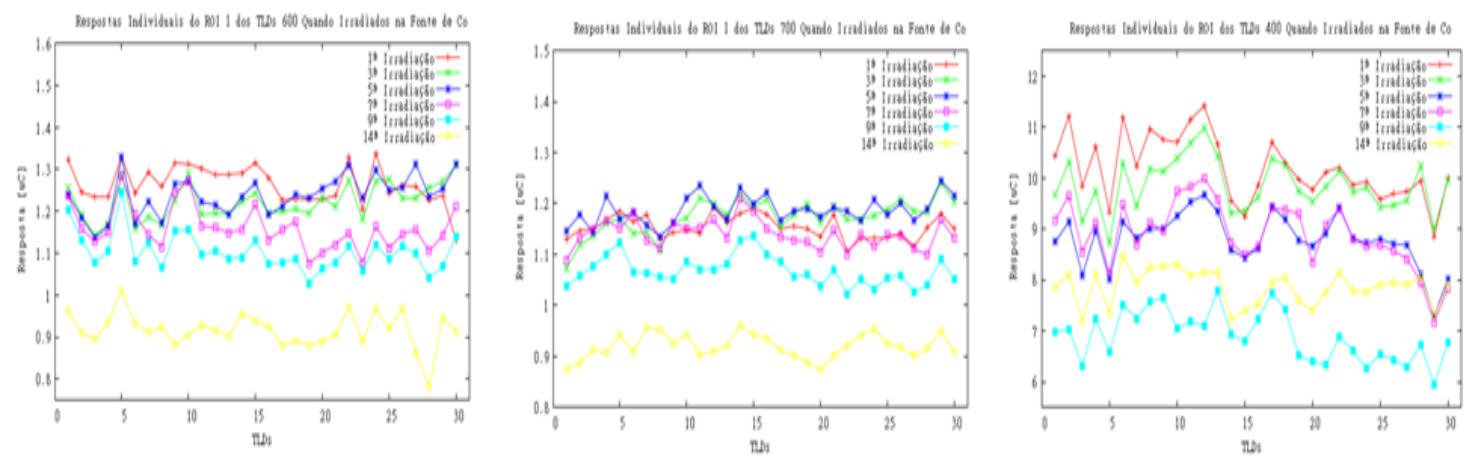

Figura 27 - Respostas individuais dos TLDs em diferentes irradiações na fonte de ${ }^{60} \mathrm{Co}$

De acordo com os dados apresentados no gráfico da Figura 27 pode-se observar a presença de dois tipos de diferenças nas respostas dos TLDs. Uma diferença 
seria fruto da diferença de sensibilidade individual de cada TLD, portanto cada TLD responde de forma diferente entre si. A outra diferença seria uma diferença coletiva das respostas dos TLDs, no qual todos os TLDs em certa irradiação sofrem uma diferença semelhante em suas respostas, seja esta para cima ou para baixo. Este diferença coletiva das respostas está ligada a alguma etapa do ciclo de uso do TLD (tratamento, irradiação e leitura).

Com este estudo foi possível perceber que um mesmo TLD apresentava um valor aproximadamente constante de razão nas diferentes irradiações, o que está de acordo com o observado na Figura 27. Portanto, é possível utilizar um fator que normalize a resposta de todos os TLDs, uma vez que é sabido o quanto a resposta de determinado TLD diferencia da média.

A este fator foi dado o nome de Fator de Normalização, e sua definição esta apresentada na próxima seção.

\subsection{Fator de Normalização}

Ao observar as respostas individuais dos TLDs em diferentes irradiações na fonte de ${ }^{60} \mathrm{Co}$, pode-se observar uma relação aproximadamente constante entre a resposta individual de um TLD com a resposta média de todos os TLDs nesta mesma irradiação. A razão pela qual a resposta individual de um TLD é aproximadamente constante com relação à resposta da média é porque a sensibilidade do TLD é bem mais reprodutível do que as condições de leitura, irradiação ou tratamento térmico dos TLDs.

Com isto foi criado um fator que normalizasse as respostas dos TLDs. A este fator foi dado o nome de Fator de Normalização, e este foi definido da seguinte maneira:

$$
\begin{gathered}
F N_{i, n}=\frac{M_{n}}{R_{i, n}} \\
M_{n}=\frac{1}{N} \sum_{i=1}^{N} R_{i, n}
\end{gathered}
$$


onde: - $i$ é o índice associado ao TLD;

- $n$ é o índice associado à irradiação;

- $R_{i, n}$ é a resposta do TLD $i$ na irradiação $n$;

- $M_{n}$ é a média das respostas do TLD na irradiação $n$;

- $F N_{i, n}$ é o Fator de Normalização do TLD $i$ na irradiação $n$.

Assim à cada TLD foi atribuído um fator de normalização para cada irradiação realizada, $F N_{n, i}$.

O fator de normalização geral de dado TLD, $F N_{i}$, foi dado pela média dos fatores de normalização deste TLD em cada irradiação. E o desvio padrão destes valores, $\sigma_{F N i}$, foi associado como a incerteza destes fatores de normalização.

$$
\begin{gathered}
F N_{i}=\frac{1}{N} \sum_{n=1}^{N} F N_{i, n} \\
\sigma_{F N_{i}}=\sqrt{\frac{\left(F N_{i}-\overline{F N_{i}}\right)^{2}}{N-1}}
\end{gathered}
$$

Portanto ao aplicar os Fatores de Normalização nas respostas dos TLDs, podemos normalizar todas as respostas, e assim eliminar as diferenças causadas pela diferença de sensibilidade dos TLDs, restando apenas as diferenças causadas durante o processo de utilização dos TLDs.

Em posse dos fatores de normalização de cada TLD, $F N_{i}$, é possível aplicá-los para que as respostas de todos os TLDs sejam normalizadas como se fosse o mesmo TLD irradiado inúmeras vezes. Para isso, em qualquer irradiação basta multiplicar o valor da resposta obtida por um determinado TLD pelo seu fator de normalização. As equações 5.5 e 5.6 mostram como isso deve ser feito para obter o valor de resposta normalizada, $R N_{i}$, deste TLD e sua incerteza, $\sigma_{R C i}$.

$$
R N_{i}=R_{i} \times F N_{i}
$$




$$
\sigma_{R N_{i}}=R N_{i} \times \sigma_{F N_{i}}
$$

No Anexo D estão apresentados os Fatores de Normalização para todos os TLDs para a fonte de gama puro e para a fonte mista de AmBe.

Para demonstrar o uso do Fator de Normalização, como exemplo foram utilizados os TLDs 600 em uma irradiação em uma fonte de ${ }^{60} \mathrm{Co}$. Na Figura 28 estão apresentados os histogramas das respostas destes TLDs quando nenhum Fator de Normalização foi utilizado nas respostas dos TLDs e quando foi utilizado, assim como a curva normal a partir destes dados.
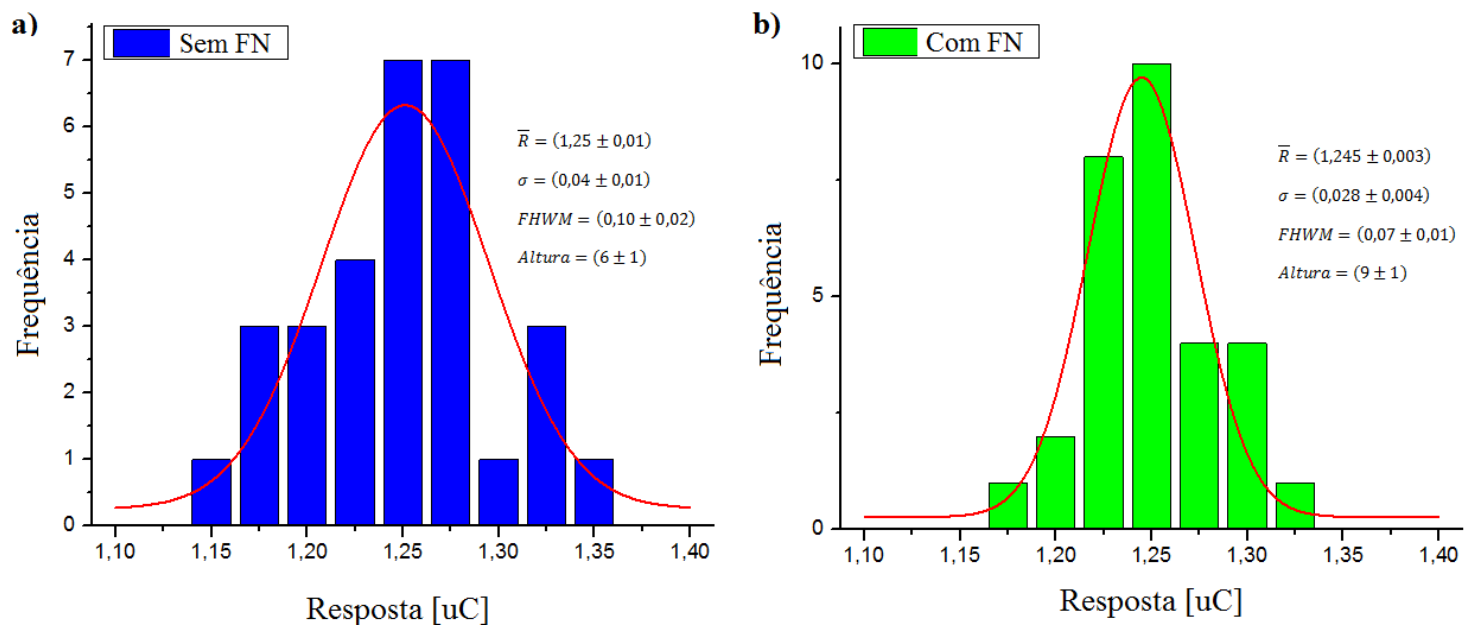

Figura 28 - Histogramas das respostas dos TLDs 600 quando aplicado (a) e não aplicado (b) o Fator de Normalização

A Figura 28 apresenta a curva normal para os dois histogramas. A partir dos valore obtidos é possível observar um melhor valor dos valores da curva normal para o caso onde há aplicação do Fator de Normalização. Portanto os dados com o uso do Fator de Normalização se mostrou com maior precisão frente aos dados onde não houve o uso do Fator de Normalização.

A partir de 30 TLDs com diferentes sensibilidades intrínsecas, pode-se normalizar as respostas destes 30 TLDs por meio da multiplicação pelo Fator de Normalização das respostas individuais destes TLDs. Assim pode-se utilizar todos estes TLDs de forma a considerar que estes TLDs tenham a mesma sensibilidade intrínseca. 
Foi feito um estudo para observar as características destes Fatores de Normalização dos TLDs 600, TLDs 700 e TLDs 400 quando estes são irradiados na fonte de ${ }^{60} \mathrm{Co}$.

\subsubsection{Fatores de Normalização para a Fonte de Gama Puro}

Foi analisada a dispersão dos Fatores de Normalização de cada TLD, e os histogramas da Figura 29, Figura 30 e Figura 31 apresentam as dispersões dos valores do Fator de Normalização para os diferentes TLDs estudados neste trabalho.

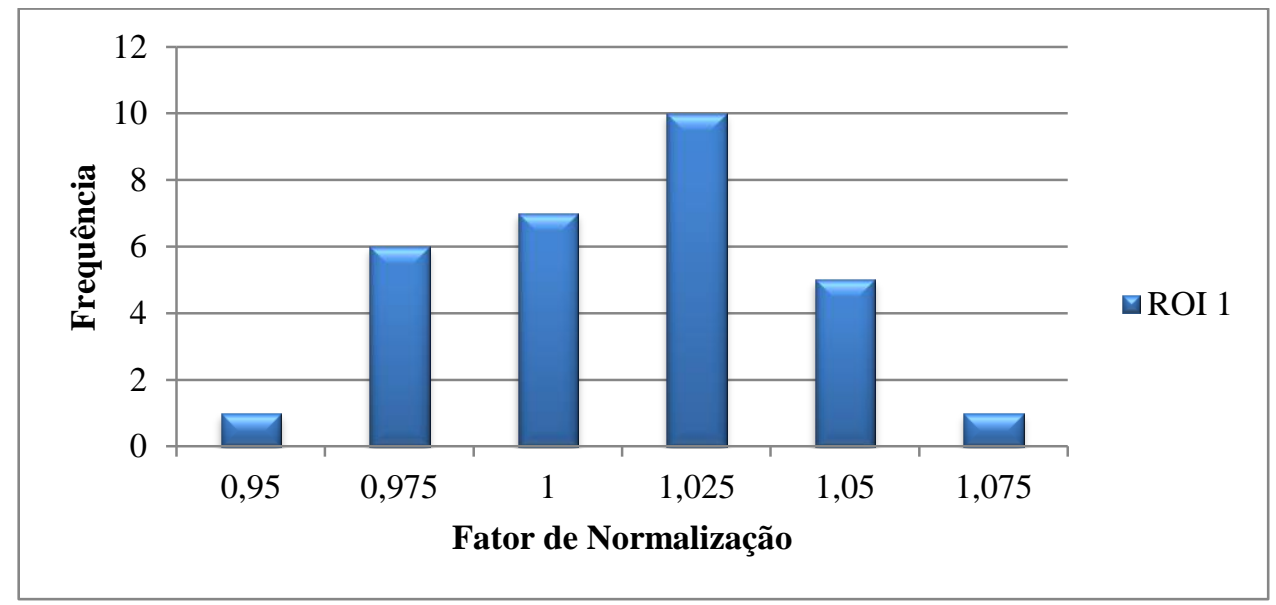

Figura 29 - Histograma dos Fatores de Normalização do TLD 600

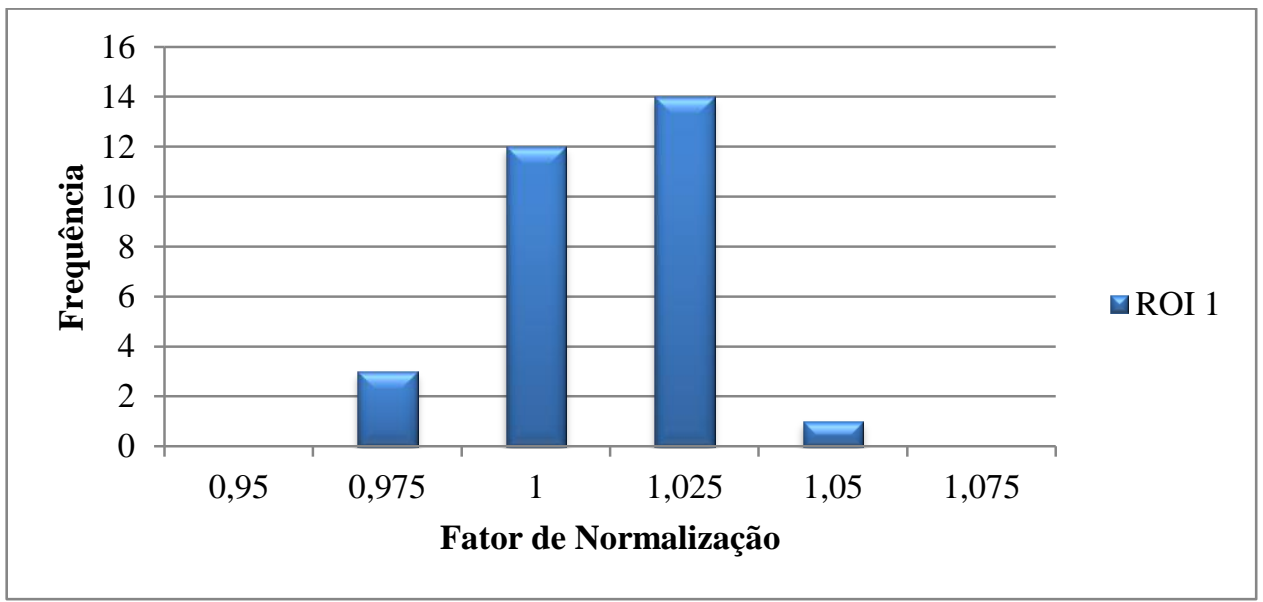

Figura 30 - Histograma dos Fatores de Normalização do TLD 700 


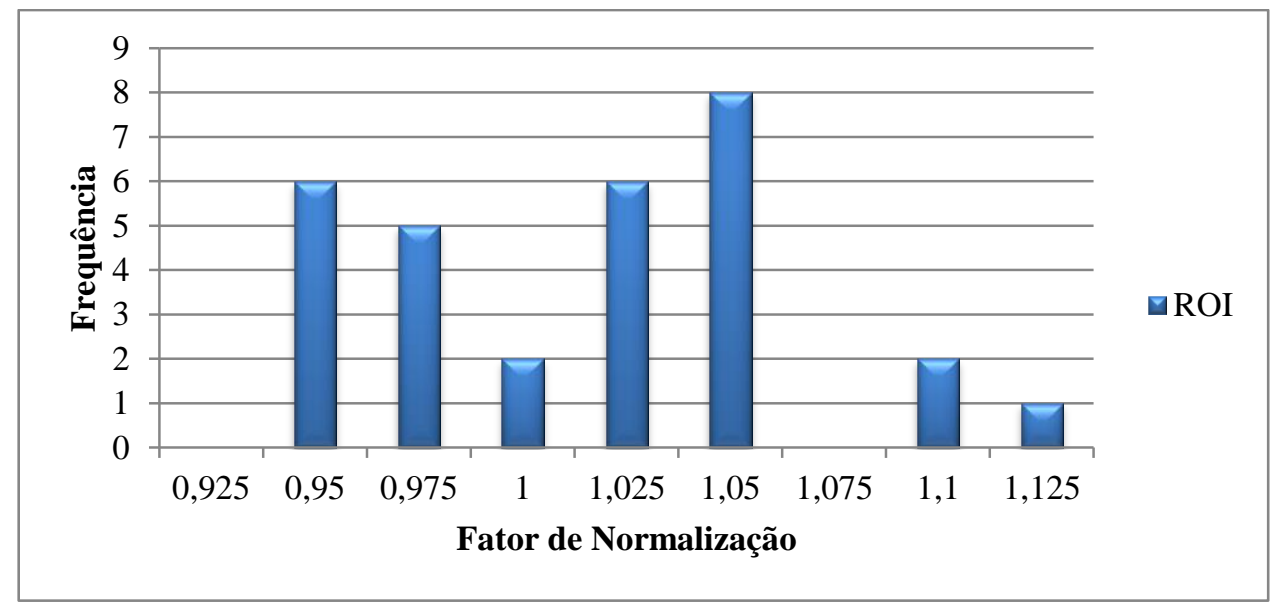

Figura 31 - Histograma dos Fatores de Normalização do TLD 400

É possível observar, a partir destes histogramas, que o TLD 400 apresenta uma maior dispersão entre as respostas de seus TLDs frente aos TLDs de LiF, uma vez que o valor do Fator de Normalização mostra o quão distante da resposta da média está a resposta de certo TLD. Já o TLD 700 foi o que apresentou a menor dispersão. Porém estas características estão associadas ao lote usado, portanto lotes diferentes podem apresentar características distintas.

Estes dados mostraram que a dispersão das respostas individuais dos TLDs é menor que a dispersão das médias das respostas dos TLDs nas diferentes irradiações, o que mostra que diferenças que possam ocorrer durante alguma etapa do ciclo do TLD (tratamento, irradiação e leitura) apresentam uma maior contribuição para a diferença das respostas.

Outro ponto observado foi a precisão na determinação dos Fatores de Normalização de cada TLD, individualmente, em cada irradiação. Isto mostra o quão reprodutível é um TLD frente à média das respostas de todos os TLDs. Estes dados estão apresentados nos histogramas das Figura 32, Figura 33 e Figura 34 para os diferentes tipos de TLDs, na qual estão apresentados os desvios padrões obtido pelos diferentes valores de Fator de Normalização que um mesmo TLD tinha nas diferentes irradiações na fonte de ${ }^{60} \mathrm{Co}$. 


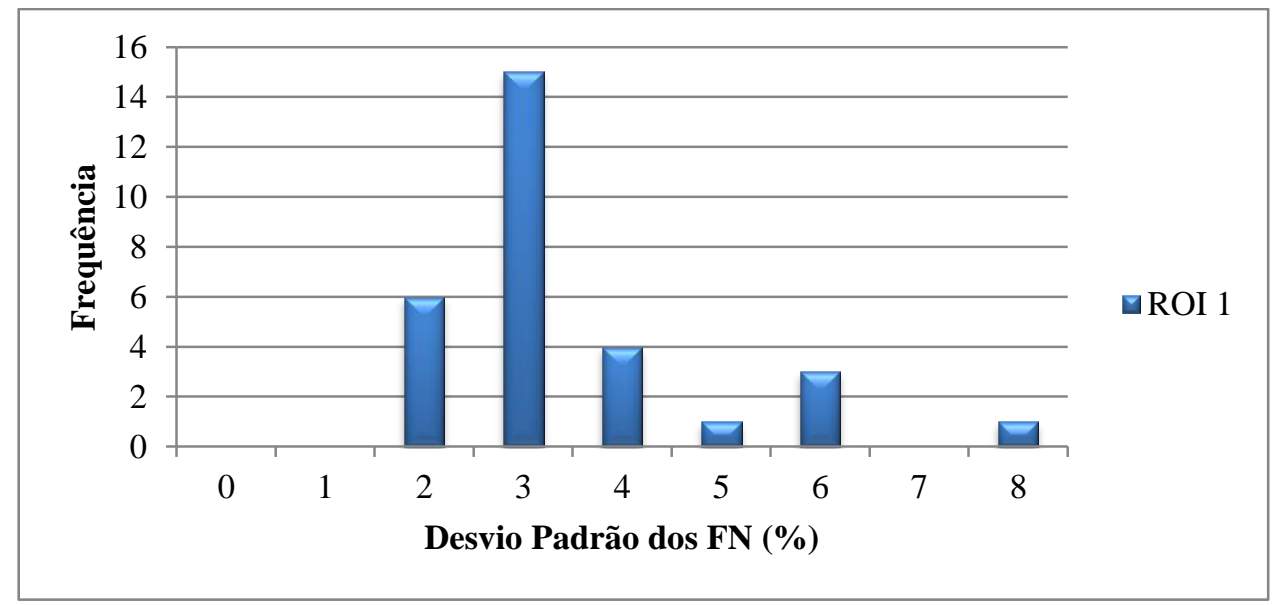

Figura 32 - Histograma com os desvios padrões do Fator de Normalização obtida pelos TLDs 600 nas diferentes irradiações na fonte de ${ }^{60} \mathrm{Co}$

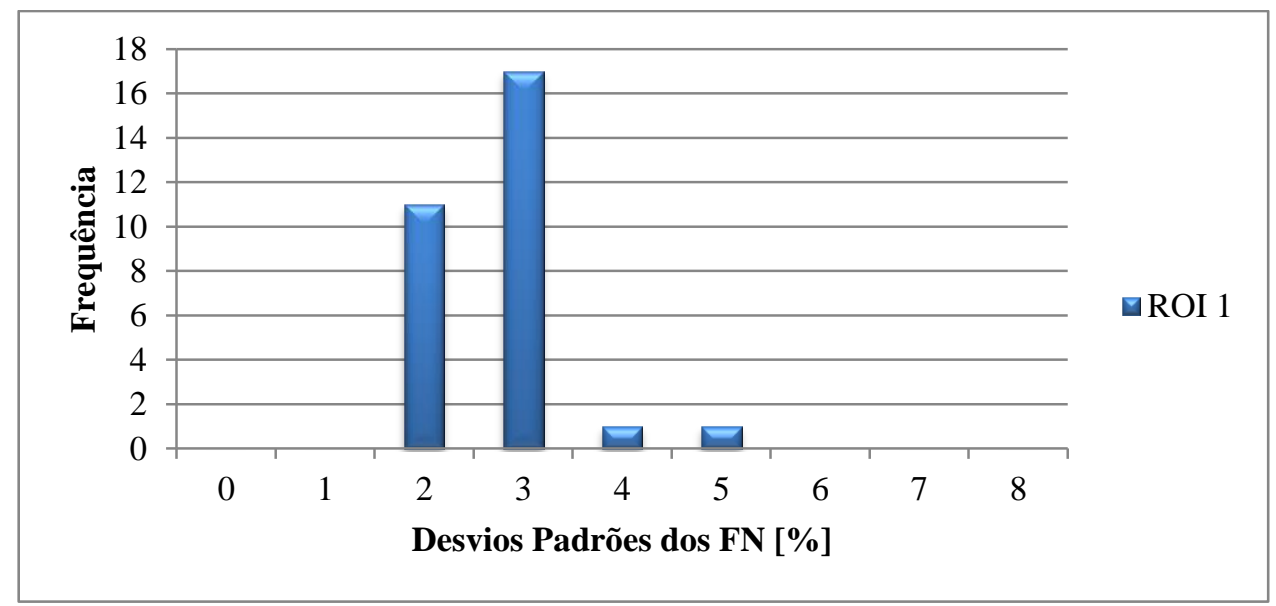

Figura 33 - Histograma com os desvios padrões dos Fatores de Normalização obtida pelos TLDs 700 nas diferentes irradiações na fonte de ${ }^{60} \mathrm{Co}$

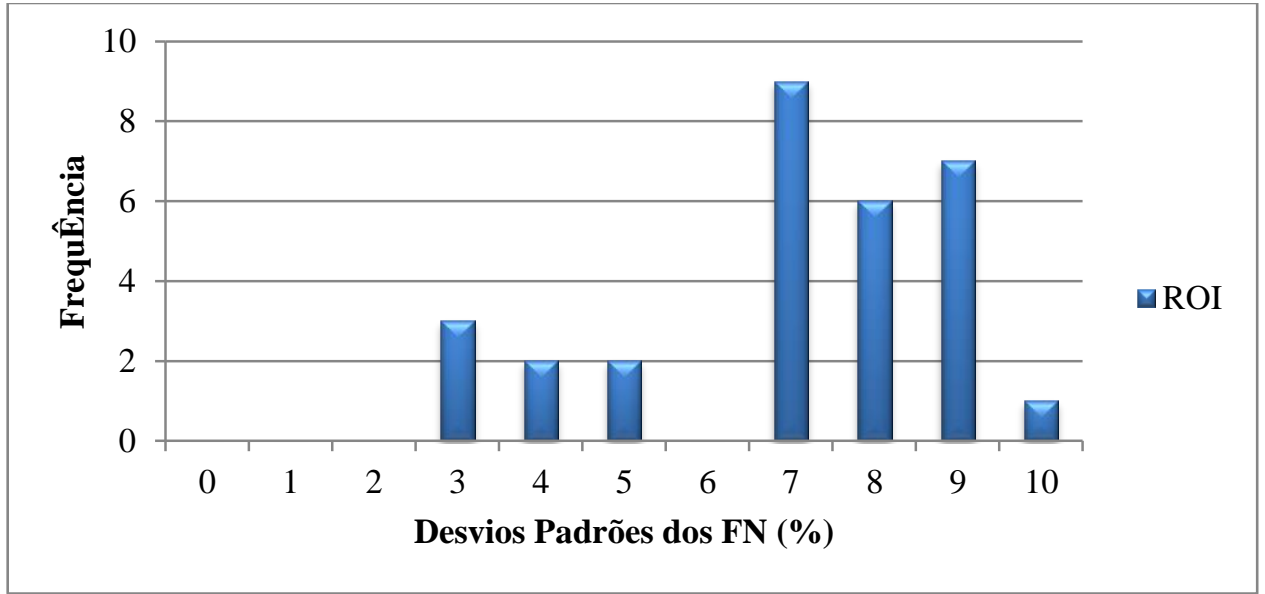

Figura 34 - Histograma com os desvios padrões dos Fatores de Normalização obtida pelos TLDs 400 nas diferentes irradiações na fonte de ${ }^{60} \mathrm{Co}$ 
Este estudo mostrou que os TLDs 700 são os mais reprodutíveis e o TLD 400 apresenta o maior valor de dispersão, sendo assim o menos reprodutível. Mas mesmo assim, o valor obtido pelo TLD 400 está dentro do aceitável, inferior a 10\%, para o uso de TLDs.

\subsection{Estudo da Reprodutibilidade dos TLDs em Campo Misto}

Para este estudo foi utilizada uma fonte de ${ }^{241} \mathrm{AmBe}$ de $2 \mathrm{Ci}$. Porém esta fonte emite preferencialmente nêutrons de alta energia, e neste estudo visava-se compreender o comportamento dos TLDs em um campo misto com nêutrons de baixa energia. Portanto, era necessário o uso de um sistema moderador para reduzir as energias dos nêutrons emitidos pela fonte.

Em trabalhos anteriores [25] realizados pelo grupo de BNCT do IPEN para o selecionamento e estudo da reprodutibilidade dos TLDs, utilizava-se um disco de parafina com um furo central onde a fonte de ${ }^{241} \mathrm{AmBe}$ foi posicionada e os TLDs foram posicionados ao redor deste disco.

Porém um estudo mais minucioso deste sistema, utilizando o MCNP5, mostrou que este sistema não foi o mais adequado (este estudo está apresentado no Anexo C). Portanto foi desenvolvido, novamente com o auxílio das simulações do MCNP5, um novo sistema para a realização dos estudos de reprodutibilidade dos TLDs para fonte mista.

Neste novo sistema foi buscada uma maior homogeneidade de dose nas diferentes posições que eram posicionados os TLDs, e para isto foi planejado um cilindro de polietileno com uma altura maior e que a fonte de AmBe ficasse posicionada no seu interior, na altura média. Os TLDs também seriam postos na altura média da lateral deste cilindro. E todo este arranjo ficava posicionado a 1,2 $\mathrm{m}$ do chão, para minimizar interferências de nêutrons ou fótons refletidos pelo chão.

Simulações foram realizadas visando encontrar as melhores dimensões para que o fluxo de nêutrons térmicos fosse o maior possível, tendo em vistas os limites de dimensões dos tarugos de polietileno em posse do grupo de BNCT. Foi realizado o projeto deste novo sistema para sua confecção. O novo sistema foi formado por um 
cilindro de polietileno que se divide em duas partes, a superior e a inferior. $\mathrm{E}$ a fonte de ${ }^{241} \mathrm{AmBe}$ era posicionada no interior da parte inferior do cilindro,que posteriormente era feixada pela parte superior. A Figura 35 apresenta as imagens deste novo sistema para o estudo da reprodutibilidade dos TLDs.
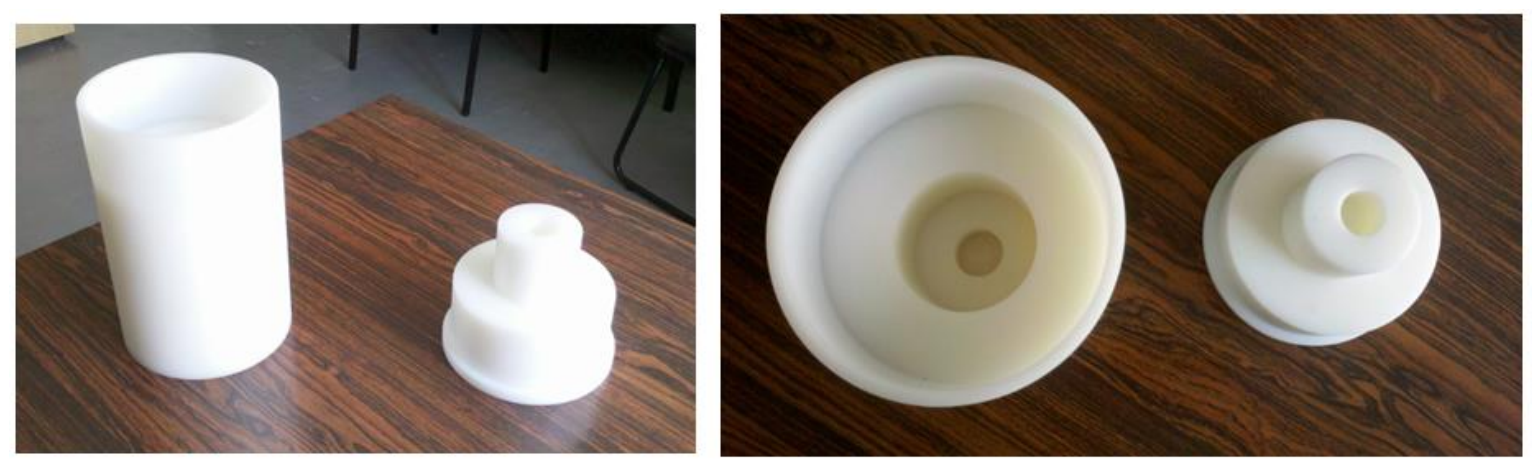

Figura 35 - Imagens do novo sistema para estuda da reprodutibilidade dos TLDs

Nas irradiações neste novo sistema cada TLD foi colocado em uma das 15 posições existentes de um suporte de isopor com distribuição matricial 3 x 5. Foram utilizados um total de 6 suportes que eram posicionados junto à superfície lateral do cilindro em sua altura média.

Foi realizado um estudo com o MCNP5 para analisar as diferenças que haveria nos valores de kerma no ar em cada uma das 15 posições do suporte de TLDs e a dose, assim como o fluxo em cada posição.

A Tabela 10 apresenta os valores de fluxo de fótons e a taxa de kerma no ar correspondente obtidos, por simulação. A Tabela 11 apresenta as estimativas dos mesmos parâmetros, fluxo e kerma no ar, para os nêutrons de cada faixa energética.

Tabela 10 - Valores médios calculados de fluxo de fótons e a respectiva taxa de kerma no ar no novo sistema de irradiação

\begin{tabular}{cccc}
\hline \multicolumn{2}{c}{ Fluxo $\left(\mathbf{1} / \mathbf{c m}^{2} . \mathbf{s}\right)$} & \multicolumn{2}{c}{ Taxa de Kerma no ar $(\mathbf{m G y} / \mathbf{h})$} \\
\hline Valor médio & Incerteza $(\%)$ & Valor médio & Incerteza $(\%)$ \\
$8,32 \mathrm{E}+04$ & 1,8 & 3,34 & 1,8 \\
\hline
\end{tabular}


Tabela 11 - Valores médios calculados de fluxo de nêutrons e respectiva taxa de kerma no ar e a fração de contribuição de cada faixa energética no novo sistema de irradiação com a fonte de $\mathrm{AmBe}$

\begin{tabular}{|c|c|c|c|c|}
\hline \multirow{3}{*}{$\begin{array}{c}\text { Contribuição dos nêutrons } \\
(\%)\end{array}$} & \multicolumn{2}{|c|}{ Fluxo $\left(1 / \mathrm{cm}^{2} . \mathbf{s}\right)$} & \multicolumn{2}{|c|}{$\begin{array}{c}\text { Taxa de Kerma no ar } \\
(\mathrm{mGy} / \mathrm{h})\end{array}$} \\
\hline & $\begin{array}{l}\text { Valor } \\
\text { médio }\end{array}$ & $\begin{array}{c}\text { Incerteza } \\
(\%)\end{array}$ & Valor médio & Incerteza $(\%)$ \\
\hline & $8,32 \mathrm{E}+04$ & 2,0 & 1,47 & 1,8 \\
\hline Térmicos & \multicolumn{2}{|c|}{26} & \multicolumn{2}{|c|}{25} \\
\hline Epitérmicos & \multicolumn{2}{|c|}{16} & \multicolumn{2}{|c|}{1} \\
\hline Rápidos & \multicolumn{2}{|c|}{58} & \multicolumn{2}{|c|}{74} \\
\hline
\end{tabular}

Vale ressaltar que os nêutrons, ao interagirem com o polietileno, produzem fótons, porém o fluxo e o kerma no ar que estes fótons produziam nas posições dos TLDs são desprezíveis frente ao fluxo e kerma no ar produzidos pelos fótons da própria fonte.

Foram realizadas 8 irradiações, de 24 horas cada uma, nesta configuração, na qual todos os 30 TLDs de cada tipo foram irradiados. Com o auxílio do MCNP5 foi possível estimar a dose que cada tipo de TLD estaria exposto nesta configuração. As estimativas de dose devido aos gamas e aos nêutrons estão apresentadas na Tabela 12.

Tabela 12 - Estimativas calculadas de doses, e componentes energéticas, devido aos nêutrons nos diferentes tipos de TLDs

\begin{tabular}{ccccc}
\hline & & TLD 600 & TLD 700 & TLD 400 \\
\hline \multirow{2}{*}{ Dose [mGy] } & Gama & $75,6 \pm 2,2$ & $75,6 \pm 2,2$ & $85 \pm 2$ \\
\cline { 2 - 5 } & Nêutrons & $(9,6 \pm 0,2) \mathrm{E}+3$ & $290 \pm 7$ & $16,6 \pm 0,4$ \\
\hline \multirow{3}{*}{ Componentes (\%) } & Térmicos & 91,5 & 86,4 & 0,07 \\
& Epitérmicos & 7,8 & 3,2 & 0,05 \\
& Rápidos & 0,7 & 10,4 & 99,88 \\
\hline
\end{tabular}

A partir dos resultados desta simulação é possível observar que o TLD 600 apresenta uma dose depositada devido a nêutrons muito maior em comparação aos outros TLDs, e que a maior parte desta dose depositada deve-se aos nêutrons térmicos. Os TLDs de LiF apresentaram uma dose depositada devido aos nêutrons superior a dose depositada devido aos gamas, inclusive para o TLD 700, que é dito não sensível a nêutrons. Já os TLDs 400 apresentaram a maior dose depositada devido aos gamas, mas a dose depositada mais baixa devido aos nêutrons. 
Deve-se observar como esta dose depositada influencia na respostas dos TLDs, para assim se ter uma estimativa da sensibilidade dos TLDs para cada componente do campo.

O estudo de reprodutibilidade em campo misto mostrou comportamentos semelhantes aos apresentados no estudo de reprodutibilidade em fonte de gama puro, sendo que em uma mesma irradiação os TLDs de mesmo tipo apresentaram diferenças em suas respostas devido às suas sensibilidades diferentes (Figura 36).

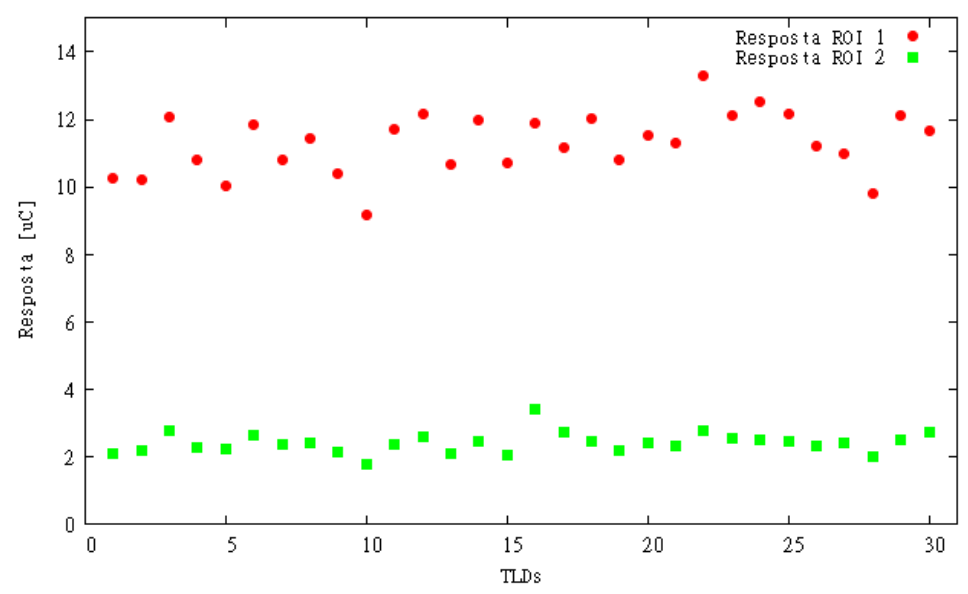

Figura 36 - Dispersão das respostas individuais (ROI 1 e ROI 2) dos TLDs 600 em uma irradiação no sistema com a fonte de AmBe

Foi feito também o gráfico de correlação entre as respostas das diferentes regiões de interesse de cada um dos TLDs apresentados no gráfico da Figura 36, cujo resultado está apresentado na Figura 37. 


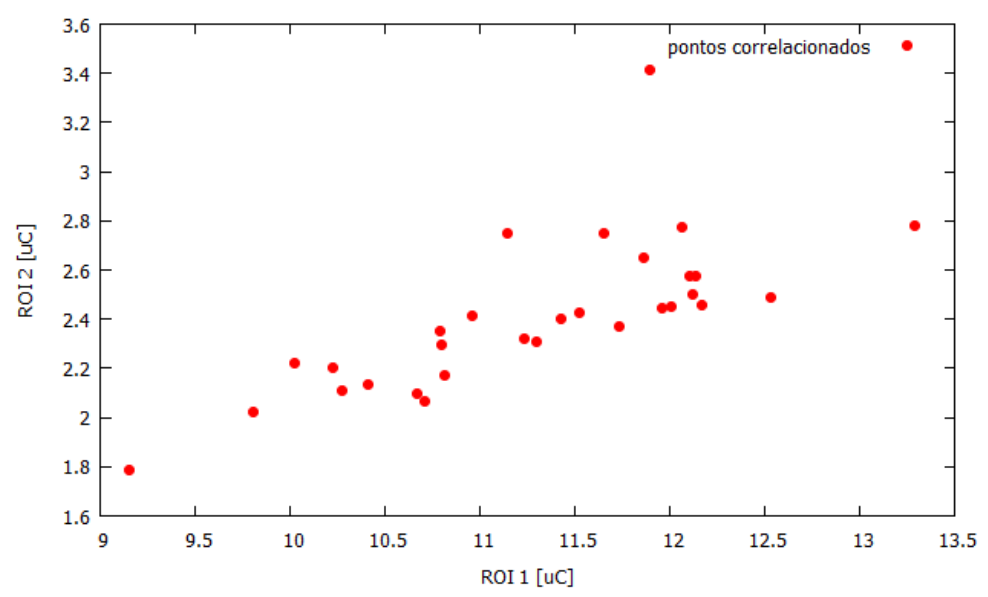

Figura 37 - Gráfico de correlação entre os valores do ROI 1 pelo ROI 2 dos TLDs 600 em uma irradiação no sistema com a fonte de ${ }^{241} \mathrm{AmBe}$

No gráfico da Figura 37 pode-se observar que a resposta das duas regiões de interesse não é constante para todos os TLDs, o que mostra que para cada região de interesse e para cada TLD haverá uma eficiência. Porém este gráfico de correlação também mostra uma tendência linear dos pontos, sendo que este dado pode vir a ser útil para a avaliação da qualidade da definição dos ROIs, e para uma possível determinação da relação entre nêutrons e gamas do feixe devido a inclinação desta reta.

As médias das respostas dos TLDs nas diferentes irradiações também variavam, como apresentado na Figura 38 para o TLD 600, Figura 39 para o TLD 700 e Figura 40 para o TLD 400.

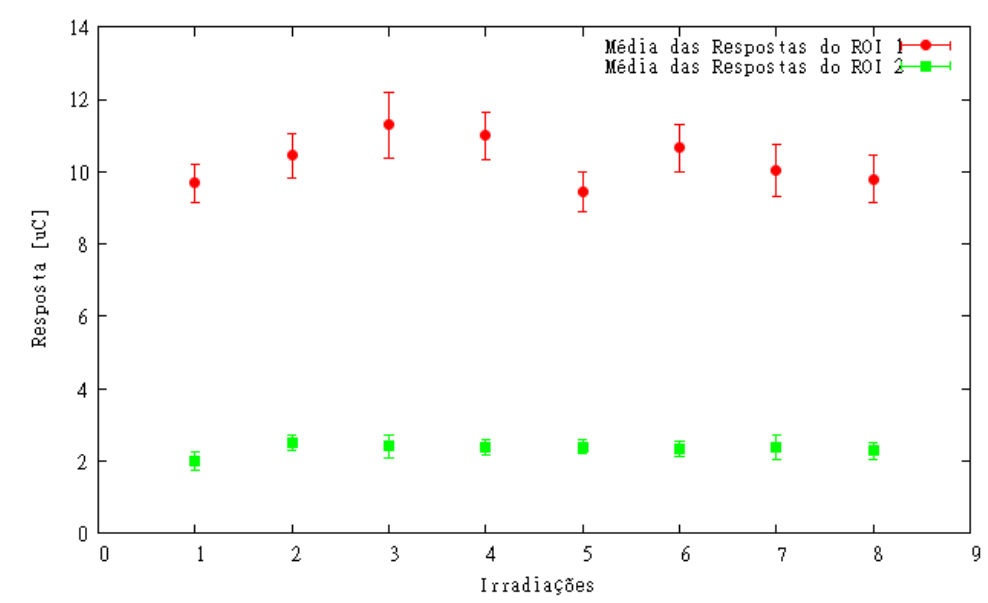

Figura 38 - Médias das Respostas dos TLDs 600 nas 8 irradiações na fonte de AmBe 


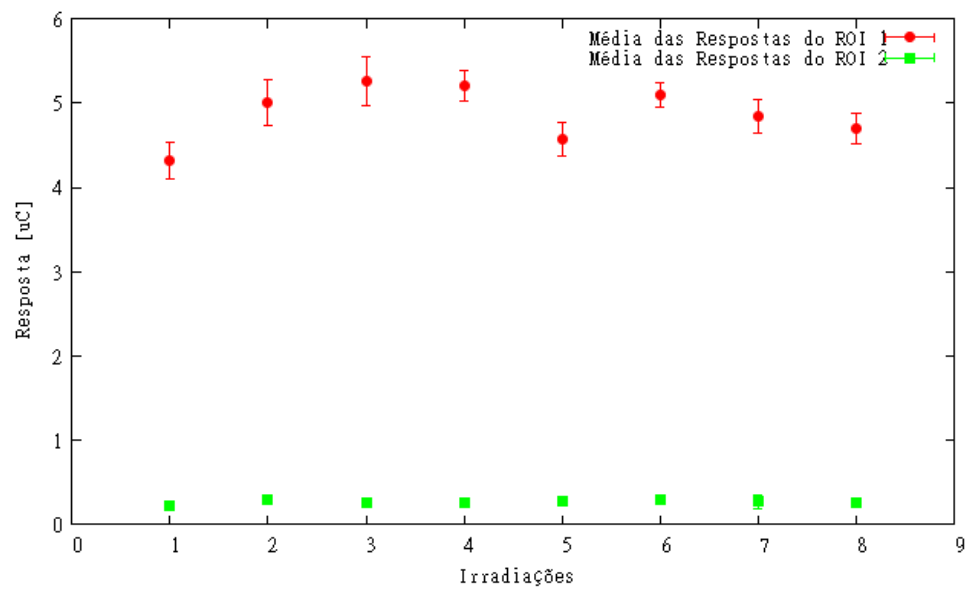

Figura 39- Médias das Respostas dos TLDs 700 nas 8 irradiações na fonte de AmBe

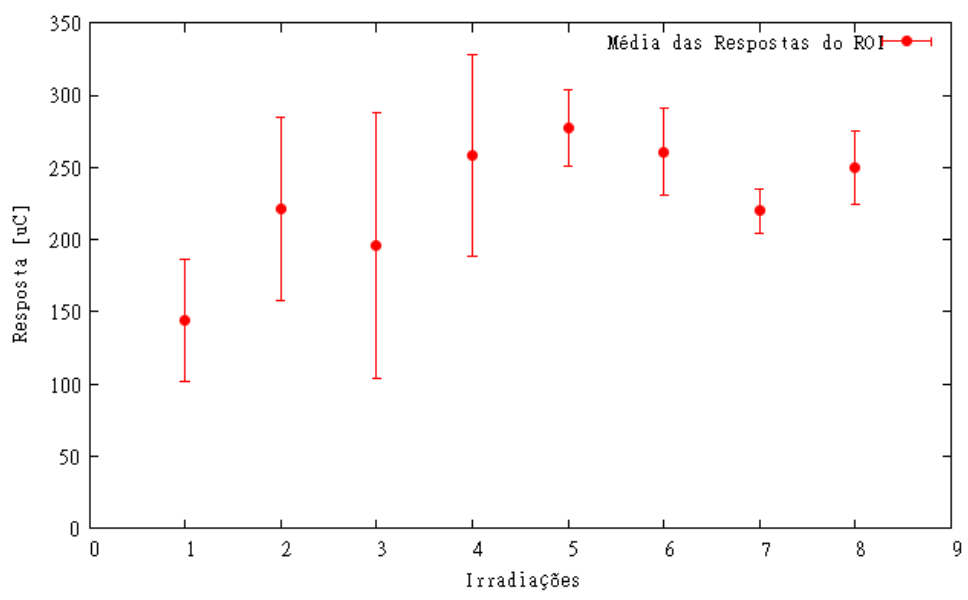

Figura 40- Médias das Respostas dos TLDs 400 nas 8 irradiações na fonte de AmBe

Nas irradiações em campo misto, os TLDs 600 e TLDs 700 apresentam comportamento semelhante, porém o TLD 600 apresenta resposta superior, uma vez que este TLD é mais sensível a nêutrons térmicos. Porém, segundo as simulações, a dose depositada nos TLDs 600 devido aos nêutrons é mais de 30 vezes maior que a dose depositada nos TLDs 700 devido aos nêutrons, mas só é observada uma resposta 2 vezes maior do TLD 600 frente ao TLD 700, o que pode ser explicado por uma autoblindagem sofrida pelos TLDs 600 devido a sua alta composição de ${ }^{6} \mathrm{Li}$.

Foi feito também o gráfico que correlaciona as respostas médias de cada irradiação entre os TLDs 600 e TLDs 700, este gráfico está apresentado na Figura 41. 


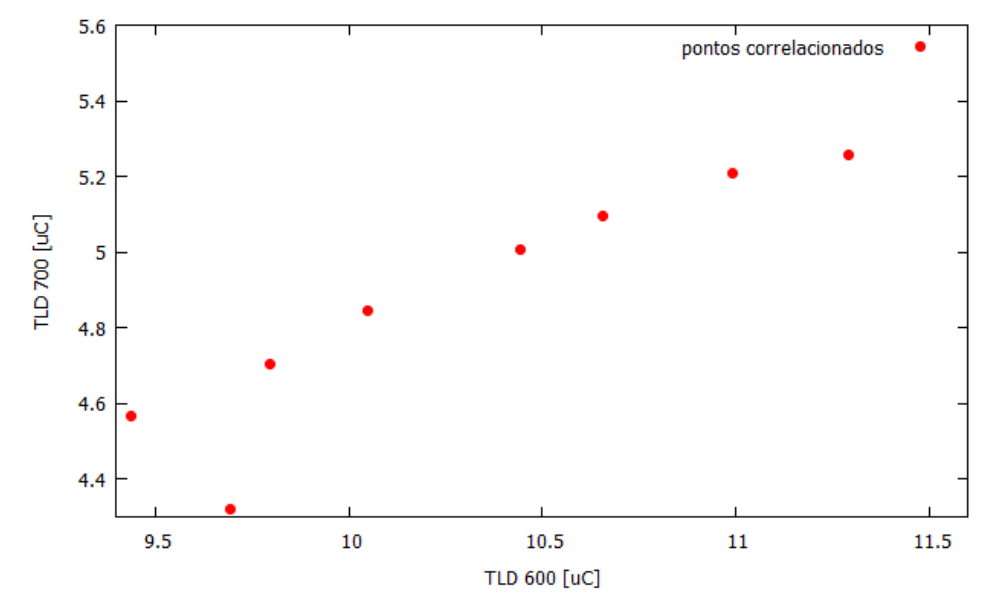

Figura 41 - Gráfico de correlação das respostas médias dos TLDs 600 e TLDs 700 nas irradiações no sistema com a fonte de AmBe

$\mathrm{Na}$ Figura 41, com a exceção do segundo ponto, pode-se observar um crescimento proporcional das respostas dos dois TLDs de LiF, o que mostra que há uma boa correlação entre estes dois TLDs quando eles são irradiados juntos.

Já os TLDs 400 se mostraram muito pouco precisos quando foram irradiados em um campo misto do sistema com a fonte de AmBe, sendo possível observar grandes divergências das respostas dos TLDs em uma mesma irradiação e também grandes divergências entre as respostas dos TLDs em diferentes irradiações.

Mesmo assim, as relações entre as respostas individuais dos TLDs com a média da irradiação mantinham uma relação quase que constante nas diferentes irradiações, como já demonstrado para o caso da fonte de ${ }^{60} \mathrm{Co}$. Isto pode ser visto na Figura 42, que mostra as respostas individuais das regiões de interesse dos diferentes tipos de TLDs em diferentes irradiações.
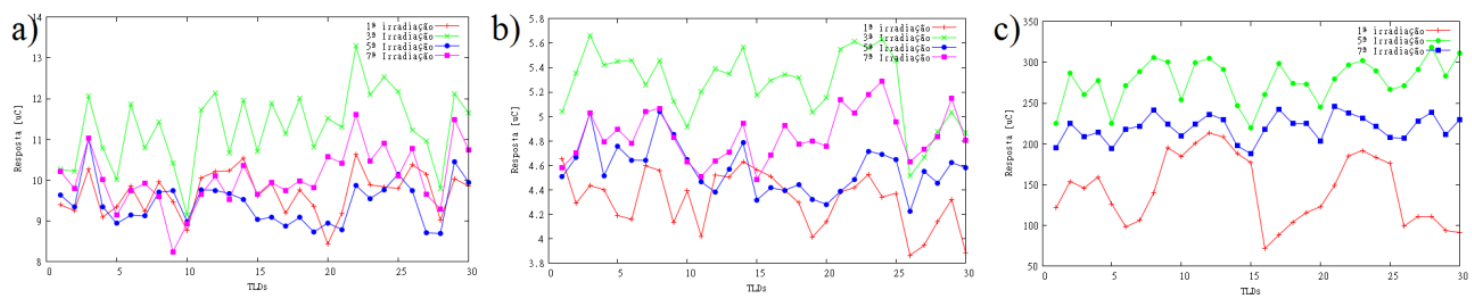

Figura 42 - Respostas das regiões de interesse individuais dos TLDs em diferentes irradiações na fonte de AmBe: a) TLD 600; b) TLD 700; c) TLD 400 
Assim, também foi possível a criação de um Fator de Normalização, como na seção 5.2, para as irradiações no campo de nêutrons e gama do sistema com a fonte de AmBe. Na seção seguinte estão as características destes Fatores de Normalização para este sistema.

\subsubsection{Fatores de Normalização para o sistema com a fonte de AmBe}

Para este caso também foram realizados os estudos para analisar a dispersão dos Fatores de Normalização dos TLDs, os histogramas contendo estes valores estão apresentados nas Figura 43, Figura 44 e Figura 45.

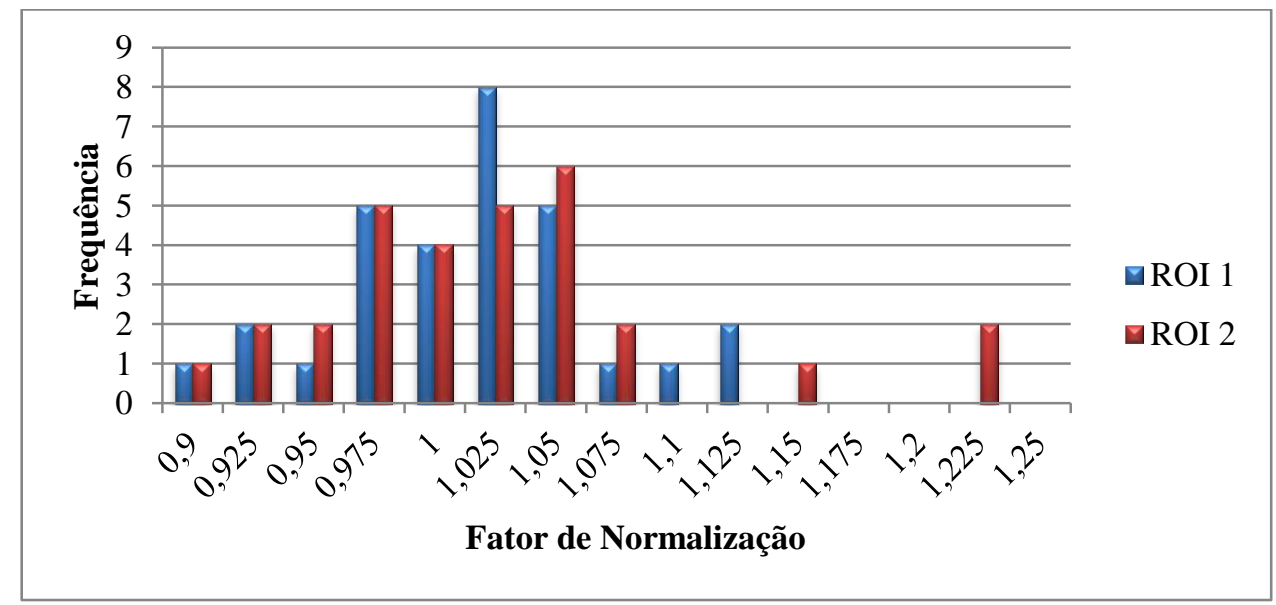

Figura 43 - Histograma com os valores do Fator de Normalização dos TLDs 600 nas irradiações no sistema com a fonte de AmBe

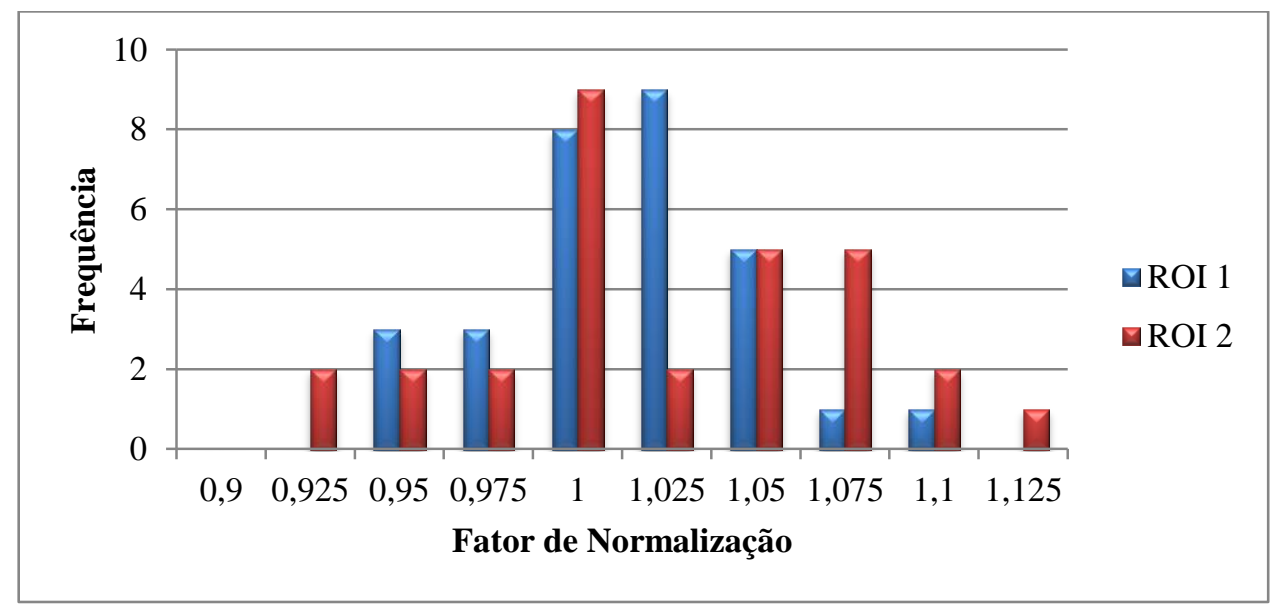

Figura 44 - Histograma com os valores do Fator de normalização dos TLDs 700 nas irradiações no sistema com a fonte de AmBe 


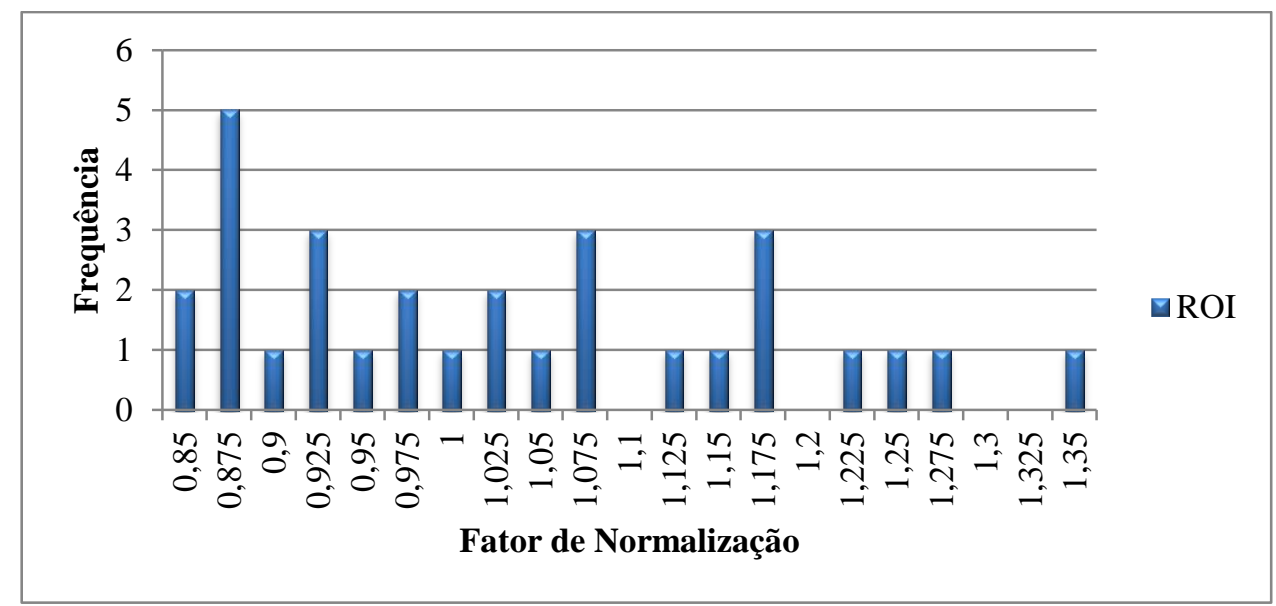

Figura 45 - Histograma com os valores do Fator de Normalização dos TLDs 400 nas irradiações no sistema com a fonte de AmBe

Foi possível observar que para os TLDs de LiF a resposta da segunda região de interesse apresentam valores mais distantes da média em comparação a resposta da primeira região de interesse, uma vez que o Fator de Normalização mostra o quão distante a resposta de certo TLD está da resposta da média. Observa-se também que o TLD 400 apresenta os valores de resposta mais distantes.

Analisando o quão reprodutíveis são estes Fatores de Normalização dos TLDs, foram feitos os histogramas com os valores de desvio padrão destes Fatores de Normalização, e estes histogramas estão apresentados nas Figura 46, Figura 47 e Figura 48.

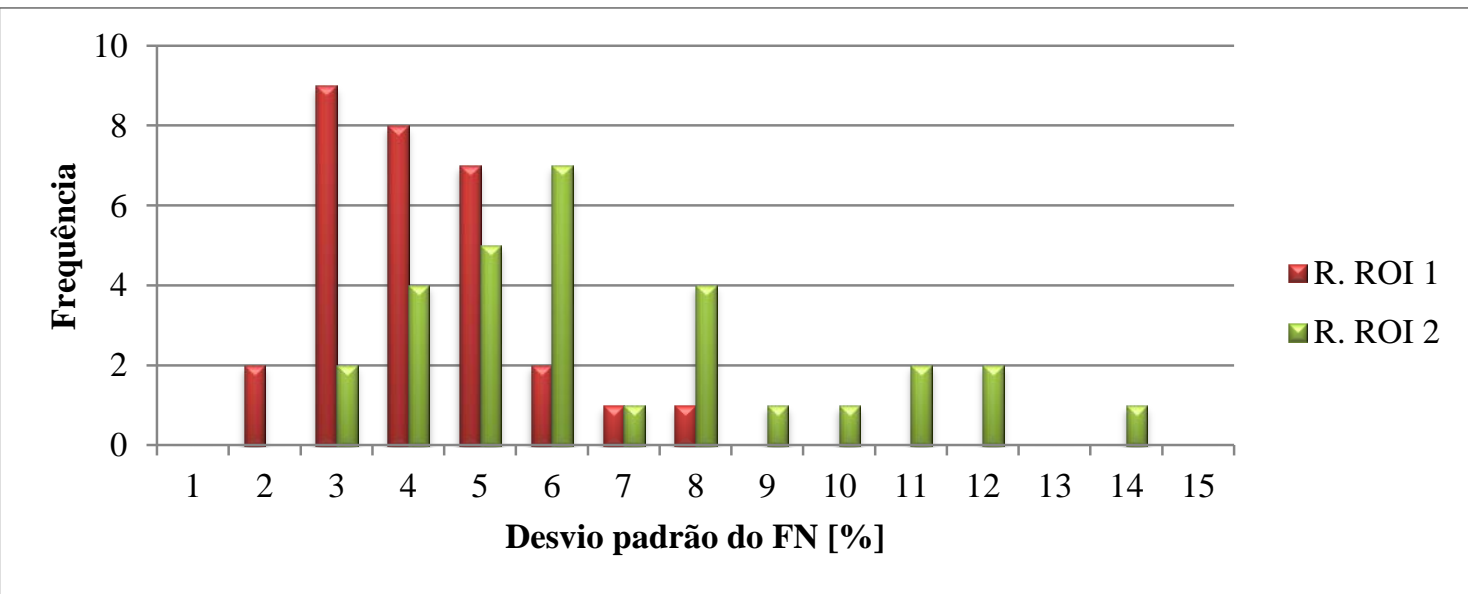

Figura 46 - Histograma com os desvios padrões do Fator de Normalização dos TLDs 600 nas irradiações no sistema com a fonte de AmBe 


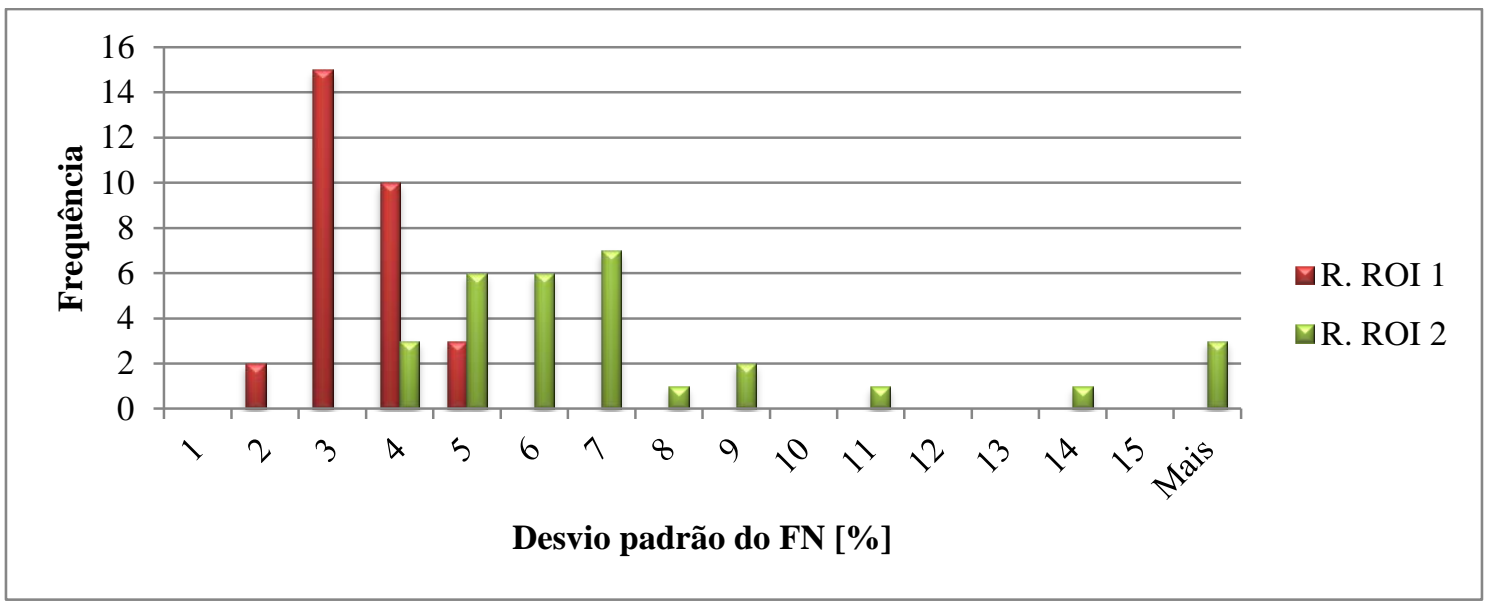

Figura 47 - Histograma com os desvios padrões do Fator de Normalização dos TLDs 700 nas irradiações no sistema com a fonte de AmBe

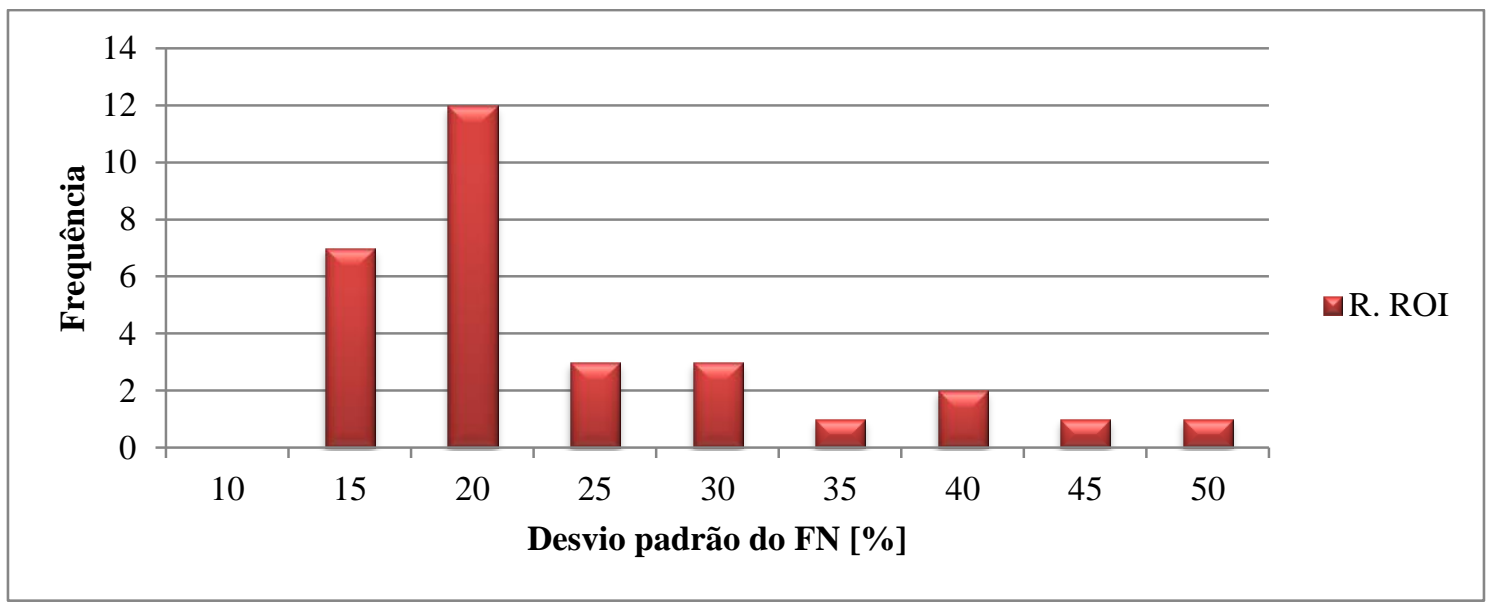

Figura 48 - Histograma com os desvios padrões do Fator de Normalização dos TLDs 400 nas irradiações no sistema com a fonte de AmBe

No estudo sobre os desvios padrões dos Fatores de Normalização dos TLDs nas diferentes irradiações no sistema com a fonte de AmBe, foi observado que para os TLDs de LiF o desvio para a segunda região de interesse é maior. Isto provavelmente vem do fato de a primeira região de interesse ser mais estável, e por isto esta é a região utilizada em muitos estudos como a região de interesse para a realização da dosimetria. Porém mesmo com o desvio maior na segunda região de interesse, este valor ainda se encontra dentro de valores utilizados em alguns estudos com TLDs [36].

Já o TLD de $\mathrm{CaF}_{2}$, TLD 400, apresentou valores muito altos de desvio, mostrando o que já se havia percebido: que os TLDs 400 não eram muito reprodutíveis neste sistema com a fonte mista de AmBe. 


\subsection{Comparação da Nova Metodologia com a Metodologia Anterior Utilizada pelo Grupo de Pesquisas em BNCT do IPEN}

Apesar da observação que as incertezas na reprodução do ciclo do uso do TLD são superiores às incertezas nas reprodutibilidades das respostas individuais dos TLDs, este trabalho adotou o uso deste Fator de Normalização como metodologia de análise dos TLDs, e não o selecionamento dos TLDs.

$\mathrm{Na}$ metodologia anterior, os TLDs eram irradiados algumas vezes na fonte de AmBe e eram selecionados aqueles TLDs que apresentavam uma resposta média semelhantes entre si. Posteriormente estes TLDs selecionados eram irradiados novamente na fonte de $\mathrm{AmBe}$ a fim de se obter um fator individual para cada TLD em relação a resposta da média, e foi criado então um fator de selecionamento que era a média dos fatores individuais de cada TLD. Este fator era multiplicado na resposta individual dos TLDs, e esta era considerada a resposta final do TLD [25]. Este fator de selecionamento era único, e era utilizado para todos os TLDs.

No trabalho de Mestrado de Rafael Muniz [25] de 99 TLDs 600 foram selecionados apenas 12 TLDs para serem utilizados.

Para mostrar as diferenças entre as metodologias, foi feita a mesma seleção realizada por Rafael Muniz, mas só que agora para os TLDs utilizados neste trabalho, para assim realizar a comparação das metodologias.

A partir dos 30 TLDs 600 disponíveis, e utilizando uma incerteza máxima de 5\% para a seleção, foram selecionados 11 TLDs segundo a metodologia anterior. Utilizando uma irradiação na fonte de AmBe e os cálculos necessários para esta metodologia anterior foi obtido uma desvio padrão da média de 5,6\% nas respostas dos 11 TLDs selecionados.

Para a mesma irradiação, mas agora utilizando a metodologia que utiliza o Fator de Normalização, foram realizados os cálculos para todos os 30 TLDs, que é o caso da metodologia proposta neste trabalho, na qual não se descarta nenhum TLD. Neste experimento, utilizando todos os TLDs, o desvio padrão da média foi de 4,1\%.

Isto mostra a maior precisão nas respostas dos TLDs quando se aplica a metodologia com o Fator de Normalização, mesmo no caso onde não houve uma prévia seleção dos TLDs e sem haver descartes de TLDs. 
Assim, a nova metodologia utiliza um maior número de TLDs, sendo possível então obter uma melhor precisão dos resultados.

Em contrapartida, na metodologia anterior não havia preocupação quanto a distinção dos TLDs. Já na nova metodologia se houver a perda da identificação individual dos TLDs, impossibilita-se seu uso, uma vez que perde-se-ia seu Fator de Normalização. Portanto um cuidado especial quanto a identificação dos TLDs deve ser tomado.

\subsection{Diferenças das Curvas Termoluminescentes em Diferentes Campos}

Como já dito, o par TLD 600 e TLD 700 pode ser utilizado para a dosimetria de nêutrons térmicos e radiação gama em campos mistos. Porém pressupor que o TLD 700 não seja sensível aos nêutrons pode se mostrar equivocado dependendo do fluxo de nêutrons e da presença de nêutrons de maior energia.

Foi estudada então a diferença da curva termoluminescente dos TLDs 600 e dos TLDs 700 para diferentes campos, para verificar as características destas curvas devido às características do campo em que os TLDs haviam sido irradiados.

Esta comparação foi feita inicialmente com as curvas termoluminescentes dos TLDs irradiados em uma fonte de gama puro $\left({ }^{60} \mathrm{Co}\right)$ e um campo misto $(\mathrm{AmBe})$. E posteriormente comparada às curvas termoluminescentes dos TLDs irradiados em diferentes posições do reator IPEN/MB-01. As diferentes posições têm diferentes espectros de radiação (gamas e nêutrons).

\subsubsection{Curvas TL (fonte de ${ }^{60} \mathrm{Co}$ e de AmBe)}

Primeiramente foi analisada a diferença na curva termoluminescente devido à presença ou não de nêutrons nos TLDs de LiF. Os TLDs 400 não foram utilizados neste estudo, pois estes se mostraram muito pouco reprodutíveis em campos mistos.

Na Figura 49 estão apresentadas estas diferenças para o TLD 600 e na Figura 50 estão apresentadas as diferenças encontradas para o TLD 700. 

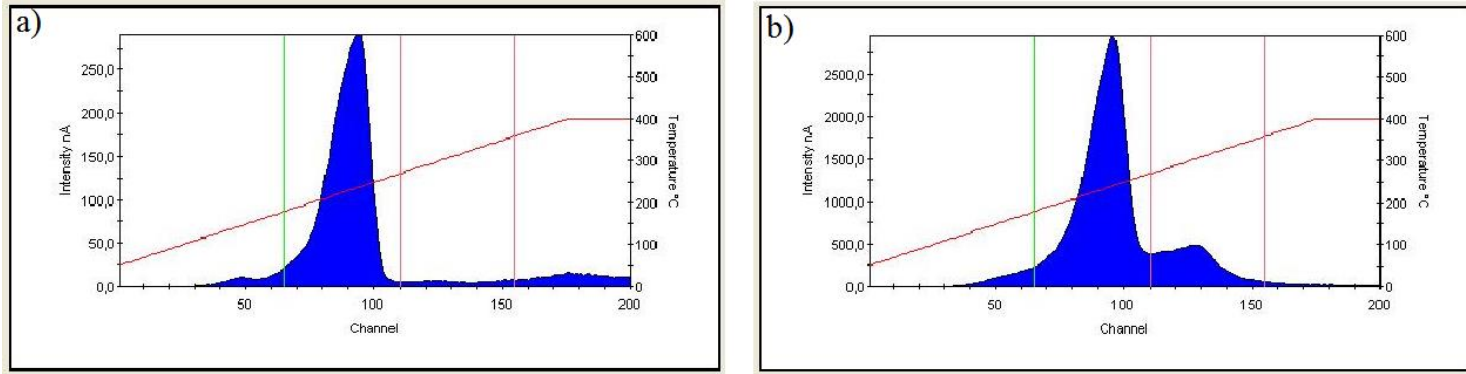

Figura 49 - Curvas termoluminescentes do TLD 600 nas irradiações em fonte de: a)

${ }^{60} \mathrm{Co}$; b) AmBe
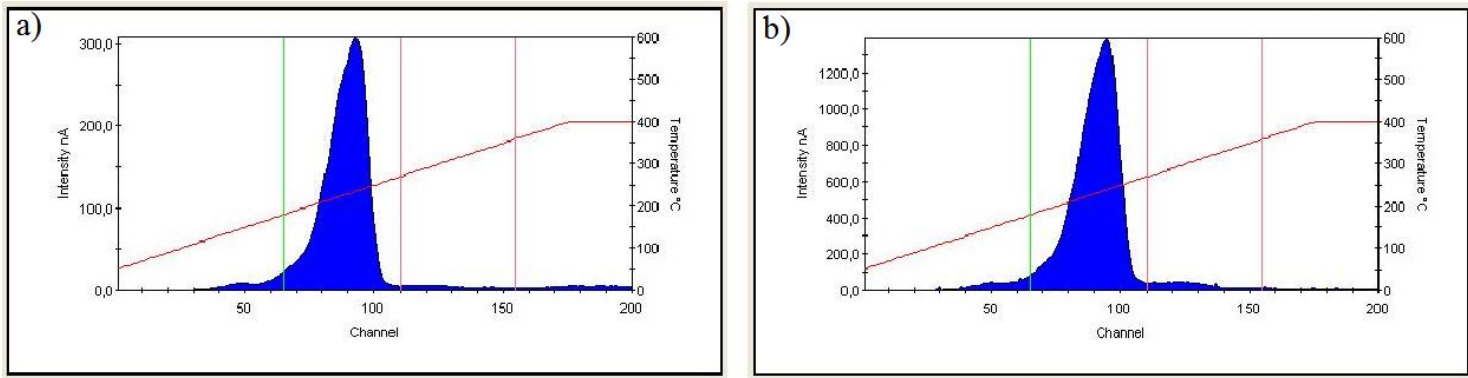

Figura 50 - Curvas termoluminescentes do TLD 700 nas irradiações em fonte de: a)

${ }^{60} \mathrm{Co}$; b) $\mathrm{AmBe}$

As doses fornecidas na irradiação com a fonte de ${ }^{60} \mathrm{Co}$ e de $\mathrm{AmBe}$ foram diferentes, e o valor destas doses em cada tipo de TLD e de kerma no ar para cada fonte estão apresentados na Tabela 13.

Na Figura 49 é possível observar o surgimento de picos dosimétricos mais acentuados na segunda região de interesse do TLD 600 quando este é irradiado com nêutrons. O TLD 700 também apresenta um ganho nos picos da segunda região de interesse (Figura 50) mas este ganho é bem menor do que o ganho observado para os TLDs 600.

Tabela 13 - Valores calculados de kerma no ar e de dose depositada nos TLDs nas irradiações com a fonte de ${ }^{60} \mathrm{Co}$ e $\mathrm{AmBe}$

\begin{tabular}{cccccccc}
\hline & \multicolumn{3}{c}{${ }^{\mathbf{6}}$ Co } & \multicolumn{3}{c}{ AmBe } \\
\hline & kerma no & \multicolumn{2}{c}{ Dose } & kerma no & \multicolumn{2}{c}{ Dose } \\
{$[$ [mGy] } & ar & TLD 600 & TLD 700 & ar & TLD 600 & TLD 700 \\
Fótons & 20 & $18,5(1)$ & $18,5(1)$ & $80,3(1,4)$ & $75,6(2,1)$ & $75,6(2,1)$ \\
Nêutrons & --- & --- & --- & $35,68(64)$ & $9,6(2) \mathrm{E}+03$ & $290(7)$ \\
\hline
\end{tabular}


$\mathrm{Na}$ Tabela 14 estão as respostas das diferentes regiões de interesse destes TLDs para estas irradiações, assim é possível verificar a sensibilidade destes TLDs devido as diferentes componentes do campo.

Tabela 14 - Resposta das diferentes regiões de interesse dos TLDs irradiados nas fontes de ${ }^{60} \mathrm{Co} \mathrm{e} \mathrm{AmBe}$ (experimentos de reprodutibilidade das seções 5.1 e 5.3)

\begin{tabular}{ccccc}
\hline \multirow{2}{*}[\mathbf{uC}]{} & \multicolumn{2}{c}{ TLD 600 } & \multicolumn{2}{c}{ TLD 700 } \\
\cline { 2 - 5 } & ROI 1 & ROI 2 & ROI 1 & ROI 2 \\
${ }^{\mathbf{6 0}} \mathrm{Co}$ & $1,15(10)$ & $0,05(1)$ & $1,11(8)$ & $0,01(2)$ \\
$\mathrm{AmBe}$ & $10,3(7)$ & $2,34(5)$ & $4,88(31)$ & $0,27(2)$ \\
\hline
\end{tabular}

A partir dos dados da Tabela 13 e da Tabela 14 é possível confirmar a maior resposta do TLD 600 a nêutrons. Pode-se observar também que a dose depositada devido aos fótons nestes TLDs é aproximadamente 4,1 vezes maior na fonte de ${ }^{241} \mathrm{AmBe}$ em relação a irradiação na fonte de ${ }^{60} \mathrm{Co}$, e que o TLD 700 apresentou um ganho de aproximadamente 4,4 vezes na resposta de sua primeira região de interesse (ROI 1) para o sistema com a fonte de AmBe, o que sugere que o TLD 700 não respondeu de forma significativa para nêutrons apesar de se observar um ganho considerável em sua segunda região de interesse (ROI 2).

Já o TLD 600 apresentou um ganho em sua primeira região de interesse de 9 vezes para a fonte de AmBe, muito superior ao ganho devido apenas aos fótons, o que sugere que esta região também responde aos nêutrons. Sua segunda região de interesse teve um ganho bem maior, o que sugere a maior sensibilidade a nêutrons dos picos dosimétricos desta região.

Pode-se observar também que na irradiação na fonte de ${ }^{60} \mathrm{Co}$ a primeira região de interesse dos TLDs 600 e TLDs 700 respondem de forma semelhante, uma vez que a sensibilidade destes TLDs a fótons é a mesma pois eles apresentam a mesma composição química. Pode-se supor então, que na irradiação com a fonte de AmBe, a primeira região de interesse destes TLDs também responde de forma semelhante aos fótons. Portanto, a diferença entre a resposta da primeira região de interesse do TLD 600 e a resposta da primeira região de interesse do TLD 700 fornece a resposta na primeira região de interesse do TLD 600 para nêutrons, o que neste caso é de 5,42 uC.

Comparando as doses depositadas nos TLDs devido aos diferentes campos de irradiação (Tabela 9 e Tabela 12) e a resposta dos TLDs em cada campo de 
irradiação, é possível observar que os TLDs de LiF são mais sensíveis a radiação gama do que a nêutrons, pois mesmo sendo depositada uma dose maior devido aos nêutrons, este não apresenta uma resposta suficientemente maior que a resposta devido à radiação gama.

\subsubsection{Irradiações no IPEN/MB-01}

Foi estudado também as repostas dos TLDs 600 e TLDs 700 para campos de maior fluxo e com diferentes espectros, ou seja, um fluxo com diferentes contribuições das diferentes componentes do campo (raios gama, nêutrons térmicos, nêutrons epitérmicos e nêutrons rápidos). Para isto foram realizadas experimentos no reator IPEN/MB-01 em 6 posições diferentes. As diferentes componentes de campo foram obtidas a partir de cálculos, através do MCNP.

Nestes experimentos o reator foi operado a baixa potência para que fosse possível adentrar no recinto do reator e recuperar os TLDs logo após o término das irradiações, minimizando a exposição dos TLDs à radiação de decaimento. Portanto, estas irradiações ocorreram em uma potência de $2 \mathrm{~W}$ durante 1 hora de operação. A configuração de operação do núcleo do reator nestes experimentos foi a cilíndrica, como apresentado no desenho esquemático da Figura 51.

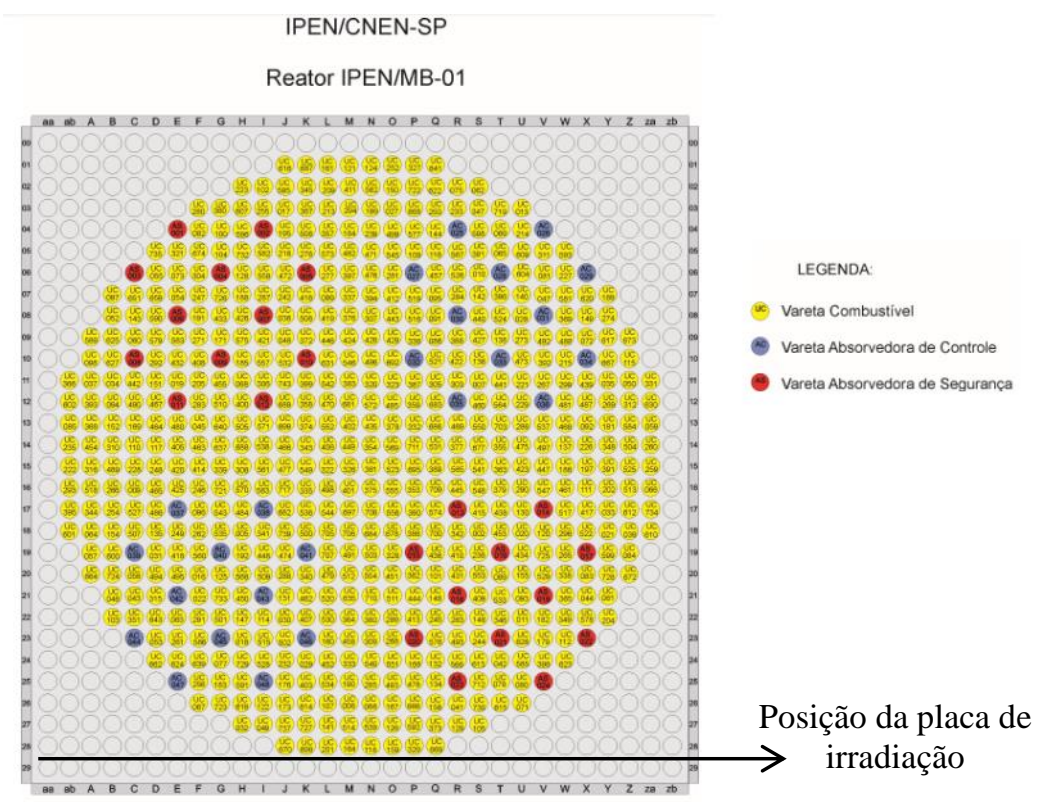

Figura 51 - Diagrama esquemático da configuração cilíndrica do reator IPEN/MB-01 
Os TLDs foram posicionados sobre onde terminavam as varetas combustíveis da face Sul do reator. Eles foram posicionados ao longo de 2 linhas, uma na altura média do combustível ativo e outra a $32 \mathrm{~cm}$ acima desta primeira linha. Em cada linha havia 3 posições de irradiação: uma na lateral do reator, outra na posição média entre a lateral e o centro do reator e a última no centro do reator. A imagem com as 6 posições onde foram posicionados os TLDs pode ser vista na Figura 52.

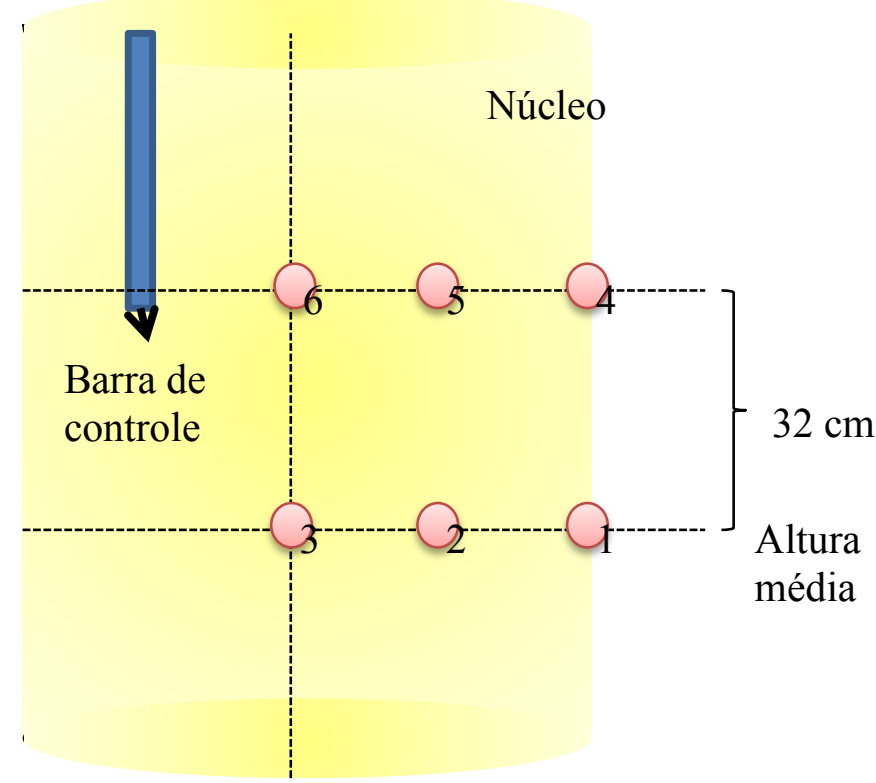

Figura 52 - Diagrama esquemático das posições de irradiação dos TLDs dentro do reator IPEN/MB-01

Nas irradiações com os TLDs, em cada posição foram posicionados 4 TLDs de cada tipo, em linhas diferentes como pode ser visto na Figura 53. Utilizando um total de 24 TLDs de cada tipo nesta irradiação.

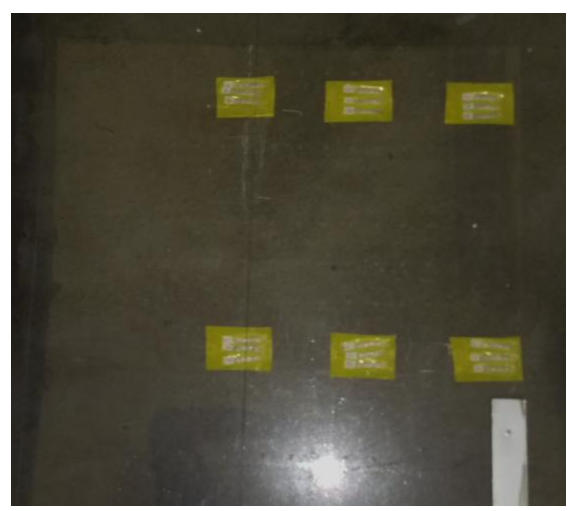

Figura 53 - Montagem da placa para a irradiação dos TLDs no reator IPEN/MB-01 
Simulações com o MCNP5 foram realizadas para se obter estimativas dos fluxos devido aos gamas e as diferentes faixas de nêutrons presentes nestas regiões. Na Figura 54 é apresentada a representação geométrica do sistema simulado com o MCNP5.

a)

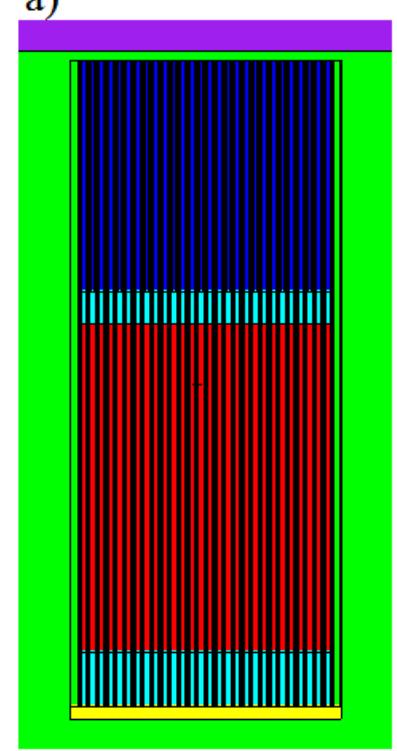

b)

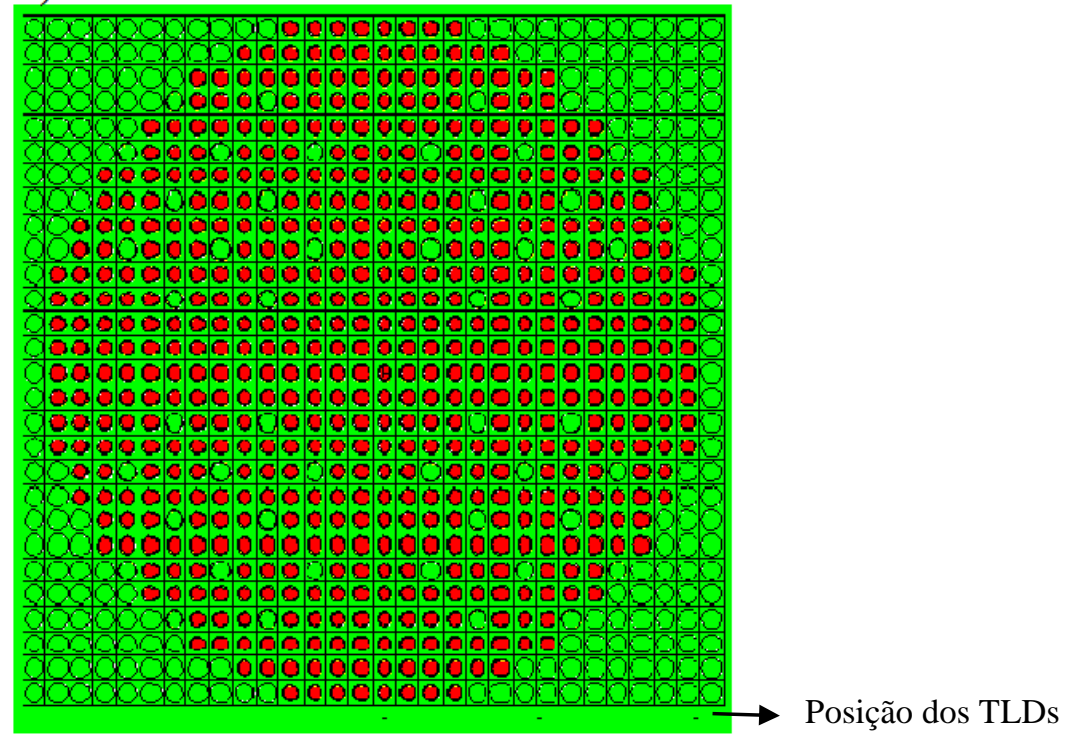

Figura 54 - Imagem das simulações do IPEN/MB-01 pelo MCNP5: a) vista da lateral do núcleo do reator; b) vista do núcleo do reator, onde podem ser vistas as posições dos TLDs

As simulações com o MCNP5 forneceram as estimativas de fluxos das diferentes componentes de campo em cada uma das seis posições de irradiação, a Figura 55 apresenta um gráfico com as frações do fluxo de cada componente de campo normalizado pelo valor máximo de fluxo de fótons encontrados para cada posição. 


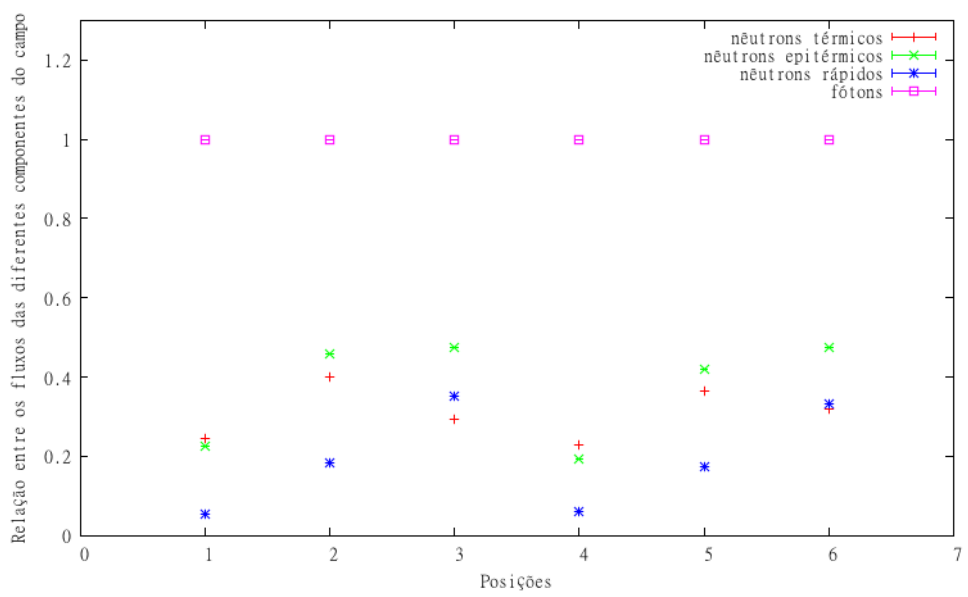

Figura 55 - Valores de fluxo normalizados para cada posição, calculados pelo MCNP5, para cada uma das 6 posições

De acordo com os dados fornecidos pelo MCNP5 na Figura 55, é possível observar que há aproximadamente três campos distintos com intensidades relativas de fluxo relativos semelhantes: um que corresponde as posições 1 e 4 , outro nas posições 2 e 5 e o último nas posições 3 e 6 .

A Figura 56 apresenta as relações entre os fluxos das diferentes componentes em relação ao fluxo de fótons mais intenso, fornecido pelas simulações com o MCNP5.

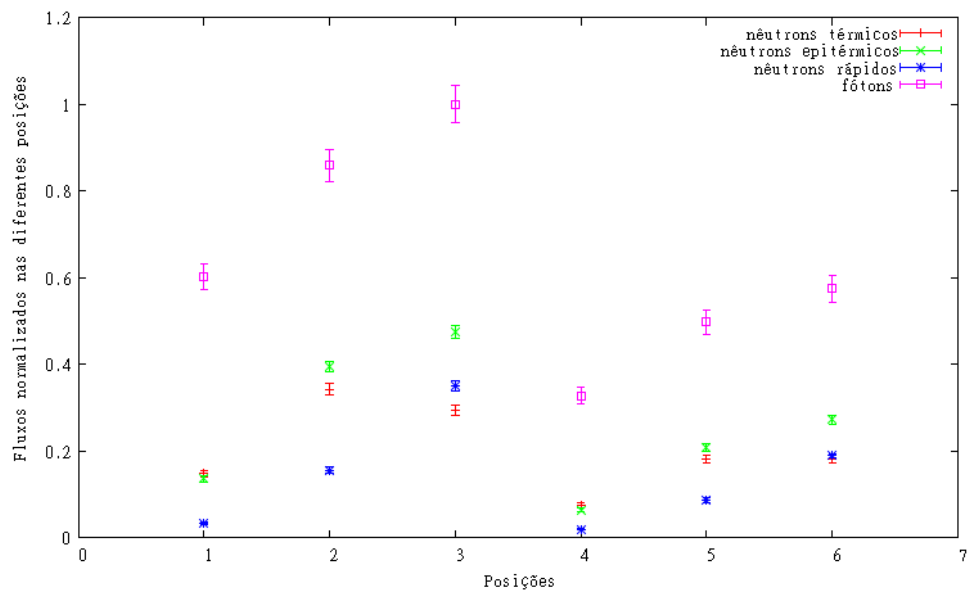

Figura 56 - Valores calculados pelo MCNP5 dos fluxos normalizados, pelo valor máximo de fluxo de fótons, das diferentes componentes de campo, nas diferentes posições 
Os dados da Figura 56 mostram que apesar da existência de 3 campos com intensidades relativas distintas, os fluxos destes campo são diferentes. Portanto, é possível realizar os experimentos na qual uma mesma composição de campo é obtida com fluxos diferentes. E também se pode observar que as posições 1 e 6 têm composições distintas de campo, porém o fluxo de fótons é semelhante.

Os TLDs irradiados tiveram suas leituras realizadas com uma tensão de $500 \mathrm{~V}$ na leitora. A Figura 57 apresenta os valores de resposta das duas regiões de interesse destes TLDs de acordo com a posição ocupada na placa (em cada posição são mostradas as respostas de 4 TLDs).

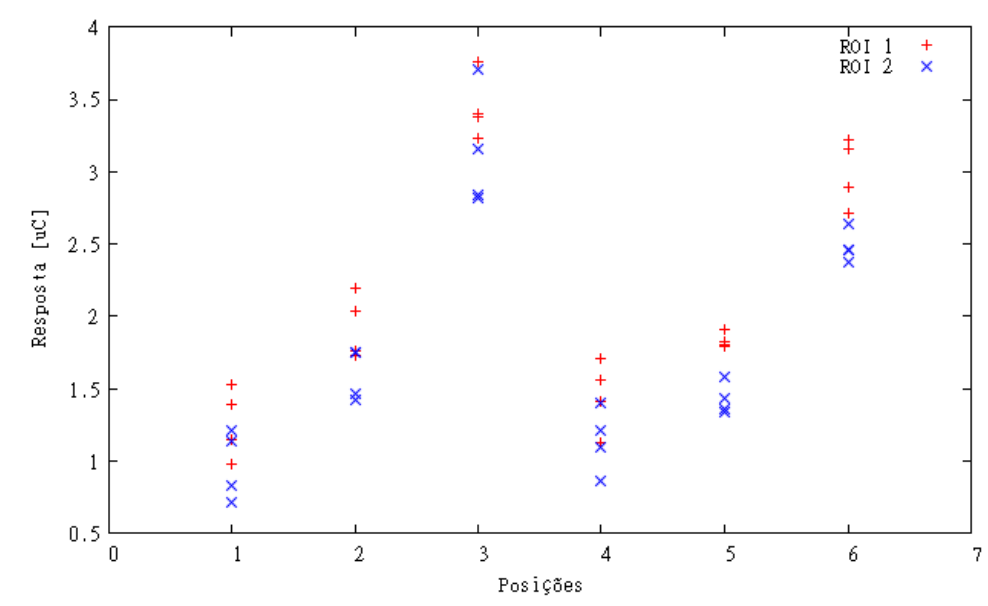

Figura 57 - Respostas das duas regiões de interesse do TLD 600 de acordo com a posição destes TLDs na irradiação no reator IPEN/MB-01

A partir da Figura 57 é possível observar que na posição 1 e 6, que apresentam aproximadamente o mesmo fluxo de fótons, a resposta dos TLDs 600 são bem diferentes. A diferença entre estas posições é a presença maior de um fluxo de nêutrons na posição 6, assim pode-se verificar que esta maior presença de nêutrons faz com que este TLD tenha um ganho de resposta em suas duas regiões de interesse.

Foi analisada a razão existente entre a segunda região de interesse pela primeira região de interesse destes TLDs, para verificar possíveis diferenças na relação entre estas regiões devido aos diferentes espectros de campo a que estes TLDs estavam expostos. Esta razão esta apresentada na Tabela 15. 
Tabela 15 - Valores da razão entre a segunda e a primeira região de interesse dos TLDs 600 para as posições de irradiação no reator IPEN/MB-01

\begin{tabular}{ccc}
\hline Posição & $\begin{array}{c}\text { Relação } \\
\text { [ROI2/ROI1] }\end{array}$ & $\begin{array}{c}\text { Incerteza } \\
\text { [\%] }\end{array}$ \\
\hline $\mathbf{1}$ & 0,76 & 6 \\
$\mathbf{2}$ & 0,82 & 3 \\
$\mathbf{3}$ & 0,84 & 2 \\
$\mathbf{4}$ & 0,79 & 3 \\
$\mathbf{5}$ & 0,81 & 6 \\
$\mathbf{6}$ & 0,83 & 5 \\
\hline
\end{tabular}

Ao analisar a Tabela 15 juntamente com os dados de fluxos relativos nas diferentes posições da Figura 55, pode-se observar que mesmo em campos de intensidades diferentes, mas que apresentam relações semelhantes entre as componentes de campo, a relação observada entre as regiões de interesse do TLD 600 é próxima o que sugere que a relação existente entre as regiões de interesse deste TLD seja um indicativo da relação existente entre as componentes do campo no qual este TLD foi exposto.

Para o TLD 700 o mesmo estudo foi realizado. Na Figura 58 observamse as respostas das duas regiões de interesse deste TLD de acordo com a posição ocupadas por eles na irradiação.

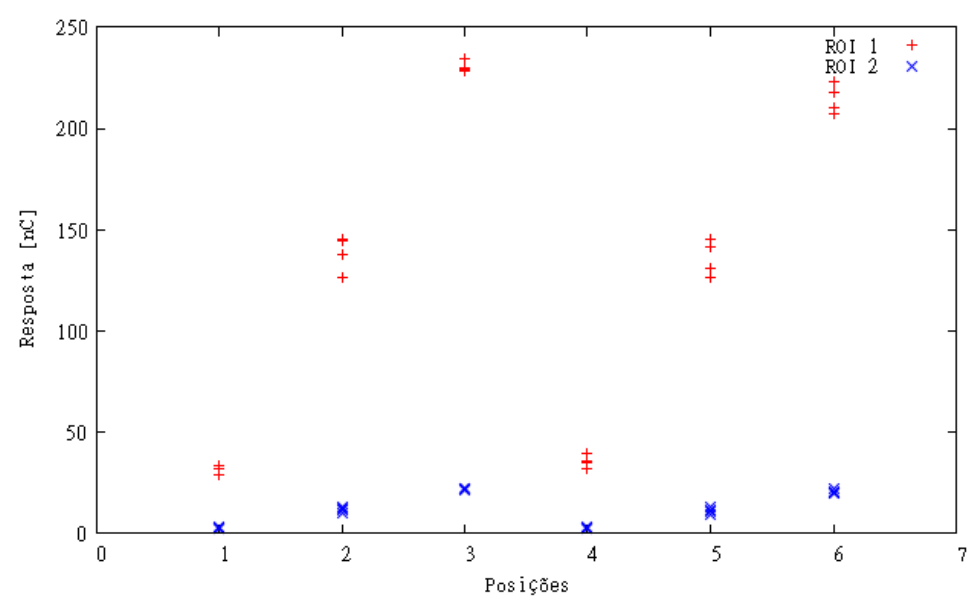

Figura 58 - Respostas das duas regiões de interesse do TLD 700 de acordo com a posição destes TLDs na irradiação no reator IPEN/MB-01

Para este TLD é possível ver claramente a menor intensidade de resposta da segunda região de interesse. A mesma observação feita para os TLDs 600 nas 
posições 1 e 6 pode ser feita para os TLDs 700, onde se observa que, apesar do fluxo de fótons semelhante em ambas as posições, o TLD 700 apresenta uma maior resposta para a posição 6. Como esta posição tem um maior fluxo de nêutrons, esta é uma clara observação da resposta dos TLDs 700 também para nêutrons. Pode-se concluir que se a simples diferença entre as respostas dos TLDs 600 e TLDs 700 for feita para se obter a resposta devido aos nêutrons, isto acarretará em uma superestimação da dose de gama e uma subestimação da dose de nêutrons.

Conforme feito para o TLD 600, as razões entre as respostas da segunda e da primeira região de interesse para os TLDs 700 estão apresentadas na Tabela 16.

Tabela 16 - Valores da razão entre a segunda e a primeira região de interesse dos TLDs 700 para as posições de irradiação no reator IPEN/MB-01

\begin{tabular}{ccc}
\hline Posição & $\begin{array}{c}\text { Relação } \\
\text { [ROI2/ROI1] }\end{array}$ & $\begin{array}{c}\text { Incerteza } \\
\text { [\%] }\end{array}$ \\
\hline $\mathbf{1}$ & 0,077 & 4 \\
$\mathbf{2}$ & 0,084 & 6 \\
$\mathbf{3}$ & 0,095 & 3 \\
$\mathbf{4}$ & 0,074 & 4 \\
$\mathbf{5}$ & 0,083 & 10 \\
$\mathbf{6}$ & 0,096 & 5 \\
\hline
\end{tabular}

Para os TLDs 700 a diferença entre as razões entre as regiões de interesse é mais sutil devido à diferença na resposta do TLD 700 devido aos nêutrons. Porém, mesmo assim é possível observar um ligeiro aumento da segunda região de interesse quando os TLDs 700 são irradiados em um campo contendo mais nêutrons.

Conforme observado no TLD 600, também o TLD 700 apresenta uma relação entre suas regiões de interesse muito parecidas em campos de espectros parecidos. Esta relação para o TLD 700, apesar de mais sutil, é um melhor indicativo da composição do campo do que a relação apresentada pelo TLD 600.

Apesar da baixa reprodutibilidade dos TLDs 400 para campos mistos, estes foram utilizados nestes experimentos para observar possíveis diferenças em suas respostas devido a presença de nêutrons. Os valores de resposta de sua região de interesse devido à posição que os TLDs ocupavam estão apresentadas na Figura 59. 


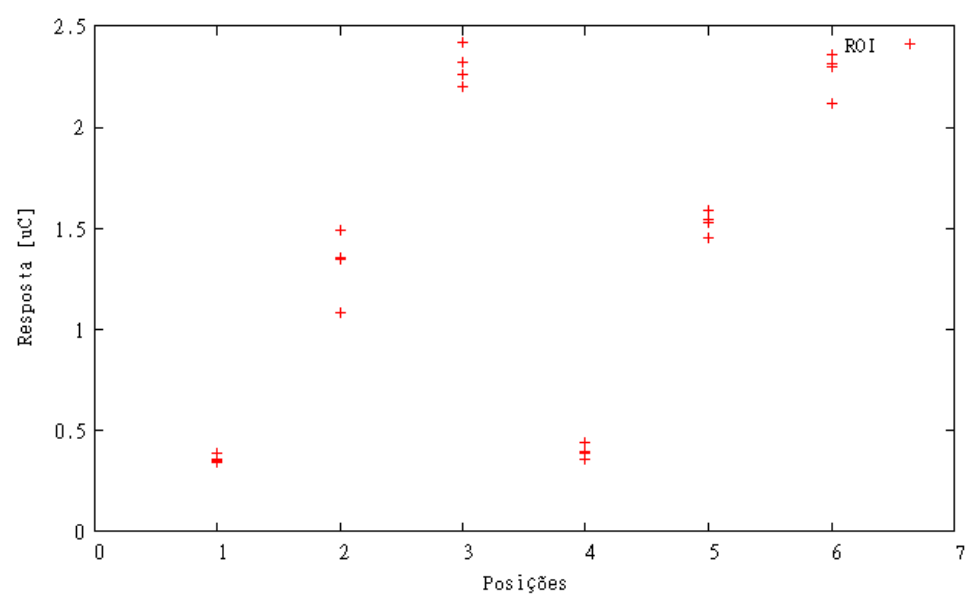

Figura 59 - Resposta da região de interesse do TLD 400 de acordo com a posição destes TLDs na irradiação no reator IPEN/MB-01

Neste experimento, mesmo em campos com fluxos de fótons semelhantes, onde a única diferença era a diferença no campo de nêutrons (posições 1 e 6), os TLDs 400 apresentaram respostas muito distintas, o que sugere que a presença de nêutrons afeta estes TLDs também.

\subsection{Calibração em Dose}

Foram realizadas as calibrações dos diferentes tipos de TLDs para a fonte de ${ }^{60} \mathrm{Co}$, fonte de gama puro, e para a fonte de ${ }^{241} \mathrm{AmBe}$, fonte de campo misto. E foram utilizados os fatores de normalização para cada caso.

\subsubsection{Fonte Gama}

Para a calibração em fonte gama foi utilizada a fonte de ${ }^{60} \mathrm{Co}$ em duas faixas de dose: uma considerada como baixa dose (entre $20 \mathrm{mGy}$ e $1 \mathrm{~Gy}$ ) na qual foi utilizada a tensão da leitora em $1000 \mathrm{~V}$; a outra foi considerada como alta dose (entre 0,5 e 5 Gy) e foi utilizada a tensão da leitora em $500 \mathrm{~V}$.

Para cada dose foram utilizados 6 TLDs de cada tipo, sendo que para as baixas doses foram feitas duas irradiações em duas faixas de dose, para cobrir toda a faixa de interesse, e para altas doses foi possível em uma mesma irradiação obter todos os pontos do gráfico. 
Os gráficos da Figura 60, Figura 61 e Figura 62 apresentam respectivamente as curvas de calibração para baixas doses dos TLDs 600, TLDs 700 e TLDs 400 e a Tabela 17 apresenta os coeficientes ajustados destas curvas.

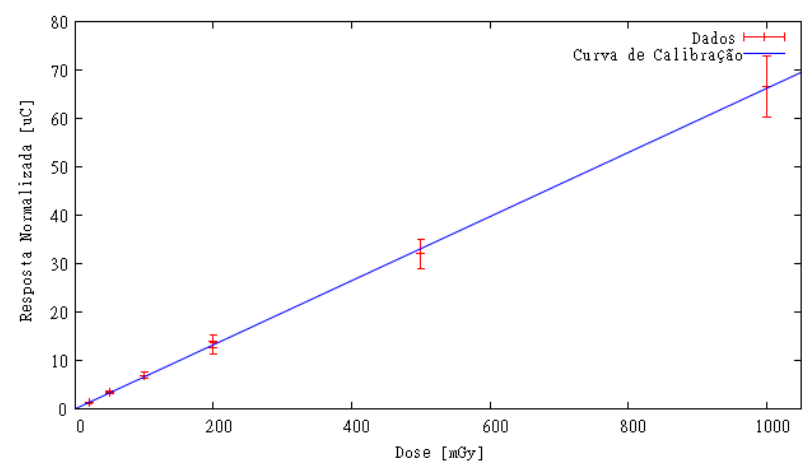

Figura 60 - Curva de calibração dos TLDs 600 para doses entre 20 mGy e 1 Gy (fonte de $\left.{ }^{60} \mathrm{Co}\right)$

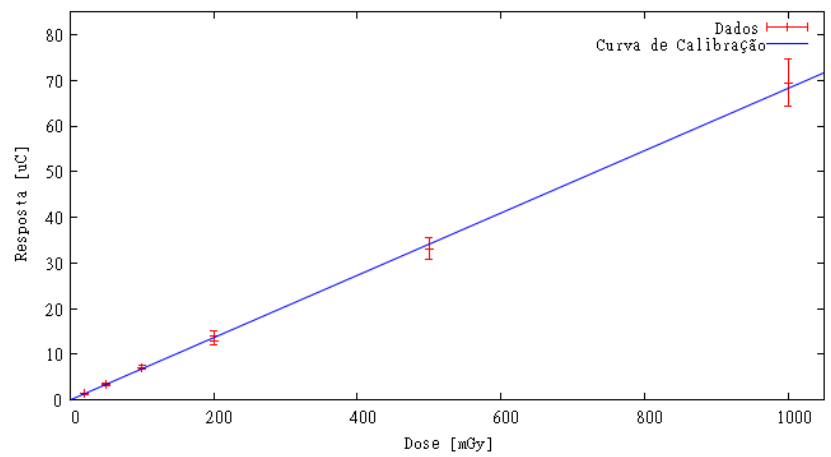

Figura 61 - Curva de calibração dos TLDs 700 para doses entre 20 mGy e 1 Gy (fonte de $\left.{ }^{60} \mathrm{Co}\right)$

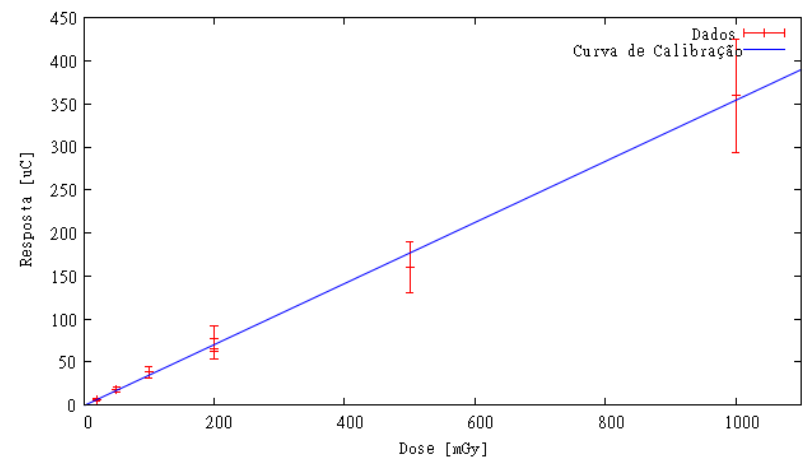

Figura 62 - Curva de calibração dos TLDs 400 para doses entre 20 mGy e 1 Gy (fonte $\mathrm{de}^{60} \mathrm{Co}$ ) 
Tabela 17 - Parâmetros da reta ajustada para a curva de calibração dos TLDs 600, TLDs 700 e TLDs 400 na fonte de ${ }^{60} \mathrm{Co}$ entre as doses de 20 mGy e 1 Gy.

\begin{tabular}{ccc}
\hline Resposta = A + B.(Dose) & A [uC $]$ & B [uC/mGy $]$ \\
\hline TLD 600 & $0,076(63)$ & $0,066(1)$ \\
TLD 700 & $-0,032(57)$ & $0,068(1)$ \\
TLD 400 & $-0,70(65)$ & $0,355(15)$ \\
\hline
\end{tabular}

Para as baixas doses, a linearidade para os 3 tipos de TLDs utilizados foi observada. Devido a maior estabilidade dos TLDs de LiF, estes apresentaram valores mais precisos em comparação aos TLDs 400, apesar do TLD 400 apresentar uma maior resposta para a radiação gama.

Os gráficos da Figura 63, Figura 64 e Figura 65 apresentam as medidas e as curvas de calibração dos TLDs para altas doses, e a Tabela 18 apresenta os coeficientes ajustados destas curvas.

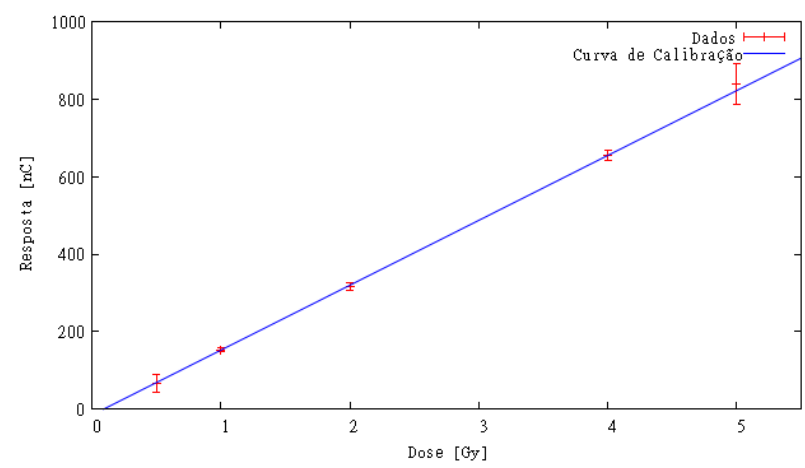

Figura 63 - Curva de calibração dos TLDs 600 para doses entre 0,5 Gy e 5 Gy (fonte de $\left.{ }^{60} \mathrm{Co}\right)$

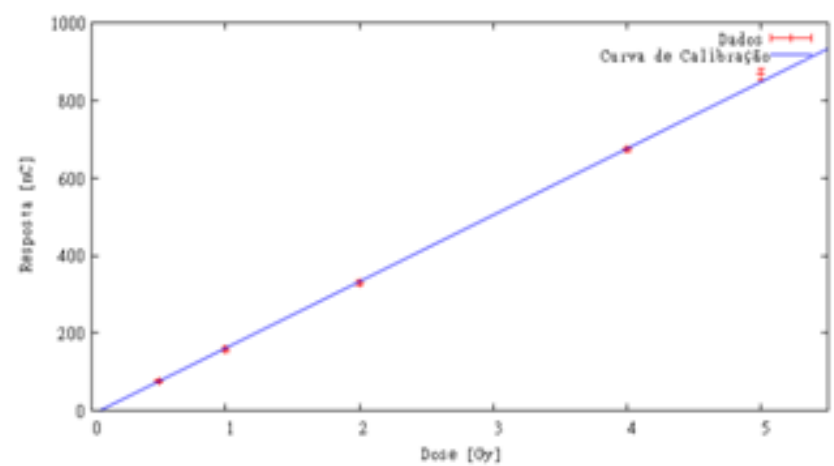

Figura 64 - Curva de calibração dos TLDs 700 para doses entre 0,5 e 5 Gy (fonte de $\left.{ }^{60} \mathrm{Co}\right)$ 


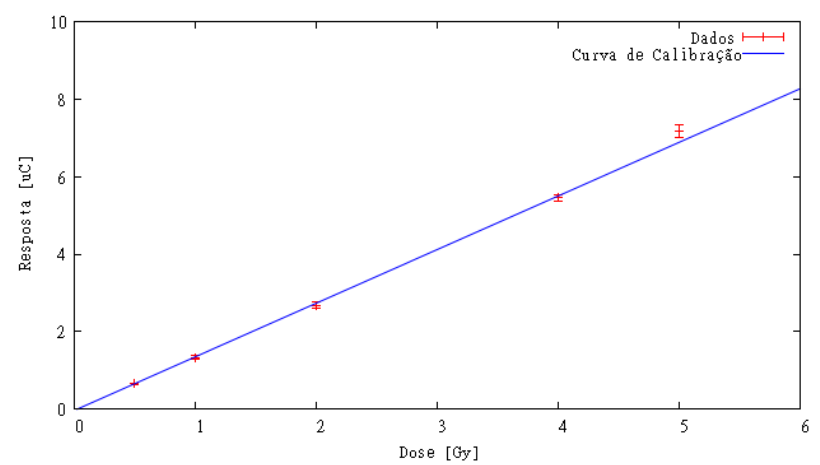

Figura 65 - Curva de calibração dos TLDs 400 para doses entre 0,5 e 5 Gy (fonte de $\left.{ }^{60} \mathrm{Co}\right)$

Tabela 18 - Parâmetros da resta ajustada para a curva de calibração dos TLDs 400 na fonte de ${ }^{60}$ Co entre as doses de 0,5 e 5 Gy.

\begin{tabular}{ccc}
\hline Resposta $=$ A + B.(Dose) & A [nC] & B [nC/Gy] \\
\hline TLD 600 & $-15(2)$ & $167(1)$ \\
TLD 700 & $-10(2)$ & $171(1)$ \\
TLD 400 & $33(19)$ & $1380(2)$ \\
\hline
\end{tabular}

Nestes experimentos de calibração em fonte de ${ }^{60} \mathrm{Co}$ todas as curvas apresentaram linearidade, sendo possível obter bons coeficientes de ajuste para estas curvas. Portanto, frente a estes resultados de calibração e aos estudos de reprodutibilidade, este trabalho adota o uso dos Fatores de Normalização e do uso de duas tensões na leitora para realizar a dosimetria de fontes de gama puro.

\subsubsection{Fonte Mista}

Para a calibração em fonte mista foi utilizada uma fonte de AmBe dentro do cilindro de polietileno, e foram feitas irradiações dos TLDs por diferentes períodos de tempo. Estes tempos foram de 1, 2, 4 e 8 dias. A Tabela 19 apresenta os valores calculados pelo MCNP5 de kerma no ar, tanto para fótons como para nêutrons, devido aos diferentes tempos de exposição. 
Tabela 19 - Valores de kerma no ar para o sistema com a fonte de AmBe nos diferentes tempos de irradiação

\begin{tabular}{ccccc}
\hline Kerma no ar & $\mathbf{1 ~ d i a}$ & $\mathbf{2}$ dias & $\mathbf{4}$ dias & $\mathbf{8}$ dias \\
\hline Fótons $[\mathbf{m G y}]$ & $80,2(1,4)$ & $160,5(2,8)$ & $321,0(5,6)$ & $642(13)$ \\
Nêutrons [mGy] & $35,75(7)$ & $71,5(1)$ & $143,0(3)$ & $286,0(6)$ \\
\hline
\end{tabular}

Lembrando que mesmo havendo a diminuição de energia dos nêutrons pelo polietileno, o fluxo predominante continua sendo o de nêutrons rápidos, conforme apresentado na Tabela 11 .

Na Figura 66 e Figura 67 são apresentadas as curvas de calibração para as diferentes regiões de interesse do TLD 600 e TLD 700, respectivamente, e os valores dos coeficientes destas curvas estão apresentados na Tabela 20. Os TLDs 400 não foram utilizados neste estudo devido à sua baixa reprodutibilidade quando irradiado no campo misto do sistema com a fonte de ${ }^{241} \mathrm{AmBe}$.

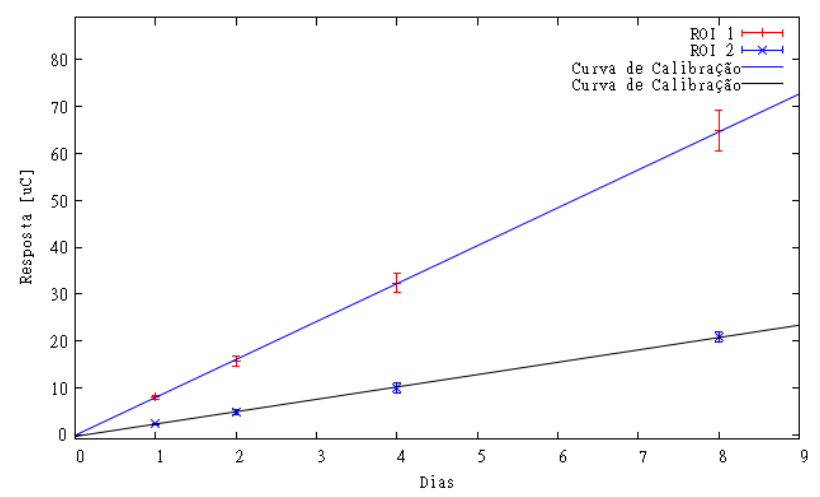

Figura 66 - Curvas de calibração para os diferentes ROIs do TLD 600 na irradiação no sistema com a fonte de AmBe

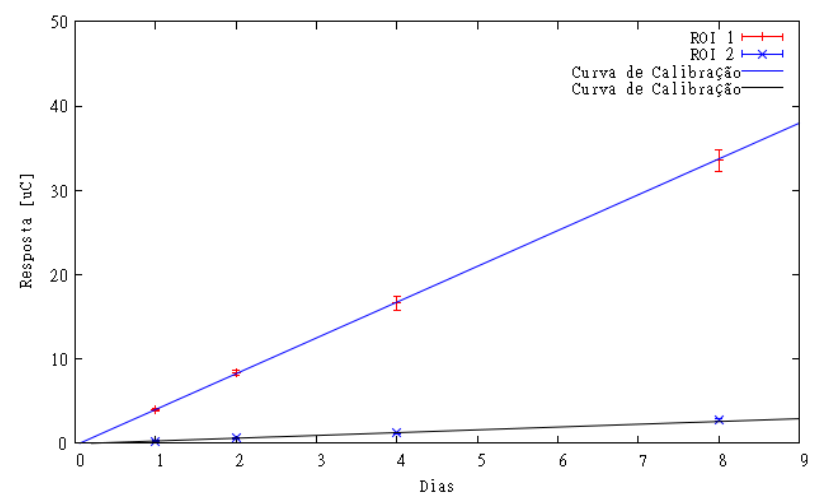

Figura 67 - Curvas de calibração para os diferentes ROIs do TLD 700 na irradiação no sistema com a fonte de AmBe 
Tabela 20 - Coeficientes das curvas de calibração para os diferentes ROIs do TLD 600 e TLD 700 nas irradiações no sistema com a fonte de ${ }^{241} \mathrm{AmBe}$

\begin{tabular}{ccccc}
\hline \multirow{2}{*}{ Resposta = A + B.(Dias) } & \multicolumn{2}{c}{ ROI 1 } & \multicolumn{2}{c}{ ROI 2 } \\
\cline { 2 - 5 } TLD 600 & A [uC] & B [uC/dia] & A [uC] & B [uC/dia] \\
TLD 700 & $-0,18(13)$ & $8,10(8)$ & $-0,04(7)$ & $2,64(4)$ \\
& $-0,26(9)$ & $4,25(6)$ & $-0,07(2)$ & $0,33(1)$ \\
\hline
\end{tabular}

Em todas as curvas de calibração apresentadas nesta seção, a linearidade foi obtida e com bons valores dos coeficientes de ajuste. Portanto, para a dosimetria de campos misto do sistema com a fonte de ${ }^{241} \mathrm{AmBe}$, este trabalho utiliza os Fatores de Normalização juntamente com as curvas de calibração obtidas nesta seção.

\subsection{Irradiação na Instalação de Pesquisa em BNCT}

Foram primeiramente utilizados TLDs de teste nas irradiações na instalação de BNCT para verificar quanto tempo os TLDs poderiam permanecer na posição de irradiação sem que estes perdessem a linearidade na resposta. Este estudo observou que em 12 minutos de irradiação nenhum dos TLDs perdiam a linearidade.

Foi feita a irradiação destes TLDs na instalação de BNCT com os tempos de: 2, 5, 7, 10 e 12 minutos, e utilizando 3 TLDs de cada tipo para cada irradiação.

Para acompanhar as doses de nêutrons térmicos e epitérmicos nestes experimentos, pares de folhas de ouro foram utilizadas. E para se ter uma estimativa da dose gama nestes experimentos, TLDs 400 foram utilizados. Estes TLDs eram utilizados para dosimetria gama do grupo de BNCT, e assim já havia um conhecimento prévio de seu funcionamento.

Na Tabela 21 estão as fluências de nêutrons térmicos, epitérmicos e dose gama medidas experimentalmente para os diferentes tempos de irradiação. 
Tabela 21 - Fluência de nêutrons térmicos e epitérmicos e dose gama para os diferentes tempos de irradiação na instalação de BNCT

\begin{tabular}{cccccc}
\hline Tempos [min] & $\mathbf{2}$ & $\mathbf{5}$ & $\mathbf{7}$ & $\mathbf{1 0}$ & $\mathbf{1 2}$ \\
\hline N. Térmicos & $2,72(17) \mathrm{E}$ & $4,22(24) \mathrm{E} 10$ & $5,85(33) \mathrm{E} 10$ & $1,24(07) \mathrm{E} 11$ & $1,46(86) \mathrm{E} 11$ \\
{$\left[\mathbf{1} / \mathbf{c m}^{2}\right]$} & 10 & & & & \\
N. Epitérmicos & $7,49(46) \mathrm{E}$ & $1,07(06) \mathrm{E} 10$ & $1,47(09) \mathrm{E} 10$ & $2,11(12) \mathrm{E} 10$ & $2,30(17) \mathrm{E} 10$ \\
{$\left[\mathbf{1} / \mathbf{c m}^{2}\right]$} & 9 & & & & \\
Gama $[\mathbf{G y}]$ & $1,13(13)$ & $1,59(18)$ & $2,63(13)$ & $3,72(22)$ & $3,91(51)$ \\
\hline
\end{tabular}

As curvas de calibração, em relação ao tempo de irradiação, foram feitas para os três tipos de TLDs. Porém o Fator de Normalização não foi utilizado, pois nos estudos anteriores se mostrou que este fator esta ligado com a sensibilidade dos TLDs para as diferentes componentes de campo e possivelmente há também um dependência energética. Então os fatores encontrados para os campos da fonte de ${ }^{60} \mathrm{Co}$ e do sistema com a fonte de AmBe não seriam compatíveis com o feixe proveniente da instalação de BNCT.

Na Figura 68 está apresentada a curva de calibração para o TLD 600, e na Tabela 22 estão os coeficientes ajustados destas curvas.

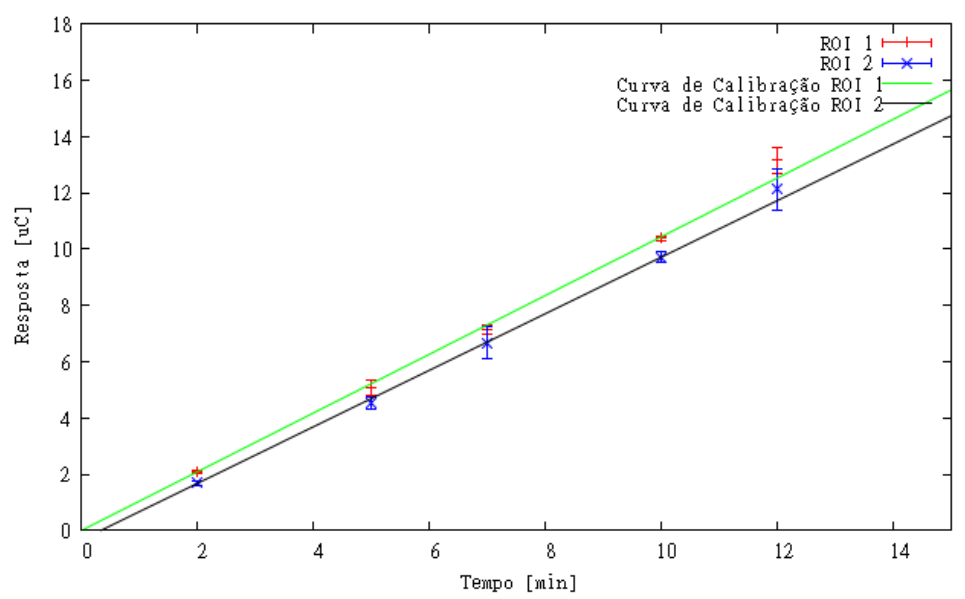

Figura 68 - Curvas de Calibração para as duas regiões de interesse do TLD 600 para as irradiações na instalação de BNCT 
Tabela 22 - Coeficientes das curvas de calibração para os TLDs 600 nas irradiações na instalação de BNCT

\begin{tabular}{ccc}
\hline $\mathbf{F}(\mathbf{x})=\mathbf{A}+\mathbf{B . x}$ & $\mathbf{A}[\mathbf{u C}]$ & $\mathbf{B}[\mathbf{u C} / \mathbf{m i n}]$ \\
\hline ROI 1 & $-0,01(9)$ & $1,045(13)$ \\
ROI 2 & $-0,347(55)$ & $1,006(11)$ \\
\hline
\end{tabular}

Na Figura 69 e Tabela 23 estão as curvas de calibração e os coeficientes destas curvas, respectivamente, para os TLDs 700 irradiados na instalação de BNCT.

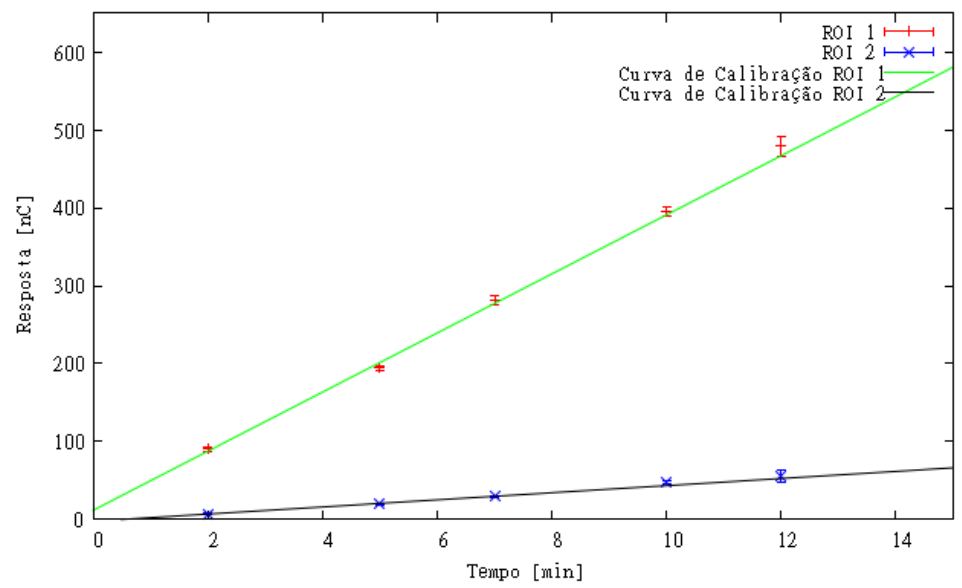

Figura 69 - Curvas de Calibração para as duas regiões de interesse do TLD 700 para as irradiações na instalação de BNCT

Tabela 23 - Coeficientes das curvas de calibração para os TLDs 700 nas irradiações na instalação de BNCT

\begin{tabular}{ccc}
\hline $\mathbf{F}(\mathbf{x})=\mathbf{A}+\mathbf{B . x}$ & $\mathbf{A}[\mathbf{n C}]$ & $\mathbf{B}[\mathbf{n C} / \mathbf{m i n}]$ \\
\hline ROI 1 & $11,7(5,5)$ & $37,9(1,1)$ \\
ROI 2 & $-2,25(73)$ & $4,57(16)$
\end{tabular}

Analisando os TLDs de LiF, na média estes TLDs apresentaram um valor de razão da segunda região de interesse (ROI 2) pela primeira região de interesse (ROI 1) de 0,96 para os TLDs 600 e de 0,12 para os TLDs 700. Estes valores, em comparação com os valores obtidos desta razão realizados nos experimentos no reator IPEN/MB-01, mostram que a intensidade relativa do fluxo de nêutrons, comparando com o fluxo de fótons, é superior na instalação de pesquisas em BNCT frente aos experimentos realizados no reator IPEN/MB-01. 


\subsubsection{Dosimetria da Instalação para Pesquisas em BNCT}

Para a dosimetria da instalação para pesquisas em BNCT, foram criadas duas curvas de dose baseadas nos experimentos realizados anteriormente neste trabalho. Como uma estimativa de dose de fótons, são utilizados os TLDs 700 com a calibração realizada em fonte gama. A equação para obtenção da dose a partir da resposta do TLD 700 esta apresentada na Eq. 5.5.

$$
D[G y]=\frac{R_{T L D 700}[\eta C]+(10 \pm 2)}{(171 \pm 1)}
$$

Para a dose de nêutrons térmicos foi feita a subtração da resposta da primeira região de interesse (ROI1) do TLD 700 pela resposta da primeira região de interesse (ROI1) do TLD 600. Esta curva de calibração foi obtida a partir dos experimentos realizados no sistema com a fonte de AmBe, e na Figura 70 está apresentada esta curva de calibração para nêutrons térmicos após a realização da subtração.

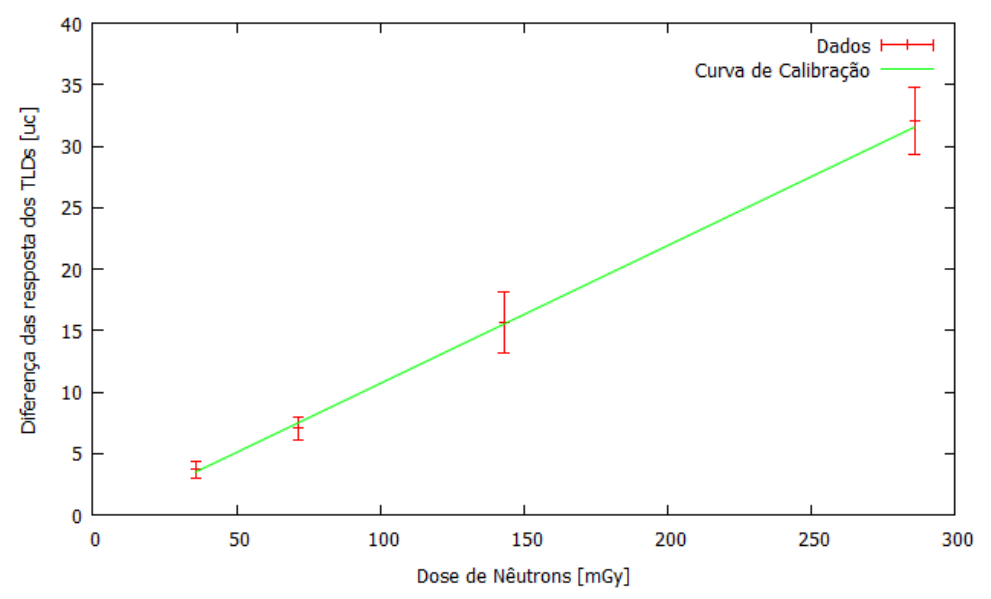

Figura 70 - Curva de calibração para nêutrons térmicos a partir da subtração das respostas dos TLDs

A equação para fornecer a dose de nêutrons térmicos é dada pela Eq. 5.6.

$$
D[m G y]=\frac{R_{T L D 600-T L D 700}[u C]+(0,53 \pm 0,34)}{(0,112 \pm 0,004)}
$$


Utilizando esta técnica para a realização da dosimetria do feixe de irradiação da instalação de BNCT junto ao reator IEA-R1 foi obtido o valor de $(14,88 \pm$ $0,48) \mathrm{Gy} / \mathrm{h}$ para a dose de radiação gama e $(0,6 \pm 0,2) \mathrm{Gy} / \mathrm{h}$ de dose de nêutrons.

Estes valores encontrados, em comparação à metodologia atualmente utilizada, mostra uma dose gama ligeiramente inferior à dose fornecida pelos TLDs 400, que era de $(20,2 \pm 2,6) \mathrm{Gy} / \mathrm{h}[25]$. E a dose de nêutrons térmicos apresentou valores bem menores do que as doses calculadas a partir das folhas de ativação, $(8,4 \pm 3,6) \mathrm{Gy} / \mathrm{h}$ [25]. 


\section{CONCLUSÕES}

O objetivo deste trabalho foi estudar a metodologia de dosimetria de campos mistos utilizando o par TLD 600 e TLD 700, e assim incorporar esta metodologia nos procedimentos do grupo de pesquisas em BNCT. E para isto foram realizadas irradiações em diferentes campos para se obter o conhecimento sobre estes TLDs. Buscou-se também comparar esta nova metodologia com a que é atualmente utilizada pelo grupo, que consiste no uso de folhas de ativação e do TLD 400.

Os estudos sobre a reprodutibilidade dos TLDs em campo de gama puro, utilizando uma fonte de ${ }^{60} \mathrm{Co}$, e em campo misto de nêutrons e gamas, utilizando um sistema com a fonte de ${ }^{241} \mathrm{AmBe}$, mostrou que os TLDs de mesmo tipo apresentam diferente sensibilidade individual, e que esta sensibilidade é diferente dependendo da componente de campo.

Estudos utilizando TLDs normalmente realizam o selecionamento destes TLDs antes de utilizá-los. Porém havendo diferença na sensibilidade dos TLDs devido às diferenças no campo de irradiação, como este trabalho mostrou, este selecionamento não seria válido se estes TLDs fossem utilizados em um campo diferente do qual foram selecionados.

Com a observação destas diferentes sensibilidades foi possível criar um Fator de Normalização para o campo da fonte de ${ }^{60} \mathrm{Co}$ e outro para o sistema com a fonte de ${ }^{241} \mathrm{AmBe}$ para cada TLD. Com o uso deste Fator de Normalização foi possível utilizar mais TLDs, pois a seleção não era mais necessária, e assim obter um resultado mais preciso das respostas dos TLDs, frente à metodologia atualmente utilizada pelo grupo de pesquisas em BNCT do IPEN. Portanto para obter as respostas de irradiações realizadas em fontes de ${ }^{60} \mathrm{Co}$ ou no sistema com a fonte de ${ }^{241} \mathrm{AmBe}$ deve-se utilizar a metodologia com o uso dos Fatores de Normalização.

O estudo da reprodutibilidade do TLD 400 em campos mistos de nêutrons e gamas do sistema com a fonte de ${ }^{241} \mathrm{AmBe}$ mostrou a baixa reprodutibilidade deste TLD neste campo. Portanto o uso dos TLDs 400 para a dosimetria gama de feixes mistos, como atualmente utilizada, não é recomendado devido à esta baixa reprodutibilidade, podendo ocasionar grandes erros de dosimetria. 
O estudo comparando as respostas dos TLDs 600 e TLDs 700 no campo de gama puro e em campo misto mostrou que ambos os TLDs tem respostas semelhantes para a radiação gama, e que as pequenas variações podem ser provenientes da diferença de lote. Porém para o campo misto há uma diferença: quando irradiado em um campo de baixo fluxo de nêutrons, tal como o sistema com a fonte de ${ }^{241} \mathrm{AmBe}$ utilizado neste trabalho, o TLD 700 não apresentou aumento em sua resposta devido aos nêutrons, mas quando irradiado em um campo mais intenso, como no reator IPEN/MB01, foi possível observar grandes diferenças na resposta do TLD 700 devido aos nêutrons.

Nas irradiações no sistema com a fonte de AmBe, foi observado que nos TLDs de LiF há uma maior dose depositada devido aos nêutrons do que devido à radiação gama, sendo esta bem maior para o TLD 600, devido sua alta concentração de ${ }^{6} \mathrm{Li}$. Porém esta maior dose depositada devido aos nêutrons não gera uma resposta maior destes TLDs frente à resposta devido à radiação gama. Logo os TLDs de LiF são mais sensíveis a radiação gama do que aos nêutrons.

A Comissão Internacional de Unidades e Medidas (ICRU) recomenda o uso de dosímetros com sensibilidades distintas para realizar a dosimetria de campos mistos, e, quando se utiliza o par TLD 600 e TLD 700, normalmente é realizada a simples subtração entre a primeira região de interesse destes TLDs para fornecer a resposta devido aos nêutrons. Este estudo mostrou que esta metodologia pode ser utilizada no caso de campos com baixo fluxo de nêutrons, como é o caso do sistema com a fonte de AmBe, pois para este campos a resposta a nêutrons do TLD 700 não é perceptível. Porém em campos com fluxos mais intensos a resposta devido aos nêutrons para o TLD 700 se torna perceptível, e se for utilizada a simples subtração entre as respostas dos TLDs, a dose gama será superestimada.

As curvas de calibração dose - resposta para a fonte de ${ }^{60} \mathrm{Co}$ e no sistema com a fonte de AmBe mostraram boa linearidade e bons valores dos coeficientes de ajuste da reta. Portanto para a realização da dosimetria nestes campos basta aplicar o Fator de Normalização e utilizar os parâmetros de calibração obtidos neste trabalho.

Nas irradiações no reator IPEN/MB-01 o Fator de Normalização não foi utilizado para corrigir as respostas dos TLDs. Isto porque o Fator de Normalização é específico para cada campo, e os Fatores obtidos neste trabalho eram para a fonte de ${ }^{60} \mathrm{Co}$ e para o sistema com a fonte de AmBe. A partir destas irradiações foi 
desenvolvido um método para se estimar o fluxo relativo entre os gamas e os nêutrons do campo, este método se baseia na análise da relação existente entre as respostas das diferentes regiões de interesse dos TLDs de LiF. A partir do TLD 600 e TLD 700 é possível obter estas relações, porém o resultado é mais acentuado no TLD 700.

A partir do fluxo mais intenso do reator IPEN/MB-01 foi possível observar que a presença maior de nêutrons gera uma mudança na resposta dos TLDs 700 e TLDs 400. Assim estes TLDs não podem ser considerados não sensíveis aos nêutrons quando irradiados em campos mistos.

Nas irradiações na instalação de BNCT, o TLD 600 e TLD 700 apresentaram linearidade em suas curvas até 12 minutos de irradiação, sendo que o Fator de Normalização também não foi utilizado para este caso. Estimativas de valores de taxa de dose para as diferentes componentes de campo foram de $(14,88 \pm 0,48) \mathrm{Gy} / \mathrm{h}$ para a radiação gama e $(0,6 \pm 0,2) \mathrm{Gy} / \mathrm{h}$ para os nêutrons. Estes valores encontrados são inferiores aos valores encontrados anteriormente pelo grupo utilizando a atual metodologia, que eram de $(20,2 \pm 2,6) \mathrm{Gy} / \mathrm{h}$ para a radiação gama e $(8,4 \pm 3,6) \mathrm{Gy} / \mathrm{h}$ para os nêutrons térmicos. 


\section{Proposição de Futuros Experimentos}

Ao final deste trabalho, e com os conhecimentos adquiridos durante sua realização, muitos outros experimentos foram imaginados para que a compreensão dos TLDs se aprimore.

Entre eles está a criação de outro sistema para a fonte de AmBe, em que se utilize água como moderador de nêutrons e que a distância entre os TLDs e a fonte possa ser variada para que possam ser obtidos diferentes campos mistos com diferentes composições de campo para um melhor estudo dos TLDs 600 e TLDs 700 quando irradiados em um campo misto de menor intensidade.

Há a proposição também de utilizar este novo sistema de moderação e até mesmo o sistema que este trabalho criou e realizar a irradiação destes TLDs em duas

partes: na fonte de AmBe e posteriormente na fonte de ${ }^{60} \mathrm{Co}$. Estes experimentos propiciariam também um melhor entendimento destes TLDs ao serem irradiados em campos mistos.

Este trabalho mostrou uma dependência energética à radiação gama dos TLDs estudados (Apêndice F). Porém um melhor estudo com maior variação de energia dos gamas, e também variando a energia dos nêutrons é necessário para a criação de uma possível relação entre a angulação destas curvas com a energia do feixe ou composição do feixe.

O uso do Fator de Normalização se mostrou satisfatório para se utilizar como metodologia no uso dos TLDs. Neste trabalho foi visto que para campos diferentes havia fatores diferentes. Um trabalho sobre a dependência deste fator devido a diferentes componentes de campo e diferentes energias dos feixes seria importante para um melhor entendimento da sensibilidade destes TLDs e uma melhor metodologia de dosimetria.

E a partir do momento que se conseguir identificar as diferenças que cada componente de campo causa na resposta dos TLDs, poderá se fazer as curvas de calibração com distinção entre nêutrons e radiação gama para a instalação de BNCT. 


\section{Bibliografia}

1. INSTITUTO NACIONAL DE CÂNCER. INCA - Instituto Nacional de Câncer, 2012. Disponível em: <http://www1.inca.gov.br/conteudo_view.asp?id=322>. Acesso em: 10 Maio 2012.

2. LOCHER, G. L. Biological Effects and Therapeutic Possibilities of Neutrons. The American Journal of Roentgenology and Radium Therapy, v. 36, n. 1, 1936.

3. MOSS, R. L. et al. The Requirements and Development of Neutron Beams for Neutron Capture Therapy of Brain Cancer. Journal of Neuro-Oncology,33, p. 27-40, 1997.

4. KOREA ATOMIC ENERGY RESEARCH INSTITUTE. Nuclear Data Center, 2000. Disponivel em: 〈http://atom.kaeri.re.kr/cgi-bin/endfform.pl〉. Acesso em: 22 Julho 2012.

5. GOLDHABER, M. Disintegration by Slow Neutron. Nature, v. 135, p. S65, 1935.

6. INTENATIONAL ATOMIC ENERGY AGENCY. Current Status of Neutron Capture Therapy. Vienna, Austria. 2001.

7. SWEET, W. H. Early History of Development of Boron Neutron Capture Therapy of Tumors, p. 19-26, 1997.

8. FARR, L. E. et al. Neutron Capture Therapy With Boron in The Treatment of Glioblastoma Multiforme. American Journal of Roentgenology and Radium Therapy, v. 71, p. 279-293, 1954.

9. SOLOWAY, S. H.; HATANAKA, H.; DAVIS, M. A. Penetration of Brain and Brain Tumor. VII. Tumor-Binding Sulfhydril Boron Compounds. J Med Chem, v. 10, p. 714-717, 1967.

10. HATANAKA, H.; KAMANO, S.; AMARO, K. Clinical Experience of BoronNeutron Capture Therapy for Gliomas: A Comparison with Conventional ChemoImmune-Radiotherapy. Boron-Neutron Capture Therapy for Tumors. Niigata, Japão: Boron-Neutron Capture Therapy for Tumors. 1986.

11. NAKAGAWA, Y.; HATANAKA, H. Recent Study of Born Neutron Capture Therapy in Patient with Malignant Tumor. 6th Int. Symp. on Neutron Capture 
Therapy. Kobe, Japão: 6th. Int. Symp. on Neutron Capture Therapy. 1995.

12. MISHIMA, Y. et al. Treatmente of Malignant Melanoma by Single Thermal Neutron Capture Therapy with Melanoma-Seeking 10B Compound. The Lancet, v. 334, p. 388-389, 1989.

13. BONECA. BONECA | BNCT - A new method to treat cancer. Site da BONECA, 2010. Disponível em: <http://www.boneca.fi/> Acesso em: 25 Maio 2012.

14. ZONTA, A. et al. Extra-Corporeal Liver BNCT for the Treatment of Diffuse Metastase: What Was Learned and What Is Still To Be Learned. Applied Radiation Isotopoes, 67, n. S67-S75, 2009.

15. HERRERA, M. S. et al. Treatment Planning Capability Assessment of a Beam Shaping Assembly for Accelerator-Based BNCT. Applied Radiation and Isotopes, 69, n. 1870-1873, 2011.

16. POZZI, E. C. C. et al. Intercalibration of Physical Neutron Dosimetry for the RA-3 and MURR Thermal Neutron Source for BNCT Small-Animal Research. Applied Radiation and Isotopes, 69, n. 1921-1923, 2011.

17. FERREIRA, D. B. M. J. et al. Estudos para a Implantação de Uma Instalação para

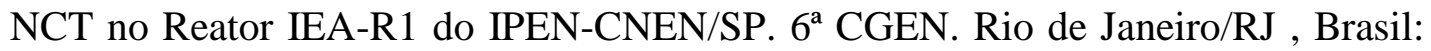
[s.n.]. 1996.

18. GUEDES, S. et al. Thermal, Epithermal and Fast Neutron Dosimetry in BNCT Using Boron Thin Films and PADC Detector. 15th International Congress on Neutron Capture Therapy. Tsukuba, Japão: [s.n.]. 2012.

19. SMILGYS, B. et al. Track Annealing Studies of PADC Track Etch Detector for the 10B(n,a)7Li Reaction Rate Measurement. 15th International Congress on Neutron Capture Therapy. Tsukuba, Japão: [s.n.]. 2012.

20. FAIÃO-FLORES, F. et al. Boron Neutron Capture Therapy Induces Cell Cycle Arrest and DNA Fragmentation in Murine Melanoma Cells. Applied Radiation and Isotopes, v. 69, p. 1741-1744, 2011.

21. FAIÃO-FLORES, F. et al. Antitumor Potencial Indication and Free Radicals Production in Melanoma Cells by Boron Neutron Capture Therapy. Applied Radiation and Isotopes, v. 69, p. 1748-1751, 2011. 
22. SOUZA, G. S. D. Projeto e Implementação de Melhorias na Blindagem Biológica da Instalação para Estudos em BNCT (Mestrado). São Paulo/SP, Brasil: Instituto de Pesquisas Energéticas e Nucleares - IPEN/CNEN, 2011.

23. INTERNATIONAL COMMISSION ON RADIATION UNITS AND MEASUREMENTS. Neutron Dosimetry for Biology and Medicine. [S.1.]. 1984.

24. GAMBARINI, G. et al. Study of a Method Based on TLD Detectors for In-Phantom Dosimetry in BNCT. Radiation Protection Dosimetry, v. 110, p. 631-636, 2004.

25. MUNIZ, R. O. R. Desenvolvimento de um Simulador Antropomórfico para Simulação e Medida de Dose e Fluxo de Nêutrons na Instalação para Estudos em BNCT (Mestrado). São Paulo/SP , Brasil: Instituto de Pesquisas Energéticas e Nucleares - IPEN-CNEN, 2010.

26. X-5 MONTE CARLO TEAM. MCNP - A General Monte Carlo N-Particle Transport Code, V.5. Los Alamos. 2005.

27. TSOULFANIDIS, N. Measurement and Detection of Radiation. U.S.A.: Taylor \& Francis, 1995.

28. SEGRE, E. Dos Raios X aos Quarks. Distrito Federal: Universidade de Brasília, 1980.

29. TAUHATA, L. et al. Radioproteção e Dosimetria - Fundamentos. Rio de Janeiro , RJ: IRD/CNEN, 2003.

30. KNOLL, G. F. Radiation Detection and Measurement. [S.1.]: John Wiley \& Sons, Inc., 2000.

31. INTERNATIONAL COMMISSION ON RADIOLOGICAL PROTECTION. Recommendations of the ICRP. ICRP 26. [S.1.]. 1997.

32. INTERNATIONAL COMMISSION ON RADIOLOGICAL PROTECTION. Recommendations of the ICRP. ICRP 60. [S.1.]. 1990.

33. ATTIX, F. H. Introduction to Radiological and Radiation Dosimetry. [S.1.]: John Wiley \& Sons, 2004.

34. TRIOLO, A. et al. Study of Glow Curves of TLD Exposed to Thermal Neutrons. Radiation Protection Dosimetry, p. 1-4, 2007. 
35. OBERHOFER, M.; SCHARMANN, A. Applied Thermoluminescence Dosimetry. Ispra: Adam Hilger Ltd, 1979.

36. HSU, F. Y. et al. Estimation of Photon and Neutron Dose Distribuitions in the THOR BNCT Treatment Room Using Dual TLD Method. Radiation Measurements, v. 43, p. 1098-1094, 2008.

37. NAGELS, S. et al. Determination of the Irradiation Field at the Research Reactor TRIGA Mainz for BNCT. Applied Radiation and Isotopes, v. 67, p. S242-S246, 2009.

38. BIELAJEW, A. F. Fundamentals of the Monte Carlo Method for Neutral and Charged Particle Transport. Michigan: University of Michigan, 2001.

39. YORIYAZ, H. Método de Monte Carlo: Princípios e Aplicações em Física Médica. Revista Brasileira de Física Médica, v. 3, p. 141-149, 2009.

40. KIRK, B. L. Overview of Monte Carlo Radiation Transport Codes. Radiation Measurements, v. 45, p. 1318-1322, 2010.

41. SHULTIS, J. K.; FAW, R. E. An MCNP Primer. Manhattan. 2011.

42. HARSHAW TLD. Materials and Assemblies for Thermoluminescence Dosimetry. [S.1.].

43. PRADHAN, A. S. Thermoluminescence Dosimetry and Its Aplications. Radiation Protection Dosimetry, v. 1, p. 153 - 167, 1981.

44. THERMO ELECTRON CORPORATION. Model 3500 Manual TLD Reader with WinRens. Ohio. 2005.

45. INTERNATIONAL ATOMIC ENERGY AGENCE. Compendium of Neutron Spectra and Detector Responses for Radiation Protection Purpose. Vienna. 2001.

46. IPEN. Instituto de Pesquisas Energética e Nucleares - IPEN, 2011. Disponível em: <http://www.ipen.br/sitio/index.php?idm=248>. Acesso em: 28 Julho 2012.

47. JUNIOR, V. C. Caracterização do Campo de Nêutrons na Instalação para Estudo em BNCT no Reator IEA-R1 (Mestrado). São Paulo/SP, Brasil: Instituto de Pesquisas Energéticas e Nucleares - IPEN/CNEN, 2008.

48. PACIFIC NORTHWEST NATIONAL LABORATORY. Compendium of Material 
Composition Data for Radiation Transport Modeling. [S.1.]. 2011.

49. ZAMBONI, C. B. Fundamentos da Física de Nêutrons. São Paulo/SP: Livraria da Física, 2007.

50. GONÇALVES, L. B. Calibração dos Canais do Reator IPEN/MB-01, Obtida a Partir da Medida de Distribuição Espacial de Fluxo de Nêutrons Térmicos no Núcleo do Reator Através da Irradiação de Folhas de Ouro Infinitamente Diluidas (Mestrado). São Paulo/SP: Instituto de Pesquisas Energéticas e Nucleares IPEN/CNEN, 2008.

51. SOLOWAY, A. H. et al. The Rationale and Requirements for the Development of Boron Neutron Capture Therapy of Brain Tumors. Journal of Neuro-Oncology, 33, p. 9-18, 1997. 


\section{Anexo A - Termoluminescência}

A termoluminescência é entendida como a propriedade de alguns materiais, após ser exposto à radiação, emitirem luz conforme são aquecidos. A intensidade de luminescência emitida pelo material é função da temperatura e da dose [35].

Os materiais termoluminescentes sofrem grandes mudanças em sua rede cristalina ao serem irradiados. Estas mudanças, juntamente com os ativadores presentes no cristal, fazem com que "armadilhas" sejam criadas na banda energética proibida. Os elétrons ao mudarem de bandas energéticas podem ficar presos nestas armadilhas. E se o material for mantido em temperatura constante, estes elétrons podem permanecer nas armadilhas por longos períodos de tempo.

Para serem presos nas armadilhas, os elétrons devem primeiramente receber energia da radiação incidente no cristal. Dependendo do tipo de cristal, diferentes tipos de radiação podem fornecer energia para a sua estrutura eletrônica. No caso dos fótons, com energias superiores a alguns $\mathrm{keVs}$, eles podem transferir suas energias para o sistema de inúmeras formas, como efeito fotoelétrico e efeito Compton. Já no caso de nêutrons térmicos, estes sofrem algum tipo de reação por algum núcleo presente no cristal gerando assim um isótopo que, ao decair, fornece energia para a excitação [35].

O elétron ao ser armadilhado deixa um "buraco" de carga energética oposta a sua em sua posição anterior na banda de valência. Quando ocorre a recombinação entre este elétron e este buraco há a emissão de um fóton.

Supondo então que um material previamente irradiado seja aquecido, ocorre a relaxação térmica, que é o mecanismo dominante em processos com dependência com a temperatura [35]. Com isto, o elétron pode escapar da armadilha e se recombinar com um buraco, emitindo luz no processo.

A probabilidade de um elétron escapar por excitação térmica é dado por:

$$
\alpha(T)=\alpha_{0} e^{\frac{-E}{k \cdot T}}
$$


onde $\alpha_{0}$ é uma constante da ordem da frequência de vibração da rede [35], $E$ é a energia de ativação térmica necessária para liberar um elétron da armadilha, $k$ é a constante de Boltzmann e $T$ a temperatura absoluta.

Então para explicar melhor o surgimento de um pico de intensidade para certa temperatura, será utilizado o modelo cinético juntamente com algumas aproximações, como a existência de apenas um nível energético das armadilhas.

Considere então as seguintes notações, que também estão representadas na Figura 71:

$\beta$ como a probabilidade de um elétron ser preso na armadilha;

$\gamma$ como a probabilidade de ocorrer recombinação entre o elétron e o buraco;

$h$ como a densidade de elétrons presos nas armadilhas;

$H$ como a densidade de níveis de armadilhas;

$n$ como a densidade de elétrons livres;

$f$ como a densidade de níveis de recombinação.

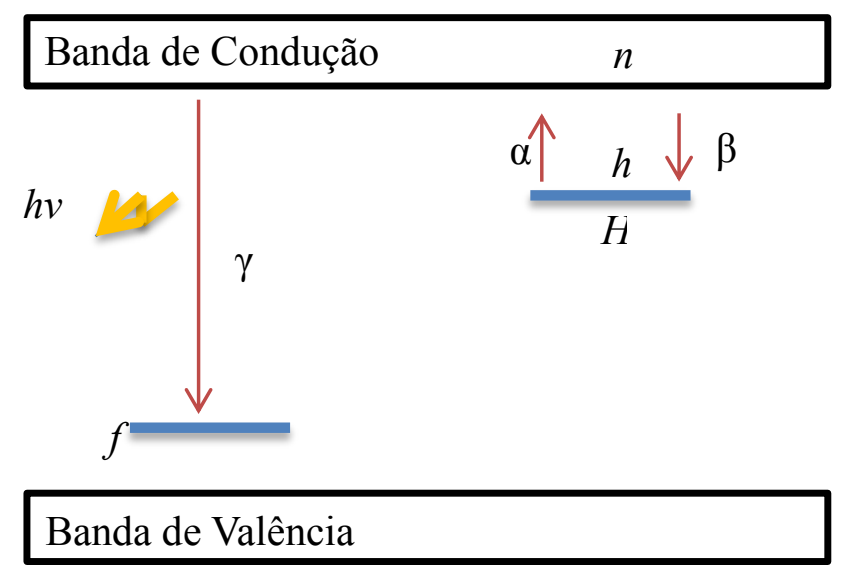

Figura 71 - Representação das transições dos elétrons dentro da rede cristalina (Adaptado de [35])

Com isso é possível calcular a mudança na densidade de elétrons nas armadilhas, Eq. A.2, e a mudança na densidade de elétrons livre na banda de condução, Eq. A.3.

$$
\frac{d h}{d t}=-\alpha h+\beta n(H-h)
$$




$$
\frac{d n}{d t}=\alpha h-\beta n(H-h)-\gamma n f
$$

Será considerada a condição de neutralidade do material, portanto a densidade de elétrons na banda de condução deve ser igual à densidade de centros de recombinação livres (buracos).

A intensidade termoluminescente é dada pelo número de transições radioativas por unidade de tempo e volume, e também é proporcional a taxa de recombinação [35], que na forma matemática esta representada na Eq. A.4

$$
I \sim \gamma n f
$$

Algumas aproximações serão inseridas agora para que seja possível solucionar as equações anteriores:

- A densidade de elétrons livres é sempre muito menor que a densidade de elétrons presos nas armadilhas e, portanto, a taxa de mudanças na densidade dos elétrons livres é menor que a taxa de mudança na densidade dos elétrons presos;

$$
n \ll h \rightarrow \frac{d n}{d t} \ll \frac{d h}{d t}
$$

- A taxa de aquecimento $(q)$ na leitura do TLD é constante;

$$
q=\frac{d T}{d t}
$$

- A probabilidade do elétron ser preso na armadilha é igual a probabilidade do elétron se recombinar com um buraco.

$$
\frac{\beta}{\gamma}=1
$$


Realizando as alterações necessárias nas Eq. A.2 e Eq. A.3, e recordando a Eq. A.8 e a condição de neutralidade, é possível obter uma nova equação para a variação da densidade de elétrons presos na armadilha pela variação da temperatura:

$$
q \frac{d h}{d T}=-\frac{\alpha h^{2}}{H}
$$

E se obtém, portanto, que a intensidade termoluminescente é proporcional a Eq. A.8. Assim basta solucionar esta equação para se obter a expressão para a intensidade.

Realizando a integral na Eq. A.8 se obtém a expressão para a variação da densidade de elétrons presos nas armadilhas:

$$
\begin{gathered}
h(T)=\frac{h_{0}}{1+\left(\frac{h_{0}}{H}\right) f(T)} \\
f(T)=\frac{\alpha_{0}}{q} \int_{T_{0}}^{T} e^{-\frac{E}{k T^{\prime}}} \cdot d T^{\prime}
\end{gathered}
$$

E assim a expressão para a intensidade termoluminescente é dada por:

$$
I \sim \frac{\alpha_{0} h_{0}}{H} \frac{e^{-\frac{E}{k T}}}{\left[1+\left(\frac{h_{0}}{H}\right) f(T)\right]^{2}}
$$

A partir da Eq. A.11 e dando valores aos parâmetros presentes nesta equação, M. Böhm e A. Scharmann obtiveram o gráfico com um pico de intensidade luminosa [35], que pode ser observado na Figura 72. 


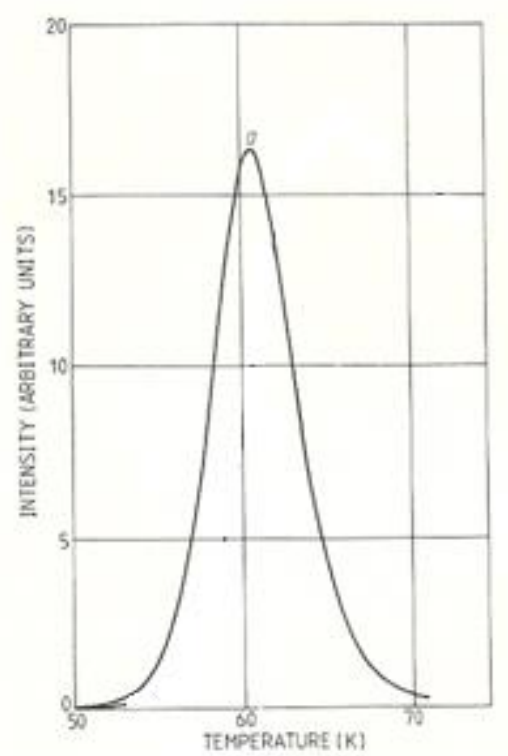

Figura 72 - Curva TL (a) calculada da Eq. $3.23 \operatorname{com} E=0,19 \mathrm{eV}, \alpha_{0}=7 \times 10^{15} \mathrm{~s}^{-1}$; $h_{0} / H=1 ; q=1 K_{.} s^{-1}[35]$ 


\section{Anexo B - Estudo dos Parâmetros de Operação da Leitora de TLDs Harshaw 3500}

O objetivo desta etapa foi definir quais as melhores tensões a serem utilizadas na leitora para cada intensidade de campo que os TLDs fossem expostos, e posteriormente definir as Regiões de Interesse (ROI) para cada tipo de TLD.

Utilizando seis TLDs de cada tipo, TLD 600, TLD 700 e TLD 400, cujas pastilhas eram utilizadas anteriormente pelo grupo de BNCT do IPEN, foram realizadas quatro irradiações em quatro campos diferentes:

- $1 \mathrm{~h}$ dentro do BH3;

- 10 ' dentro do BH3;

- 50' dentro da instalação de BNCT mas fora do BH3;

- 22h25' na fonte de AmBe de $2 \mathrm{Ci}$ com a presença de um disco de parafina.

Estas irradiações foram divididas em dois grupos, uma na qual a dose devido ao campo de irradiação seria maior (os dois primeiros casos) e outra na qual a dose seria menor (dois últimos casos). Estes TLDs foram lidos na leitora com diferentes tensões para verificar qual tensão melhor se aplicava a cada caso ou se haveria uma tensão que seria possível utilizar na leitura de todas as irradiações.

Os parâmetros utilizados na leitora foram os mesmos já utilizados pelo grupo de BNCT na outra leitora do grupo, e podem ser vistos na Tabela 5 .

As tensões testadas foram: 500, 850 e $1000 \mathrm{~V}$. A princípio foi testada se a tensão de $850 \mathrm{~V}$ poderia ser utilizada para os dois grupos de irradiação, mas para esta tensão o grupo cuja dose seria maior saturou a resposta da leitora, como pode ser visto na Figura 73. Portanto esta tensão não poderia ser utilizada para o grupo sujeito a uma dose alta de radiação. Porém, para as doses mais baixas esta tensão mostrou-se, a princípio, adequada. 


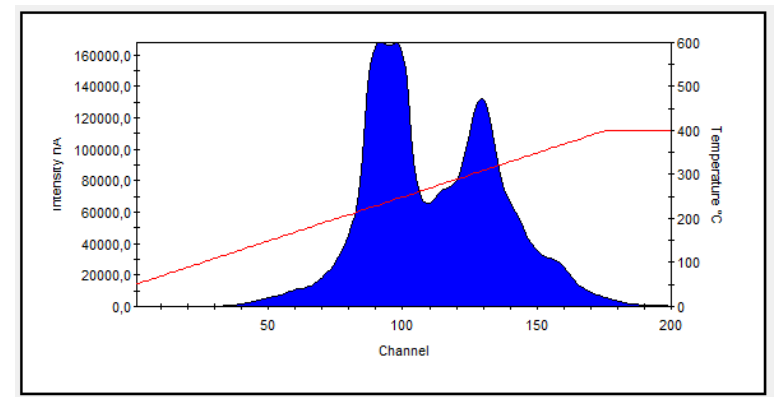

Figura 73 - Curva Termoluminescente saturada no caso da tensão de $850 \mathrm{~V}$ para um TLD de LiF

Ao testar então a tensão de $500 \mathrm{~V}$, o grupo sujeito a uma maior dose obteve boas respostas de suas curvas termoluminescentes, mas para o grupo sujeito a doses menores não apresentou uma resposta satisfatória sendo possível observar somente o espectro de fundo da leitora.
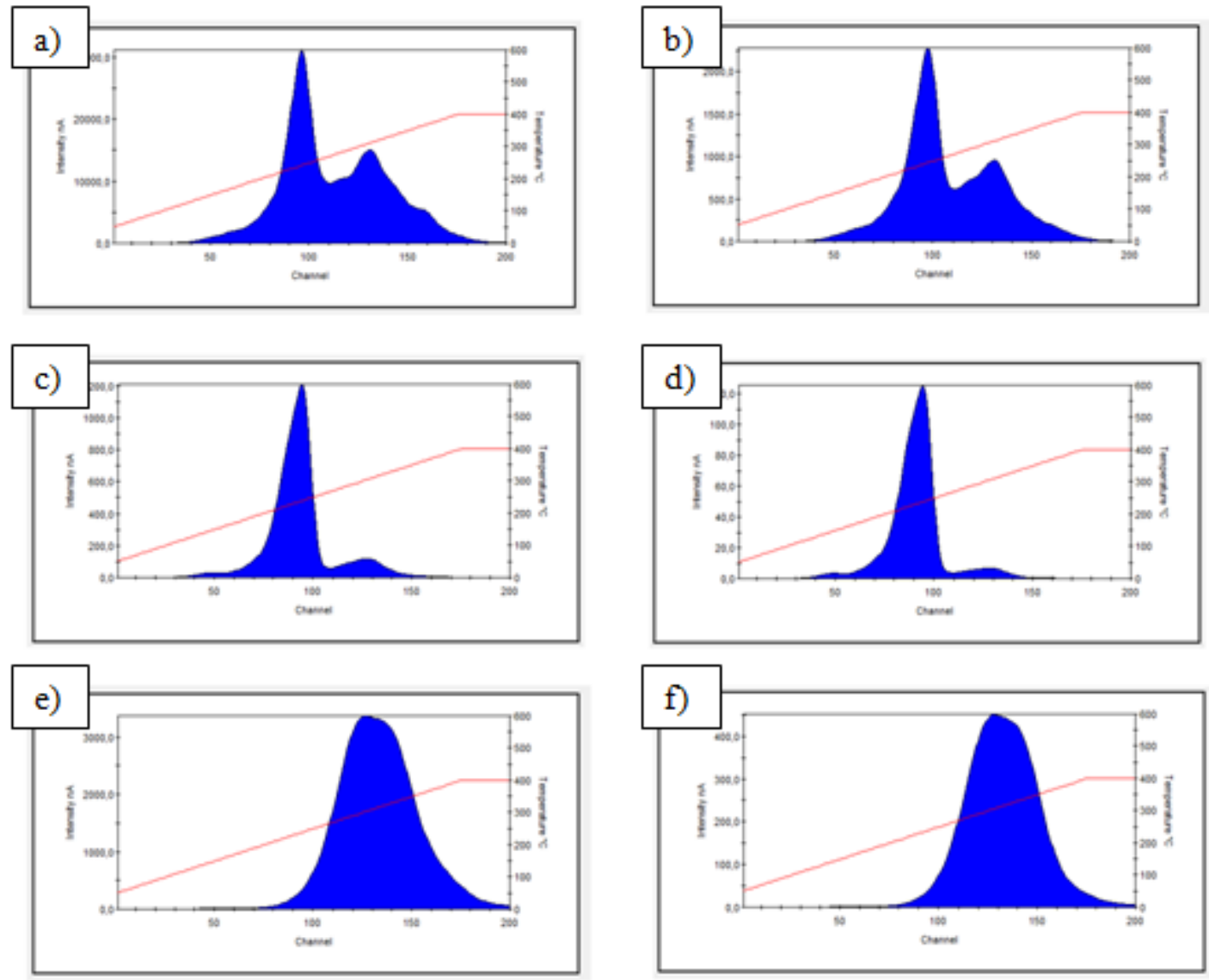

Figura 74 - Curvas Termoluminescentes dos TLDs obtidas com a leitora operando a 500V: Linha 1 - TLD 600; Linha 2 - TLD 700; Linha 3 - TLD 400; Coluna 1 Irradiações por $1 \mathrm{~h}$ no BH3; Coluna 2 - Irradiações de 10' no BH3 
Foi testada a tensão de $1000 \mathrm{~V}$ para os TLDs expostos a uma menor dose para verificar se esta tensão seria melhor que a de $850 \mathrm{~V}$. A tensão se $1000 \mathrm{~V}$ se mostrou melhor para este caso pois, devido ao ganho maior da fotomultiplicadora as curvas termoluminescentes apresentavam uma maior intensidade e melhor definição.
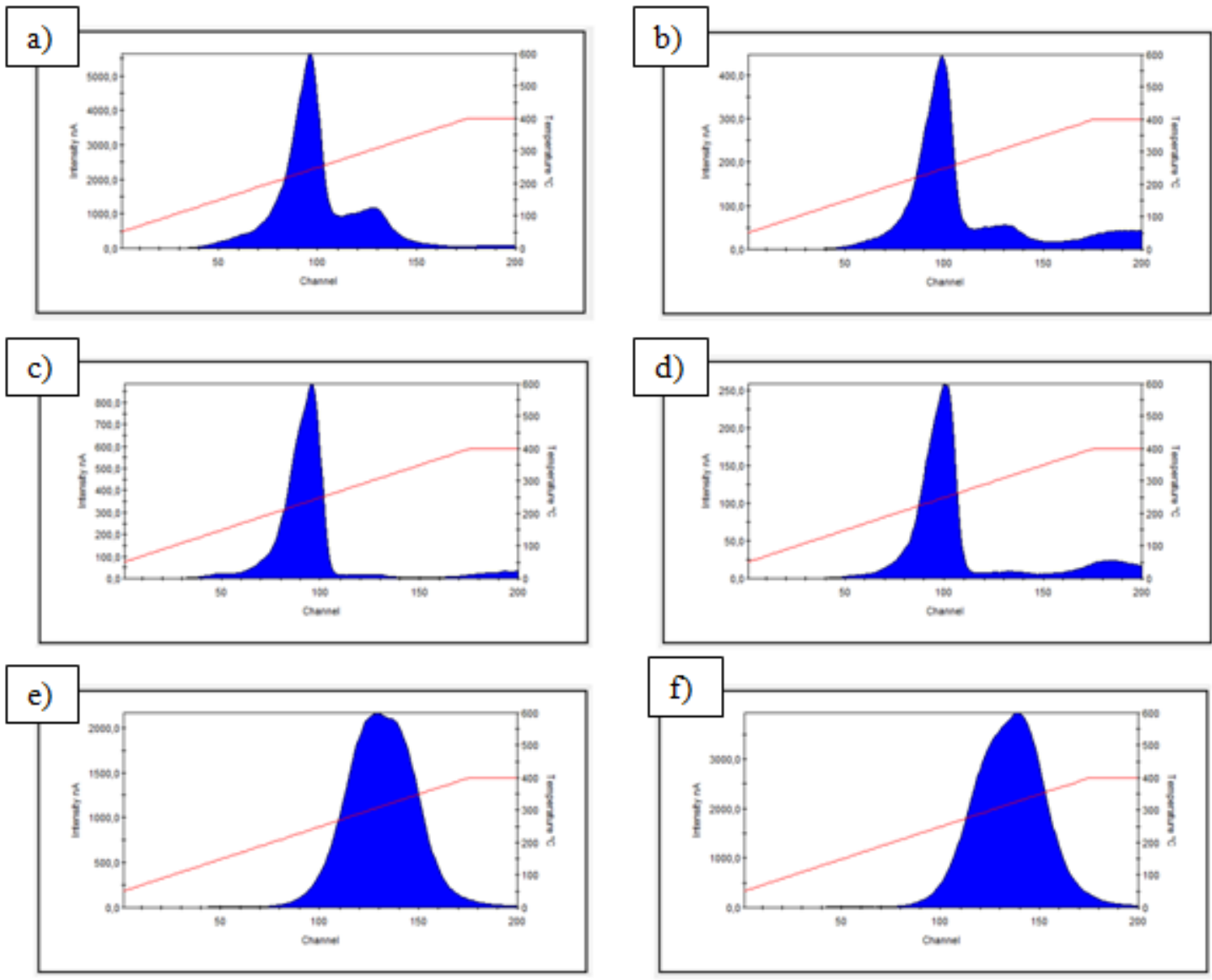

Figura 75 - Curvas Termoluminescentes dos TLDs obtidas com a leitora operando a 500V: Linha 1 - TLD 600; Linha 2 - TLD 700; Linha 3 - TLD 400; Coluna 1 Irradiações por 50' fora do BH3; Coluna 2 - Irradiações na fonte de AmBe

Portanto, ficou definido que para altas doses seria utilizada a tensão de $500 \mathrm{~V}$, e para doses mais baixas a tensão utilizada seria de $1000 \mathrm{~V}$.

O outro estudo realizado para a leitora Harshaw 3500 foi definir as Regiões de Interesse para os diferentes tipos de TLDs. Para isto foram utilizados os dados obtidos para o estudo da tensão da leitora e foram definidos os limites das regiões que apresentassem os picos dosimétricos de interesse.

A leitora Harsahw 3500 tem um total de 200 canais, e ao analisar individualmente as respostas de cada tipo de TLD foi possível observar que havia 
desvios nas posições dos picos dos TLDs, mesmo estes sendo do mesmo tipo, como pode ser visto na Figura 76.
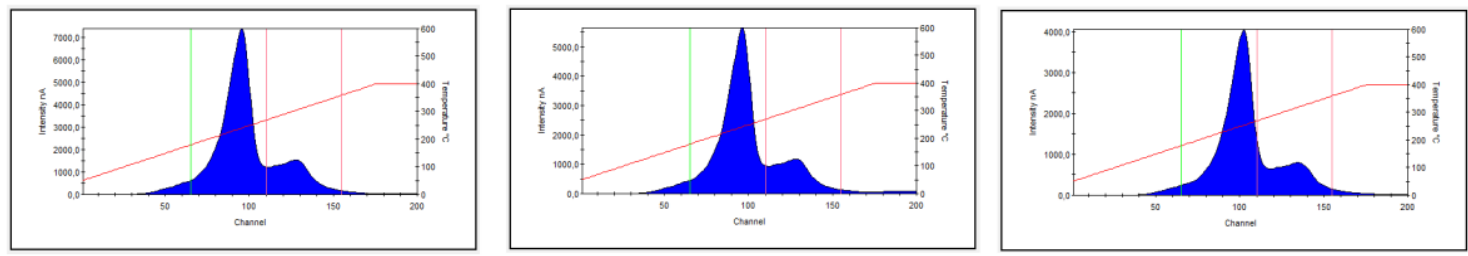

Figura 76 - Diferenças nas posições do pico de três TLDs 600 irradiados na mesma condição

Porém, mesmo com estes desvios, foram definidas as regiões onde os picos da maioria dos TLDs do mesmo tipo se encontravam centrados. Os TLDs 600 e TLDs 700, por serem do mesmo tipo, apresentavam os picos em regiões muito próximas, e por tanto foram definidas as mesmas regiões de interesse para estes dois tipos de TLDs.

Foram definidas duas regiões de interesse para os TLDs de LiF, e uma região de interesse para o TLD de $\mathrm{CaF}_{2}$, com os parâmetros da leitora definidos conforme a Tabela 5. Os valores dos canais para cada região estão demonstrados na Tabela 24, e na Figura 77 estão representadas as curvas termoluminecentes com estas regiões definidas.

Tabela 24 - Canais correspondentes a cada Região de Interesse de cada tipo de TLD

\begin{tabular}{ccc}
\hline TLD & ROI 1 & ROI 2 \\
\hline LiF & 65 ao 110 & 110 ao 155 \\
$\mathbf{C a F}_{2}$ & 90 ao 145 & --- \\
\hline
\end{tabular}



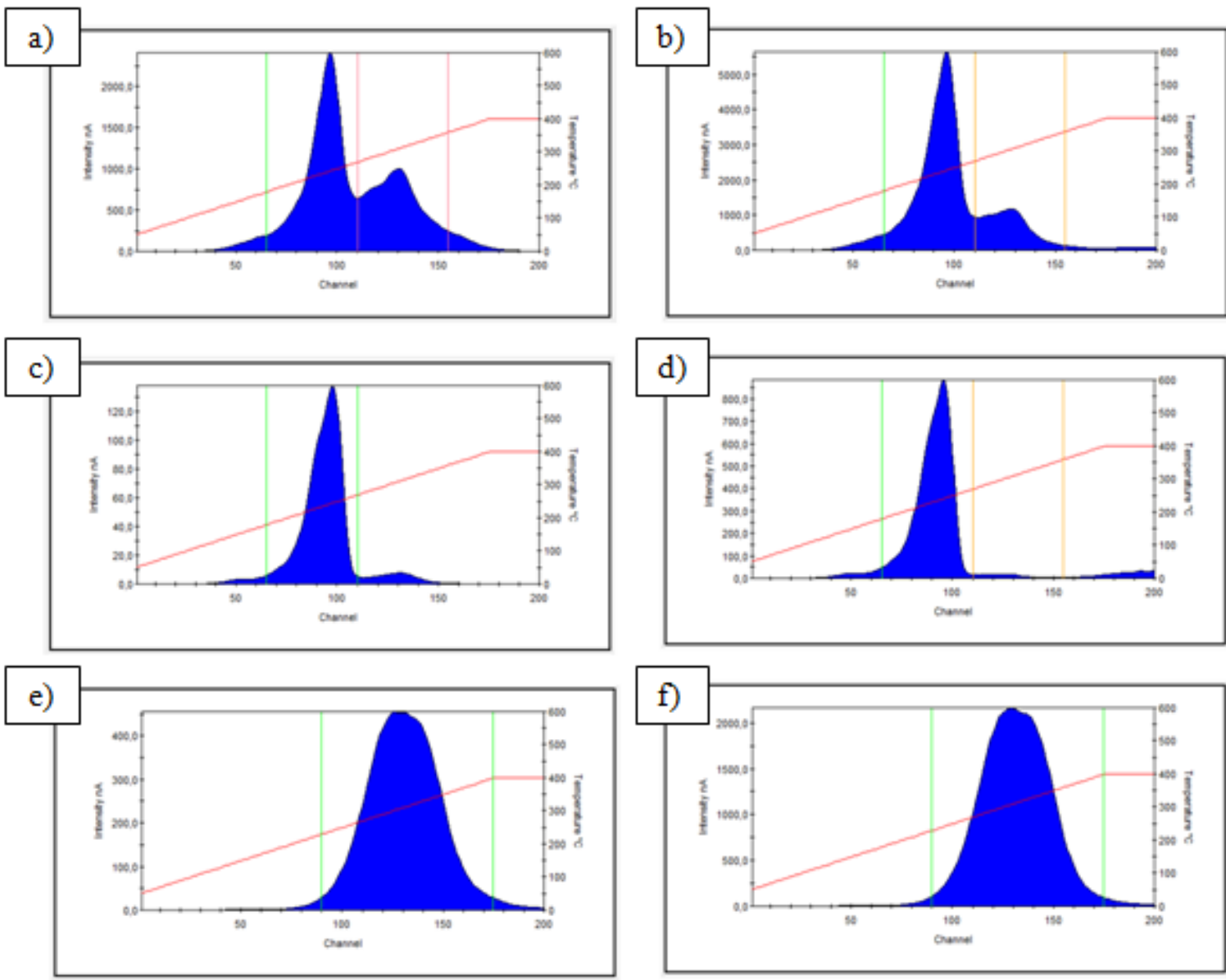

Figura 77 - Exemplo da posição dos picos para as definições das áreas de interesse: a) e b) são TLDs 600 ; c) e d) são TLDs 700; e e) e f) são TLDs 400 


\section{Anexo C - Estudo dos Sistemas de Moderação para a Fonte de AmBe}

\section{C.1 Sistema Original}

O sistema original utilizado pelo grupo de pesquisas em BNCT do IPEN para realizar o selecionamento e o estudo de reprodutibilidade em radiação com nêutrons consiste de uma fonte de $\mathrm{AmBe}$ de $2 \mathrm{Ci}$ posicionada no interior de um furo central, de $2 \mathrm{~cm}$ de raio, de um disco de parafina com $4 \mathrm{~cm}$ de altura e $9 \mathrm{~cm}$ de raio.

Este disco de parafina, juntamente com a fonte em seu interior, era colocado em cima de uma armação de alumínio com madeira na superfície, para que o sistema ficasse a aproximadamente 1 metro do chão, e assim minimizasse a interferência da radiação com o solo.

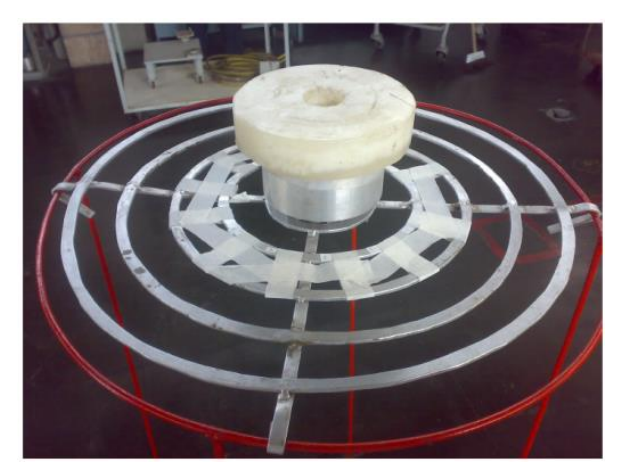

Figura 78 - Arranjo inicialmente utilizado nas irradiações para selecionamento e estudo de reprodutibilidade dos TLDs

Os TLDs eram colocados em um suporte de acrílico, e estes eram colocados ao redor do disco de parafina. Estes suportes tinham uma matriz 3 x 3 , onde eram colocados os TLDs, e tinham o formato de "L", para ser possível posicioná-los de pé ao redor do cilindro de parafina.

Dados obtidos neste sistema [25] mostravam certas discrepâncias dos resultados dos TLDs, então um estudo mais a fundo sobre este sistema foi realizado com o código computacional baseado no método de Monte Carlo. 


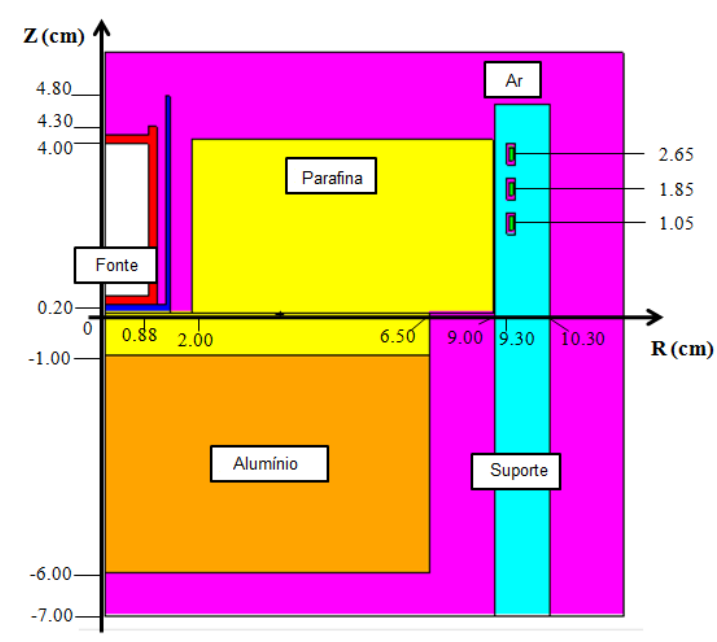

Figura 79 - Desenho da geometria da simulação com MCNP5 do sistema de selecionamento e reprodutibilidade dos TLDs para campo misto

Os resultados das simulações foram comparados com os resultados dos TLDs obtidos no trabalho de Mestrado do Rafael Muniz [25]. Os resultados dos TLDs 600 foram separados nos diferentes suportes, sendo então a resposta de cada suporte a soma individual dos nove TLDs deste suporte. O resultado normalizado de cada suporte está representado na Figura 80.

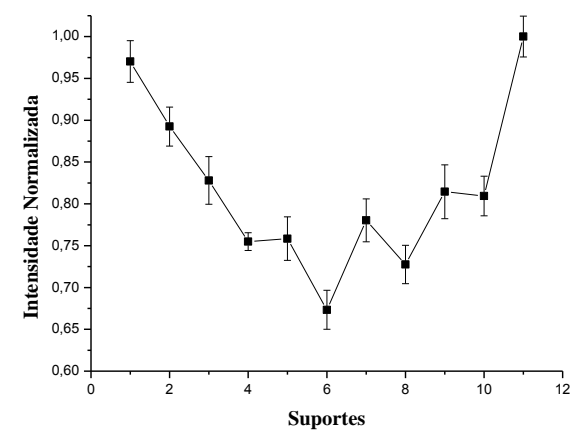

Figura 80 - Resposta TL para os suportes. Valores normalizados

A partir do perfil de intensidade de repostas dos TLDs da Figura 80, foi feita a suposição de que a fonte de AmBe não estaria perfeitamente centralizada no disco de parafina, uma vez que o furo central do disco era maior que o diâmetro da fonte, e sua colocação para irradiação não era precisa.

A simulação foi realizada para emissão de ambas as partículas para verificar se a relação seria a mesma. Nesta simulação não havia a presença dos suportes e dos TLDs, pois o objetivo era analisar o fluxo de partículas nas posições onde os 
TLDs estariam. Na simulação mantendo a fonte perfeitamente centralizada com o disco de parafina, não foi observado nenhuma diferença nas intensidades de fluxo que atingiam cada um dos suportes. Foi realizada então a simulação com a fonte descentralizada, e os dados obtidos nesta configuração estão apresentados na Figura 81, que apresenta os fluxos normalizados aparir do ângulo polar.
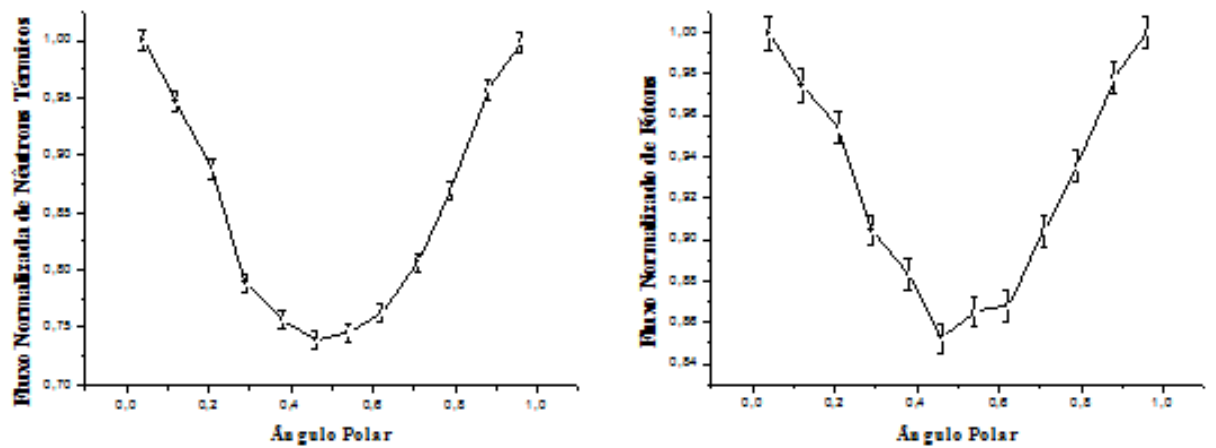

Figura 81 - Fluxos de nêutrons e fótons obtidos pela simulação com o MCNP5

Através da simulação foi possível verificar que a região em que foram dispostos os suportes apresentou variações de acordo com a proximidade dos suportes com a fonte. Sendo que os suportes mais próximos da fonte recebiam um maior fluxo tanto de nêutrons térmicos quanto de fótons. Sendo que a maior diferença seria para nêutrons térmicos (chegando a $25 \%$ de diferença na posição de diferentes suportes). E para a radiação gama a diferença seria menor (cerca de 15\%) mas mesmo assim, significativa.

Analisando as respostas dos TLDs obtidas também foi possível observar que os TLDs que estariam em alturas diferentes no suporte poderiam estar sujeitos a diferentes intensidades de fluxo. Os dados dos TLDs foram somados e normalizados para as diferentes alturas, e os dados obtidos estão representados na Tabela 25.

Tabela 25 - Respostas normalizadas dos TLDs nas mesmas alturas

\begin{tabular}{cc}
\hline Posição das Linhas & Resposta Normalizada \\
\hline Superior & 0,75 \\
Central & 0,93 \\
Inferior & 1,00 \\
\hline
\end{tabular}


Foi realizada a simulação com o MCNP5 para verificar esta diferença de fluxos nas diferentes alturas que os TLDs estariam e se o acrílico, por ser um material que termalise os nêutrons, estaria afetando significativamente o fluxo de nêutrons na região.

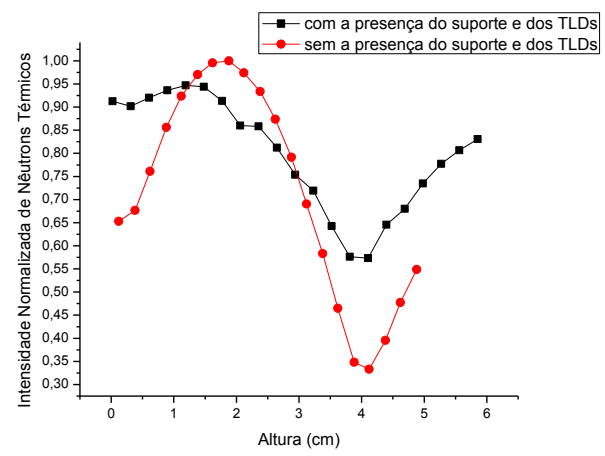

Figura 82 - Fluxos normalizados de nêutrons térmicos obtidos pelo MCNP5 nos casos com e sem a presença do suporte e dos TLDs

Com a simulação foi possível analisar as diferenças nas estimativas de dose de nêutrons térmicos nas diferentes alturas de posicionamento dos TLDs.

Portanto chegou-se a conclusão que o atual sistema é inadequado para a realização de irradiações para selecionamento dos TLDs e, assim foi estudado e construído um novo sistema para a realização deste estudo.

\section{C.2 Estudo Para o Novo Sistema de Moderação}

No novo sistema foi proposto uma busca por maior homogeneidade de dose nas diferentes alturas que os TLDs estariam posicionados. Para isto foi proposto um sistema constituído por um cilindro de polietileno com uma altura maior e que a fonte de AmBe ficasse posicionada no seu interior e em sua altura média. Os TLDs também seriam posicionados na altura média da lateral deste cilindro. 


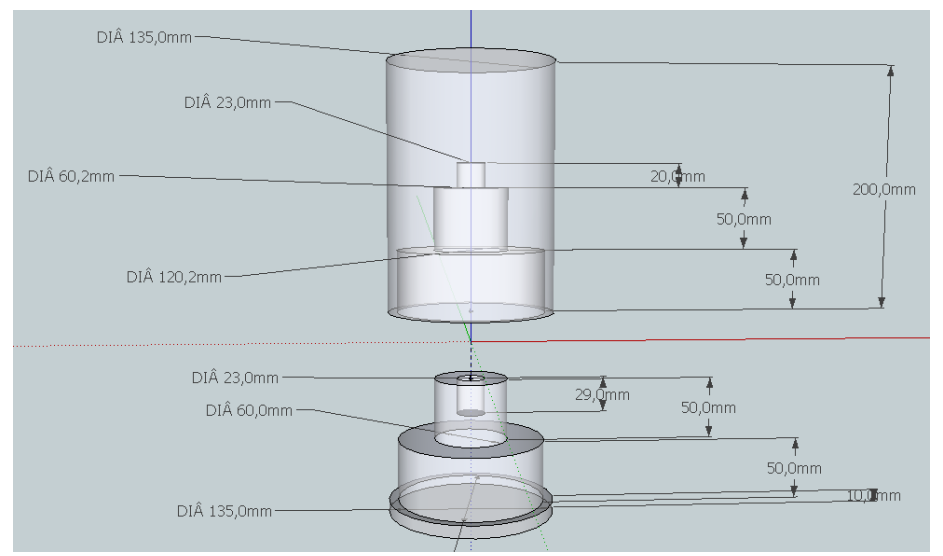

Figura 83 - Esquema para construção do novo sistema para estudo da reprodutibilidade dos TLDs

O projeto inicial utilizava um cilindro com um raio maior, para que uma maior quantidade de nêutrons de baixa energia atingisse os TLDs, mas devido à dificuldade em se obter um cilindro de polietileno com dimensões maiores, foi utilizado um cilindro que o grupo de BNCT do IPEN já possuia. O projeto foi enviado para a oficina do IPEN, onde foi construído.
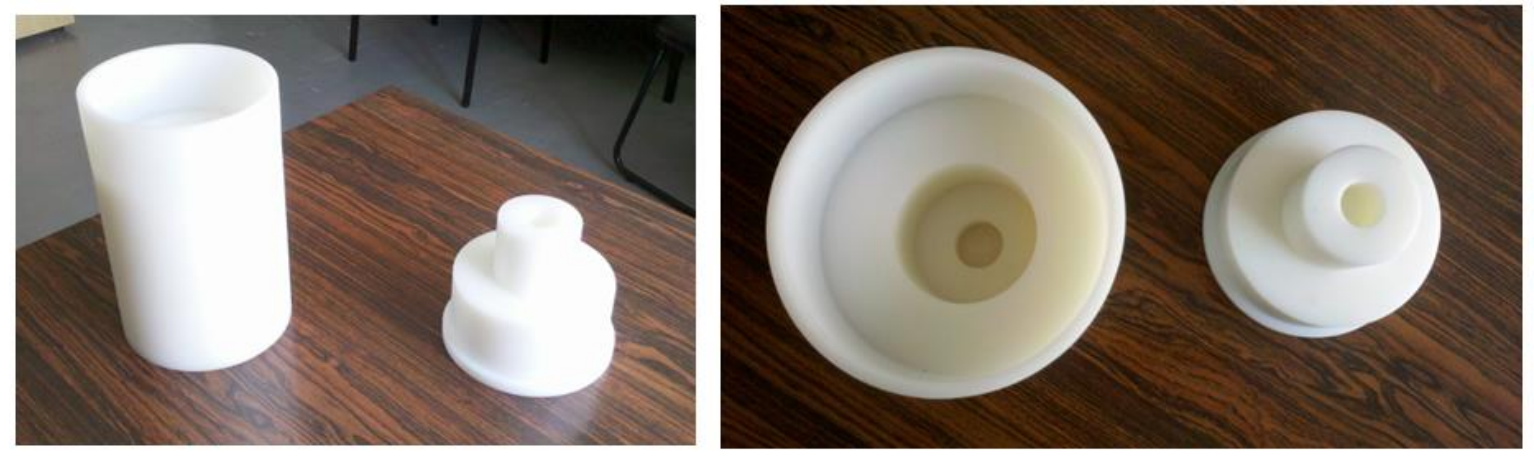

Figura 84 - Fotos das duas peças que constituem o novo sistema de irradiação

Nas irradiações neste novo sistema os TLDs eram colocados em um suporte simétrico de isopor, que continha 3 linhas com 5 TLDs em cada.

Foi feito o estudo com o MCNP5 para obter as diferenças que haveriam nas doses de kerma no ar em cada uma das 15 posições dos TLDs e a dose média assim como o fluxo em cada posição e a média. 
A Tabela 26 apresenta os valores médios e seus desvios obtidos para os fótons. A Tabela 27 apresenta os mesmos valores para os nêutrons, e neste caso há a contribuição de cada faixa energética dos nêutrons.

Vale ressaltar que os nêutrons ao interagirem com o polietileno produzem fótons, porém o fluxo e o kerma no ar que estes fótons produzem nas posições dos TLDs são desprezíveis (inferior a 1\%) frente ao fluxo e kerma no ar produzidos pelos fótons da própria fonte.

Tabela 26 - Valores médios calculados de fluxo de fótons e o respectivo kerma no ar no novo sistema de irradiação

\begin{tabular}{cccc}
\hline \multicolumn{2}{c}{ Fluxo $\left(\mathbf{1} / \mathbf{c m}^{\mathbf{2}} \mathbf{s}\right)$} & \multicolumn{2}{c}{ Kerma no $\mathbf{~ a r}(\mathbf{m G y} / \mathbf{h})$} \\
\hline Valor médio & Incerteza (\%) & Valor médio & Incerteza $(\%)$ \\
$8,32 \mathrm{E}+04$ & 1,8 & 3,34 & 1,8 \\
\hline
\end{tabular}

Tabela 27 - Valores médios calculados de fluxo de nêutrons e respectivo kerma no ar e a fração de contribuição de cada faixa energética no novo sistema de irradiação com a fonte de AmBe

\begin{tabular}{|c|c|c|c|c|}
\hline \multirow[b]{2}{*}{$\begin{array}{c}\text { Contribuição dos nêutrons } \\
(\%)\end{array}$} & \multicolumn{2}{|c|}{ Fluxo $\left(1 / \mathrm{cm}^{2} . \mathbf{s}\right)$} & \multicolumn{2}{|c|}{ Kerma no ar (mGy/h) } \\
\hline & $\begin{array}{c}\text { Valor } \\
\text { médio } \\
8,32 \mathrm{E}+04\end{array}$ & $\begin{array}{c}\text { Incerteza } \\
(\%) \\
2,0\end{array}$ & $\begin{array}{c}\text { Valor } \\
\text { médio } \\
1,47\end{array}$ & $\begin{array}{c}\text { Incerteza } \\
(\%) \\
1,8\end{array}$ \\
\hline Térmicos & \multicolumn{2}{|c|}{26} & \multicolumn{2}{|c|}{25} \\
\hline Epitérmicos & \multicolumn{2}{|c|}{16} & \multicolumn{2}{|c|}{1} \\
\hline Rápidos & \multicolumn{2}{|c|}{58} & \multicolumn{2}{|c|}{74} \\
\hline
\end{tabular}




\section{Anexo D - Fatores de Normalização dos TLDs}

Apresentado a seguir os valores adotados para os Fatores de Normalização de cada um dos TLDs utilizados neste trabalho (30 TLDs 600, 30 TLDs 700 e 30 TLDs 400). A coluna 1 apresenta os valores para a irradiação na fonte de ${ }^{60} \mathrm{Co}$, a coluna 2 os valores para as duas regiões de interesse nas irradiações no sistema com a fonte de AmBe.

Tabela 28 - Fatores de Normalização do TLD 600

\begin{tabular}{|c|c|c|c|c|c|c|}
\hline \multirow{3}{*}{$\begin{array}{c}\text { TLD } 600 \\
\text { TLDs }\end{array}$} & \multirow{2}{*}{\multicolumn{2}{|c|}{$\frac{\text { F.N. para fonte de }{ }^{60} \mathrm{Co}}{\text { ROI } 1}$}} & \multicolumn{4}{|c|}{ F.N. para fonte de AmBe } \\
\hline & & & \multicolumn{2}{|c|}{ ROI 1} & \multicolumn{2}{|c|}{ ROI 2} \\
\hline & Valor & Incerteza & Valor & Incerteza & Valor & Incerteza \\
\hline $6 \mathrm{~A} 1$ & 0,961 & 0,02 & 1,005 & 0,04 & 1,019 & 0,06 \\
\hline $6 \mathrm{A2}$ & 1,016 & 0,03 & 1,040 & 0,03 & 1,062 & 0,02 \\
\hline $6 A 3$ & 1,018 & 0,06 & 0,915 & 0,04 & 0,870 & 0,04 \\
\hline 6B1 & 1,027 & 0,03 & 1,016 & 0,04 & 1,007 & 0,05 \\
\hline $6 \mathrm{~B} 2$ & 0,933 & 0,05 & 1,117 & 0,06 & 1,136 & 0,09 \\
\hline $6 \mathrm{~B} 3$ & 1,031 & 0,03 & 1,003 & 0,03 & 0,976 & 0,06 \\
\hline $6 \mathrm{C} 1$ & 1,009 & 0,02 & 1,032 & 0,02 & 0,989 & 0,05 \\
\hline $6 \mathrm{C2}$ & 1,032 & 0,02 & 0,993 & 0,05 & 0,966 & 0,09 \\
\hline $6 \mathrm{C3}$ & 1,008 & 0,12 & 1,057 & 0,08 & 1,021 & 0,14 \\
\hline 6D1 & 0,969 & 0,03 & 1,123 & 0,05 & 1,203 & 0,08 \\
\hline 6D2 & 0,985 & 0,03 & 0,996 & 0,03 & 1,046 & 0,06 \\
\hline 6D3 & 1,000 & 0,02 & 0,963 & 0,02 & 1,002 & 0,06 \\
\hline $6 \mathrm{E} 1$ & 1,016 & 0,02 & 1,007 & 0,05 & 1,044 & 0,05 \\
\hline $6 \mathrm{E} 2$ & 0,994 & 0,02 & 0,957 & 0,03 & 0,954 & 0,07 \\
\hline $6 \mathrm{E} 3$ & 0,965 & 0,02 & 1,023 & 0,02 & 1,072 & 0,05 \\
\hline $6 \mathrm{~F} 1$ & 1,022 & 0,03 & 0,994 & 0,03 & 0,924 & 0,10 \\
\hline $6 \mathrm{~F} 2$ & 1,020 & 0,01 & 1,029 & 0,02 & 0,995 & 0,06 \\
\hline $6 \mathrm{F3}$ & 1,001 & 0,02 & 1,005 & 0,03 & 1,031 & 0,02 \\
\hline $6 \mathrm{G1}$ & 1,046 & 0,02 & 1,043 & 0,02 & 1,039 & 0,12 \\
\hline $6 \mathrm{G} 2$ & 1,011 & 0,03 & 1,025 & 0,06 & 1,041 & 0,08 \\
\hline $6 G 3$ & 1,010 & 0,02 & 1,015 & 0,05 & 1,038 & 0,04 \\
\hline $6 \mathrm{H} 1$ & 0,967 & 0,02 & 0,896 & 0,03 & 0,948 & 0,05 \\
\hline $6 \mathrm{H} 2$ & 1,029 & 0,02 & 0,972 & 0,02 & 0,979 & 0,03 \\
\hline $6 \mathrm{H} 3$ & 0,959 & 0,02 & 0,960 & 0,03 & 0,916 & 0,10 \\
\hline 611 & 0,999 & 0,02 & 0,988 & 0,06 & 0,952 & 0,07 \\
\hline 612 & 0,984 & 0,02 & 0,957 & 0,02 & 0,938 & 0,11 \\
\hline 613 & 0,990 & 0,04 & 1,036 & 0,04 & 1,010 & 0,07 \\
\hline $6 J 1$ & 1,066 & 0,06 & 1,097 & 0,03 & 1,207 & 0,05 \\
\hline $6 J 2$ & 0,990 & 0,03 & 0,913 & 0,03 & 0,955 & 0,04 \\
\hline $6 J 3$ & 0,967 & 0,04 & 0,946 & 0,03 & 0,963 & 0,05 \\
\hline
\end{tabular}


Tabela 29 - Fatores de Normalização do TLD 700

\begin{tabular}{|c|c|c|c|c|c|c|}
\hline \multirow{3}{*}{$\begin{array}{c}\text { TLD } 700 \\
\text { TLDs }\end{array}$} & \multirow{2}{*}{\multicolumn{2}{|c|}{$\begin{array}{c}\text { F.N. para fonte de } 60 \text { Co } \\
\text { ROI } 1\end{array}$}} & \multicolumn{4}{|c|}{ F.N. para fonte de $\mathrm{AmBe}$} \\
\hline & & & \multicolumn{2}{|c|}{ ROI 1} & \multicolumn{2}{|c|}{ ROI 2} \\
\hline & Valor & Incerteza & Valor & Incerteza & Valor & Incerteza \\
\hline 7A1 & 1,041 & 0,03 & 1,008 & 0,04 & 0,993 & 0,08 \\
\hline $7 A 2$ & 1,022 & 0,02 & 0,991 & 0,03 & 1,037 & 0,06 \\
\hline $7 A 3$ & 1,007 & 0,02 & 0,940 & 0,03 & 0,939 & 0,06 \\
\hline 7B1 & 0,999 & 0,03 & 1,003 & 0,02 & 0,978 & 0,06 \\
\hline 7B2 & 0,993 & 0,03 & 0,988 & 0,02 & 0,993 & 0,06 \\
\hline 7B3 & 1,012 & 0,04 & 0,995 & 0,03 & 0,998 & 0,04 \\
\hline 7C1 & 1,007 & 0,03 & 0,979 & 0,02 & 1,003 & 0,06 \\
\hline $7 C 2$ & 1,011 & 0,04 & 0,946 & 0,02 & 0,998 & 0,06 \\
\hline $7 C 3$ & 1,006 & 0,02 & 0,989 & 0,03 & 1,051 & 0,03 \\
\hline 7D1 & 0,988 & 0,02 & 1,016 & 0,03 & 1,027 & 0,08 \\
\hline 7D2 & 0,995 & 0,02 & 1,043 & 0,02 & 1,064 & 0,06 \\
\hline 7D3 & 0,994 & 0,02 & 1,022 & 0,04 & 1,083 & 0,07 \\
\hline 7E1 & 0,999 & 0,01 & 0,990 & 0,02 & 1,050 & 0,05 \\
\hline 7E2 & 0,962 & 0,02 & 0,946 & 0,02 & 1,000 & 0,05 \\
\hline $7 E 3$ & 0,974 & 0,02 & 1,029 & 0,04 & 1,053 & 0,07 \\
\hline $7 F 1$ & 0,977 & 0,01 & 1,006 & 0,03 & 1,019 & 0,06 \\
\hline $7 F 2$ & 1,005 & 0,02 & 1,001 & 0,02 & 0,997 & 0,04 \\
\hline $7 F 3$ & 1,007 & 0,01 & 1,009 & 0,02 & 1,062 & 0,06 \\
\hline $7 \mathrm{G1}$ & 1,009 & 0,02 & 1,045 & 0,03 & 1,105 & 0,04 \\
\hline $7 G 2$ & 1,023 & 0,02 & 1,044 & 0,03 & 1,032 & 0,04 \\
\hline $7 G 3$ & 0,995 & 0,02 & 0,995 & 0,04 & 1,035 & 0,04 \\
\hline $7 \mathrm{H} 1$ & 1,008 & 0,03 & 0,972 & 0,02 & 0,954 & 0,06 \\
\hline $7 \mathrm{H} 2$ & 1,002 & 0,03 & 0,955 & 0,01 & 0,916 & 0,14 \\
\hline $7 \mathrm{H3}$ & 1,007 & 0,03 & 0,967 & 0,03 & 0,956 & 0,13 \\
\hline 711 & 0,996 & 0,02 & 1,001 & 0,03 & 0,986 & 0,10 \\
\hline 712 & 0,999 & 0,02 & 1,088 & 0,04 & 1,088 & 0,04 \\
\hline 713 & 1,017 & 0,03 & 1,053 & 0,04 & 1,070 & 0,05 \\
\hline 7J1 & 1,000 & 0,03 & 1,018 & 0,03 & 0,946 & 0,16 \\
\hline $7 J 2$ & 0,957 & 0,02 & 0,983 & 0,03 & 0,909 & 0,20 \\
\hline $7 \mathrm{~J} 3$ & 0,996 & 0,02 & 1,036 & 0,05 & 0,996 & 0,08 \\
\hline
\end{tabular}


Tabela 30 - Fatores de Normalização do TLD 400

\begin{tabular}{|c|c|c|}
\hline \multirow{2}{*}{ TLD 400 } & \multicolumn{2}{|c|}{ F.N. para fonte de 60 Co } \\
\cline { 2 - 3 } & \multicolumn{2}{|c|}{ ROI } \\
\hline TLDs & Valor & Incerteza \\
\hline 4A1 & 1,009 & 0,02 \\
\hline 4A2 & 0,963 & 0,03 \\
\hline 4A3 & 1,083 & 0,03 \\
\hline 4B1 & 0,975 & 0,06 \\
\hline 4B2 & 1,095 & 0,08 \\
\hline 4B3 & 0,940 & 0,06 \\
\hline 4C1 & 1,000 & 0,07 \\
\hline 4C2 & 0,950 & 0,07 \\
\hline 4C3 & 0,956 & 0,08 \\
\hline 4D1 & 0,960 & 0,06 \\
\hline 4D2 & 0,945 & 0,04 \\
\hline 4D3 & 0,934 & 0,04 \\
\hline 4E1 & 0,947 & 0,04 \\
\hline 4E2 & 1,037 & 0,06 \\
\hline 4E3 & 1,042 & 0,07 \\
\hline 4F1 & 1,028 & 0,03 \\
\hline 4F2 & 0,941 & 0,06 \\
\hline 4F3 & 0,964 & 0,06 \\
\hline 4G1 & 1,013 & 0,08 \\
\hline 4G2 & 1,030 & 0,07 \\
\hline 4G3 & 1,002 & 0,08 \\
\hline 4H1 & 0,967 & 0,08 \\
\hline 4H2 & 1,014 & 0,08 \\
\hline 4H3 & 1,033 & 0,08 \\
\hline 4I1 & 1,041 & 0,08 \\
\hline 4I2 & 1,038 & 0,09 \\
\hline 4I3 & 1,040 & 0,10 \\
\hline 4J1 & 0,998 & 0,08 \\
\hline 4J2 & 1,112 & 0,10 \\
\hline Hy & 1,012 & 0,08 \\
\hline
\end{tabular}




\section{Anexo E - Arquivo de Entrada do MCNP para Simulações das Irradiações no Reator IPEN/MB-01}

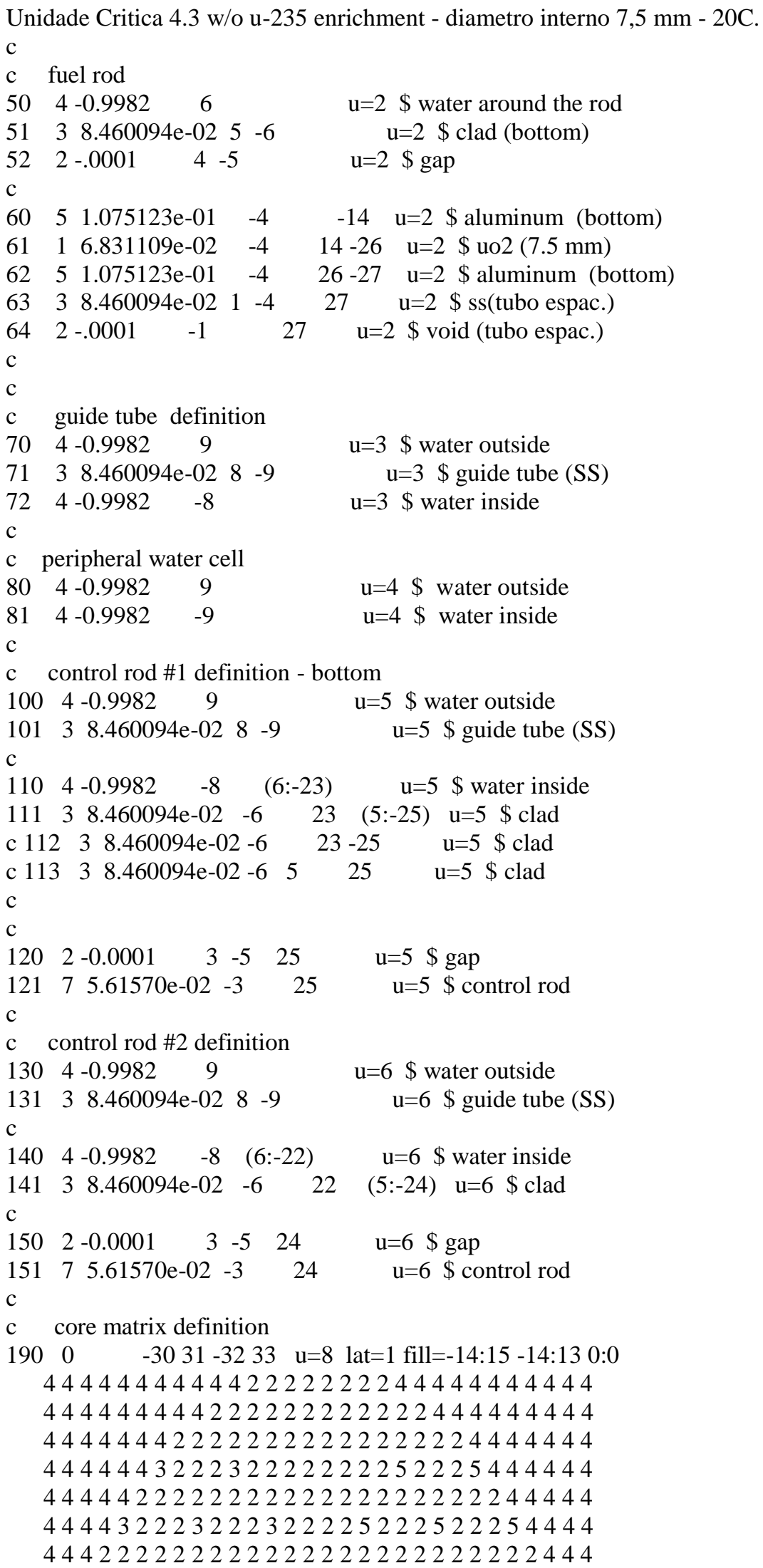




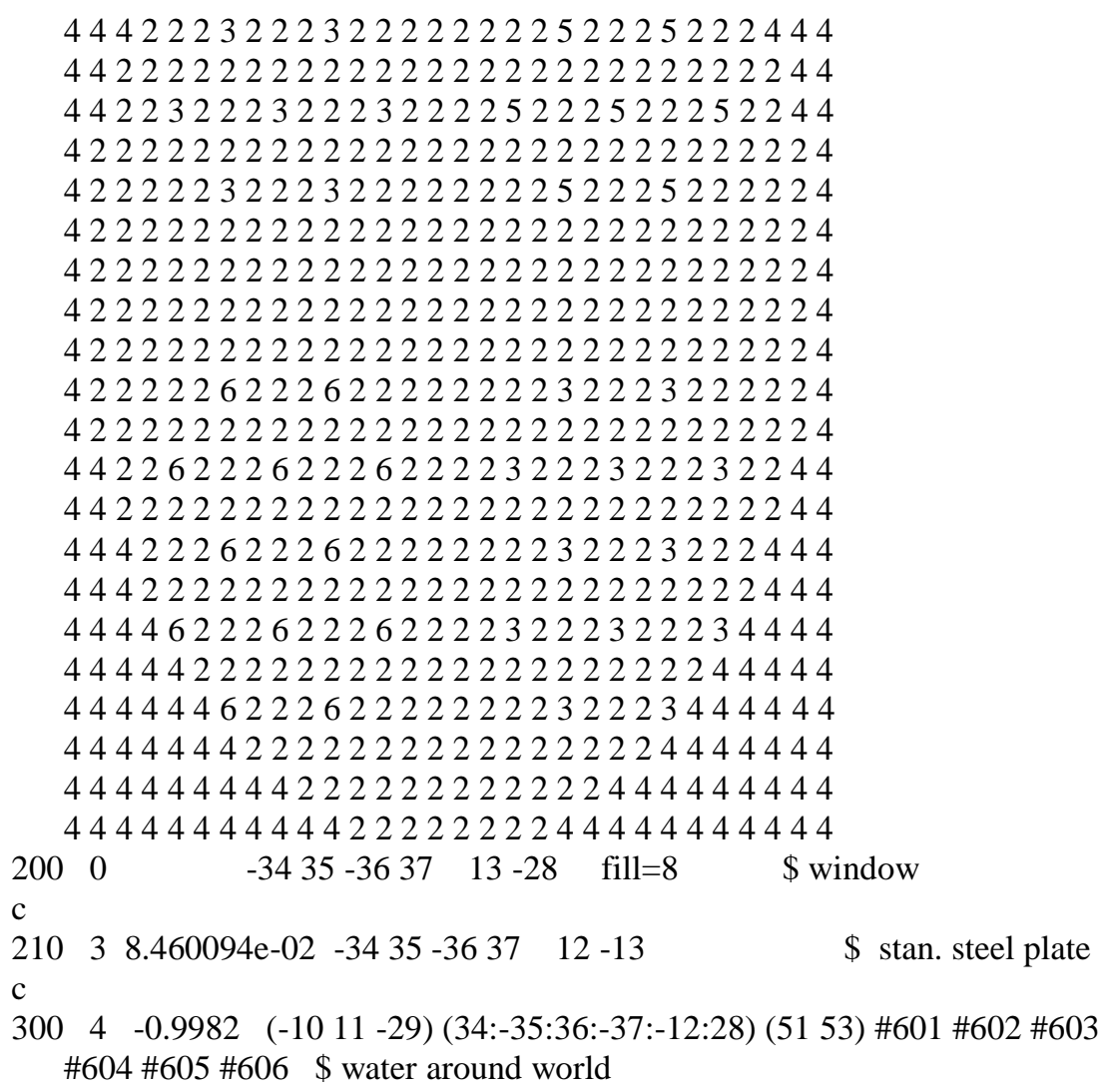




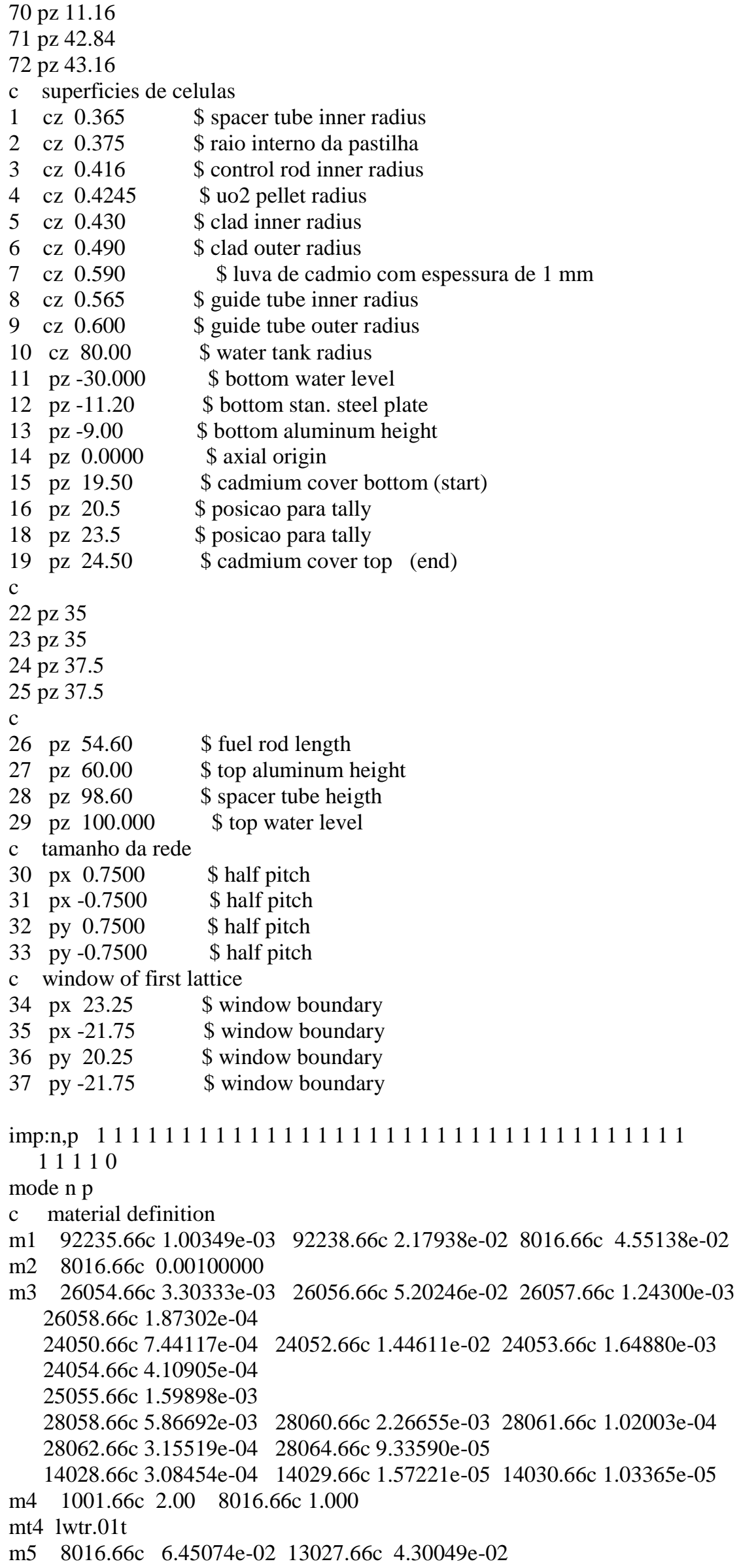


m7 $47107.66 \mathrm{c} \quad 2.35462 \mathrm{e}-02 \quad 47109.66 \mathrm{c} \quad 2.18835 \mathrm{e}-02$

$49000.66 \mathrm{c} 8.002466 \mathrm{e}-03$

48106.66 c $3.32440 \mathrm{e}-05 \quad 48108.66 \mathrm{c} \quad 2.39793 \mathrm{e}-05$ 48110.66cc 3.37618e-04

$48111.66 \mathrm{c} 3.47155 \mathrm{e}-04 \quad 48112.66 \mathrm{c} \quad 6.55888 \mathrm{e}-04$ 48113.66c 3.34075e-04

$48114.66 \mathrm{c} 7.86412 \mathrm{e}-04$ 48116.66 $2.06549 \mathrm{e}-04$

c kcode 100001.02509550

c ksrc 0.00 .020 .0

c Tallies

FMESH64:n geom=xyz origin=-25 20.250

imesh $=25$ iints $=200$

jmesh $=21.25$ jints $=1$

$\mathrm{kmesh}=54 \quad$ kints $=216$

out=ik

emesh $=0.5 \mathrm{e}-7,1 \mathrm{e}-2,100$ eints $=1,1,1$

FMESH74:p geom=xyz origin=-25 20.250

imesh $=25$ iints $=200$

jmesh $=21.25$ jints $=1$

kmesh $=54$ kints $=216$

out=ik

F4:n 601602603604605606

E4 0.5e-7 1e-2 100

F14:p 601602603604605606

E14 0.5151020

F24:n 601602603604605606

FM24 1.22580E-01 11 (105:91)

F34:n 601602603604605606

FM34 1.22580E-01 12 (105:91)

F44:n 601602603604605606

$\mathrm{c}$ fonte

sdef pos $00-18$ axs 001 rad d1 ext d2 par 1 erg d 3

si1 02.5

sp1 $-21 \quad 1$

si2 06

$\operatorname{sp} 2 \quad 0 \quad 1$

si3 1.00E-09 2.15E-09 4.64E-09 1.00E-08 2.15E-08 4.64E-08 $1.00 \mathrm{E}-07$

$2.15 \mathrm{E}-07 \quad 4.64 \mathrm{E}-07 \quad 1.00 \mathrm{E}-06 \quad 2.15 \mathrm{E}-06 \quad 4.64 \mathrm{E}-06 \quad 1.00 \mathrm{E}-05 \quad 2.15 \mathrm{E}-05$

4.64E-05 1.00E-04 2.15E-04 4.64E-04 1.00E-03 2.15E-03 4.64E-03

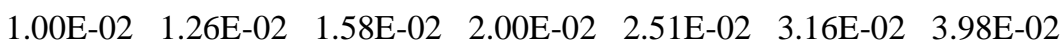

$\begin{array}{lllllll}5.01 \mathrm{E}-02 & 6.31 \mathrm{E}-02 & 7.94 \mathrm{E}-02 & 1.00 \mathrm{E}-01 & 1.26 \mathrm{E}-01 & 1.58 \mathrm{E}-01 & 2.00 \mathrm{E}-01\end{array}$

$2.51 \mathrm{E}-01 \quad 3.16 \mathrm{E}-01 \quad 3.98 \mathrm{E}-01 \quad 5.01 \mathrm{E}-01 \quad 6.31 \mathrm{E}-01 \quad 7.94 \mathrm{E}-01 \quad 1.00 \mathrm{E}+00$

$\begin{array}{lllllll}1.26 \mathrm{E}+00 & 1.58 \mathrm{E}+00 & 2.00 \mathrm{E}+00 & 2.51 \mathrm{E}+00 & 3.16 \mathrm{E}+00 & 3.98 \mathrm{E}+00 & 5.01 \mathrm{E}+00\end{array}$

$\begin{array}{lllll}6.31 \mathrm{E}+00 & 7.94 \mathrm{E}+00 & 1.00 \mathrm{E}+01 & 1.58 \mathrm{E}+01 & 2.51 \mathrm{E}+01\end{array}$

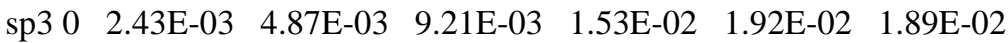

$\begin{array}{lllllll}1.41 \mathrm{E}-02 & 1.31 \mathrm{E}-02 & 1.39 \mathrm{E}-02 & 1.38 \mathrm{E}-02 & 1.37 \mathrm{E}-02 & 1.38 \mathrm{E}-02 & 1.39 \mathrm{E}-02\end{array}$

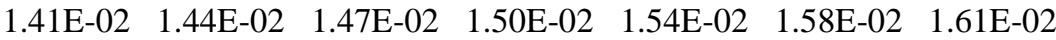

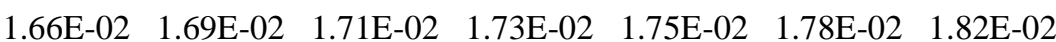

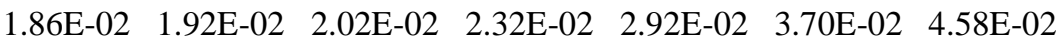

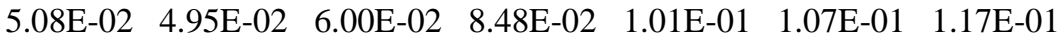

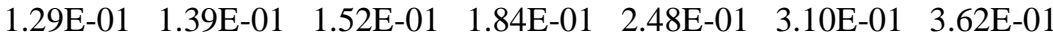

3.73E-01 2.96E-01 1.74E-01 5.44E-02 1.91E-02

ctme 5050

$\mathrm{O}$ arquivo de entrada do MCNP para as simulações das irradiações no reator IPEN/MB-01 continham exatamente as informações da geometria do experimento. As barras de controle foram simuladas o mais próximo da posição real, porém tomando o cuidado de se obter uma valor de $k$ o mais próximo possível de 1 , mas nunca igual a 1 pois se isto ocorresse a simulação seria infinita. 
Como o experimento foi realizado a baixa potência $(2 \mathrm{~W})$, foi simulado primeiramente com o kcode e posteriormente com a fonte fixa de AmBe posicionada a baixo do reator.

Os experimentos com a fonte fixa e com o kcode não apresentaram grandes variações nas respostas. 


\section{Anexo F - Estudo da Dependência Energética dos TLDs para Fontes de Gama puro}

Foram realizadas irradiações dos TLDs 600, TLDs 700 e TLDs 400 para duas fontes de gama puro com espectros de energia diferentes (fonte de ${ }^{60} \mathrm{Co}$ e de ${ }^{137} \mathrm{Cs}$ ). A partir das curvas de calibração resposta $\mathrm{x}$ dose foi possível observar diferenças no coeficiente angular $(B)$ das curvas dos TLDs quando irradiados em fontes diferentes.

A Figura 85 apresenta as curvas de calibração para o TLD 600 para as duas fontes. Os coeficientes ajustados para estas curvas estão apresentados na Tabela 31.
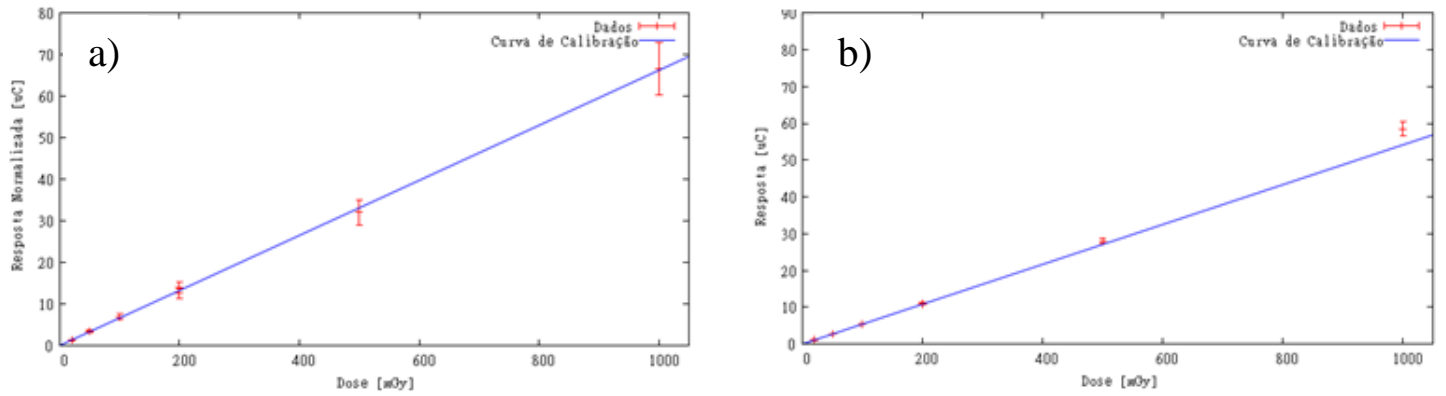

Figura 85 - Curvas de calibração do TLD 600 para baixas doses: a) ${ }^{60} \mathrm{Co}$; b) ${ }^{137} \mathrm{Cs}$

Tabela 31 - Coeficientes ajustados para as curvas de calibração do TLD 600

\begin{tabular}{ccc}
\hline $\mathbf{F}(\mathbf{x})=\mathbf{A}+\mathbf{B x}$ & ${ }^{\mathbf{6}} \mathbf{C o}$ & ${ }^{{ }^{137} \mathbf{C s}}$ \\
\hline $\mathbf{A}[\mathbf{u C}]$ & $0,076(63)$ & $0,018(62)$ \\
$\mathbf{B}[\mathbf{u C} / \mathbf{m G y}]$ & $0,066(1)$ & $0,0541(8)$ \\
\hline
\end{tabular}

Pode-se observar diferenças nas inclinações das curvas de calibração do TLD 600 quando irradiado nas diferentes fontes. Para uma melhor visualização, está apresentada na Figura 86 a comparação das curvas ajustadas para os dois casos. 


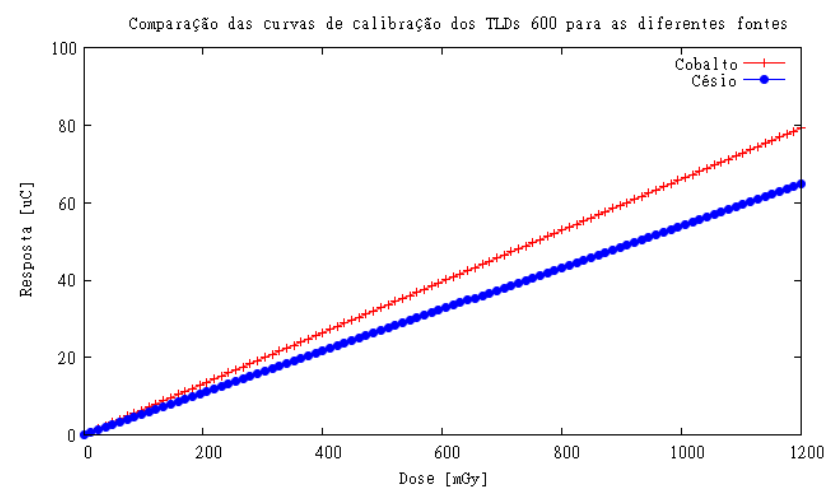

Figura 86 - Comparação entre as curvas de calibração dos TLDs 600 para baixas doses entre as fontes de ${ }^{60} \mathrm{Co} \mathrm{e}{ }^{137} \mathrm{Cs}$

O mesmo estudo foi realizado para os TLDs 700 e 400, e as curvas de calibração destes TLDs nas diferentes fontes, assim como os coeficientes ajustados e o gráfico comparando as duas curvas estão apresentados a seguir.
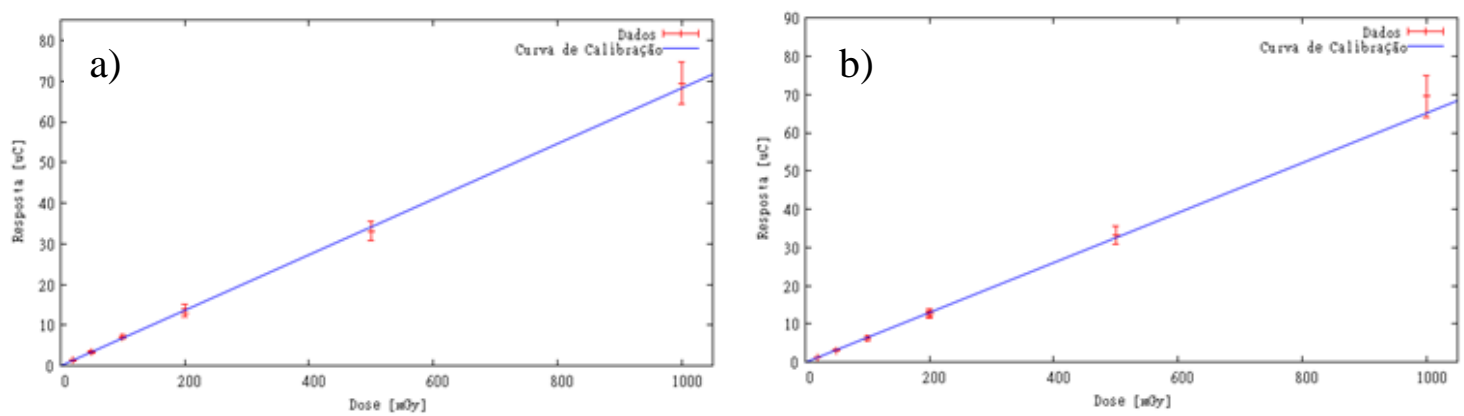

Figura 87 - Curvas de calibração do TLD 700 para baixas doses: a) ${ }^{60} \mathrm{Co}$; b) ${ }^{137} \mathrm{Cs}$

Tabela 32 - Coeficientes ajustados para as curvas de calibração do TLD 700

\begin{tabular}{ccc}
\hline $\mathbf{F}(\mathbf{x})=\mathbf{A}+\mathbf{B x}$ & ${ }^{\mathbf{6}} \mathbf{C o}$ & ${ }^{137} \mathbf{C s}$ \\
\hline $\mathbf{A}[\mathbf{u C}]$ & $-0,032(57)$ & $-0,014(59)$ \\
$\mathbf{B}[\mathbf{u C} / \mathbf{m G y}]$ & $0,0682(12)$ & $0,065(1)$ \\
\hline
\end{tabular}




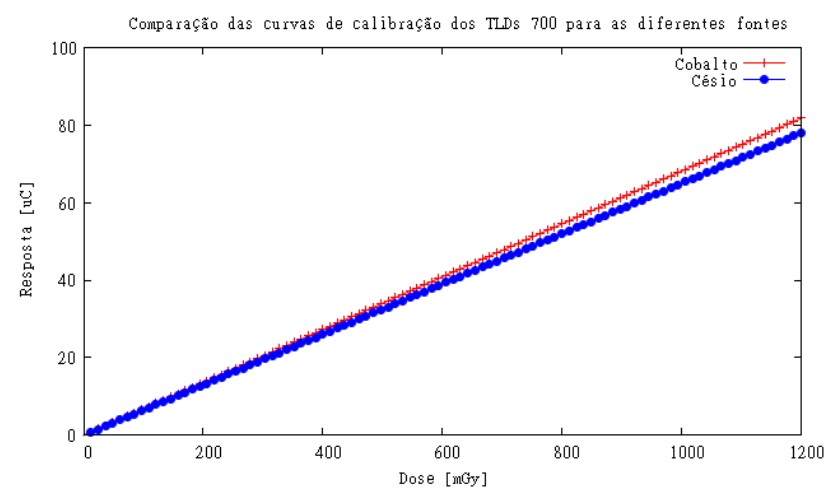

Figura 88 - Comparação entre as curvas de calibração dos TLDs 700 para baixas doses entre as fontes de ${ }^{60} \mathrm{Co}$ e ${ }^{137} \mathrm{Cs}$
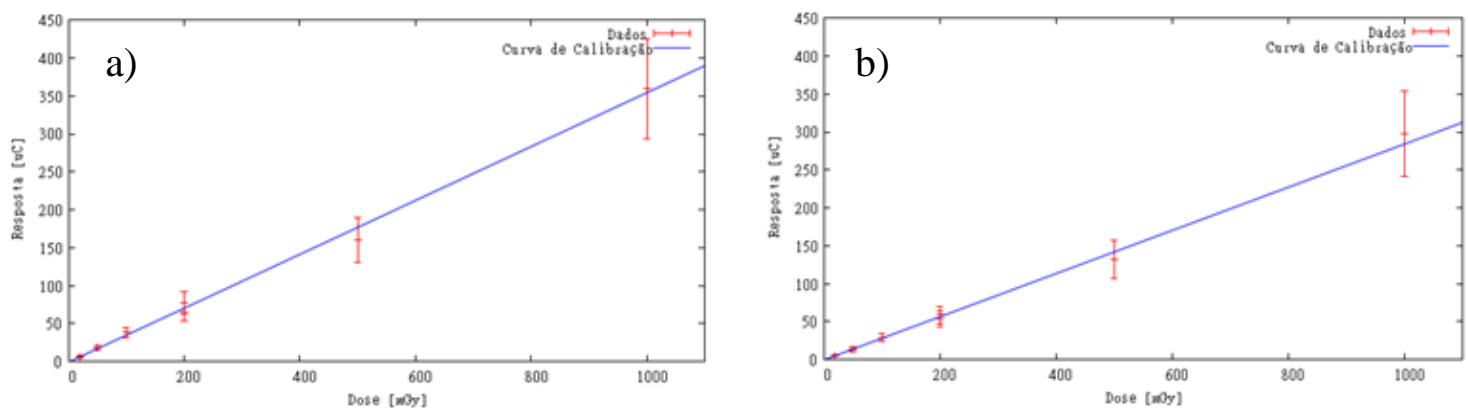

Figura 89 - Curvas de calibração do TLD 400 para baixas doses: a) ${ }^{60} \mathrm{Co}$; b) ${ }^{137} \mathrm{Cs}$

Tabela 33 - Coeficientes ajustados para as curvas de calibração do TLD 400

\begin{tabular}{ccc}
\hline $\mathbf{F}(\mathbf{x})=\mathbf{A}+\mathbf{B x}$ & ${ }^{\mathbf{6 0}} \mathbf{C o}$ & ${ }^{\mathbf{1 3 7}} \mathbf{C s}$ \\
\hline $\mathbf{A}[\mathbf{u C}]$ & $-0,070(65)$ & $-0,33(32)$ \\
$\mathbf{B}[\mathbf{u C} / \mathbf{m G y}]$ & $0,355(15)$ & $0,284(7)$ \\
\hline
\end{tabular}

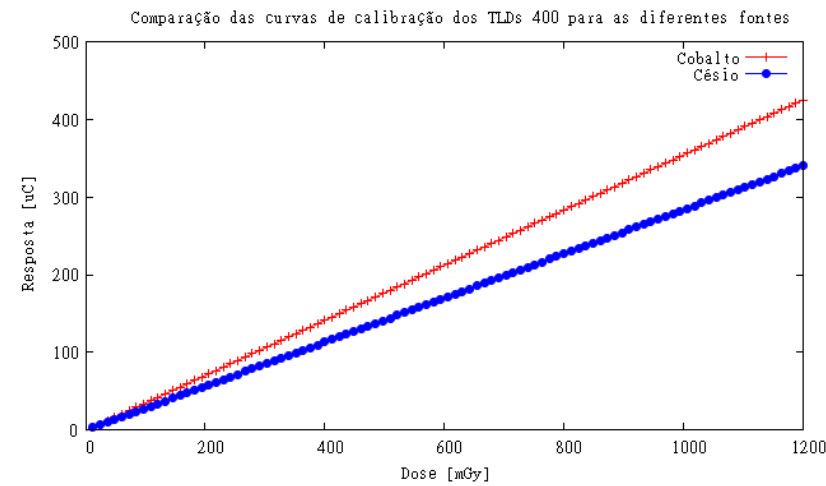

Figura 90 - Comparação entre as curvas de calibração dos TLDs 400 para baixas doses entre as fontes de ${ }^{60} \mathrm{Co} \mathrm{e}{ }^{137} \mathrm{Cs}$ 
Analisando estes resultados é possível observar que o TLD 400 apresenta a maior diferença entre seus coeficientes angulares. O TLD 600 também apresenta uma diferença significativa entre seus coeficientes angulares, o que causa também discrepâncias nas respostas das duas fontes. Já o TLD 700 é o que apresenta menor diferença, e a incerteza gerada pela diferença de seus coeficientes angulares não é maior que as incertezas geradas pelas próprias incertezas das respostas dos TLDs.

Assim, deve-se estar atento ao utilizar as calibrações dos TLDs, pois estas funcionam apenas para certa energia dos fótons. Usar as curvas de calibrações para uma energia que não a sua pode acarretar em grandes diferenças de dose.

Uma proposta para futuros trabalhos é encontrar também a dependência energética dos TLDs para a energia média os feixes de nêutrons. 